\title{
Targeting microglial CSF1R in health and disease
}

\author{
Dissertation \\ for the award of the degree \\ "Doctor rerum naturalium" \\ of the Georg-August-Universität Göttingen
}

within the doctoral program Center for Systems Neuroscience (CSN)

of the Göttingen Graduate Center for Neurosciences,

Biophysics, and Molecular Biosciences (GGNB)

and of the Georg-August University School of Science (GAUSS)

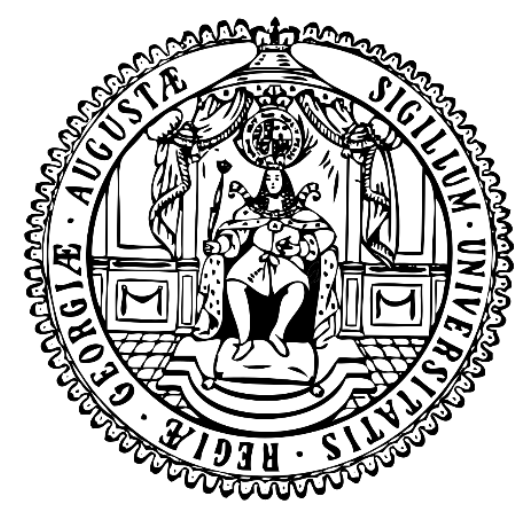

submitted by

Laura Fernández García-Agudo

born in Madrid, Spain

Göttingen, 2020 
Thesis Advisory Committee:

Prof. Dr. Dr. Hannelore Ehrenreich ( $1^{\text {st }}$ reviewer)

Clinical Neuroscience

Max Planck Institute of Experimental Medicine (Göttingen, Germany)

Prof. Dr. Silvio O. Rizzoli ( $2^{\text {nd }}$ reviewer)

Neuro- and Sensory Physiology

University Medical Center (Göttingen, Germany)

Prof. Dr. Tiago Fleming Outeiro

Experimental Neurodegeneration

University Medical Center (Göttingen, Germany)

\section{Examination Board:}

Prof. Klaus-Armin Nave, Ph.D.

Neurogenetics

Max Planck Institute of Experimental Medicine (Göttingen, Germany)

Prof. Dr. Susann Boretius

Functional Imaging

German Primate Center (Göttingen, Germany)

Prof. Dr. Martin Göpfert

Cellular Neurobiology

Schwann-Schleiden Research Center (Göttingen, Germany)

Date of thesis submission: December $18^{\text {th }}, 2020$

Date of oral examination: March $4^{\text {th }}, 2021$ 


\section{Declaration of independent work}

I hereby declare that this thesis "Targeting microglial CSF1R in health and disease" has been written independently and with no other sources and aids than quoted. 


\section{Acknowledgements}

I want to give my first and foremost thank you to Prof. Dr. Dr. Hannelore Ehrenreich. Under your supervision, I have felt inspired to be in a continuous process of studying, I have strongly improved my analytical skills, and I have learnt to truly strive and persevere in science. I am deeply indebted to the support you have shown me during this entire experience and grateful for all you have invested on me.

I would also like to show my dear appreciation to Prof. Dr. Silvio O. Rizzoli, with whom I have had the pleasure to collaborate and who has been, together with Prof. Dr. Tiago Fleming Outeiro and Prof. Klaus-Armin Nave, Ph.D., an inestimable help, guidance, and source of motivation from the beginning of my doctoral studies. I kindly extend my gratitude to Prof. Dr. Susann Boretius and Prof. Dr. Martin Göpfert, for taking an interest in my work and the time to appraise it.

Every member I have had the pleasure to meet at Clinical Neuroscience has always shown a helping hand or a kind word not only in moments of need, but also in the everyday life. I feel very fortunate to have fulfilled this big accomplishment in such a great laboratory, and use this opportunity to particularly address Nadine Schopf: a more than excellent technician with the highest personal value. Thank you for all you have done for me and for being a true companion.

My gratefulness goes also to my family for the boundless support shown during the six years I have been living in Germany, as well as to my friends, to every single day on the terrace, and to the members of the $G$ office, where so much wonder has happened.

To finalize, I would like to humbly acknowledge the lives of all the mice I have sacrificed for the achievement of this thesis. 
To my parents,

for being the example

of commitment and effort that the scientific work requires. 


\section{Table of contents}

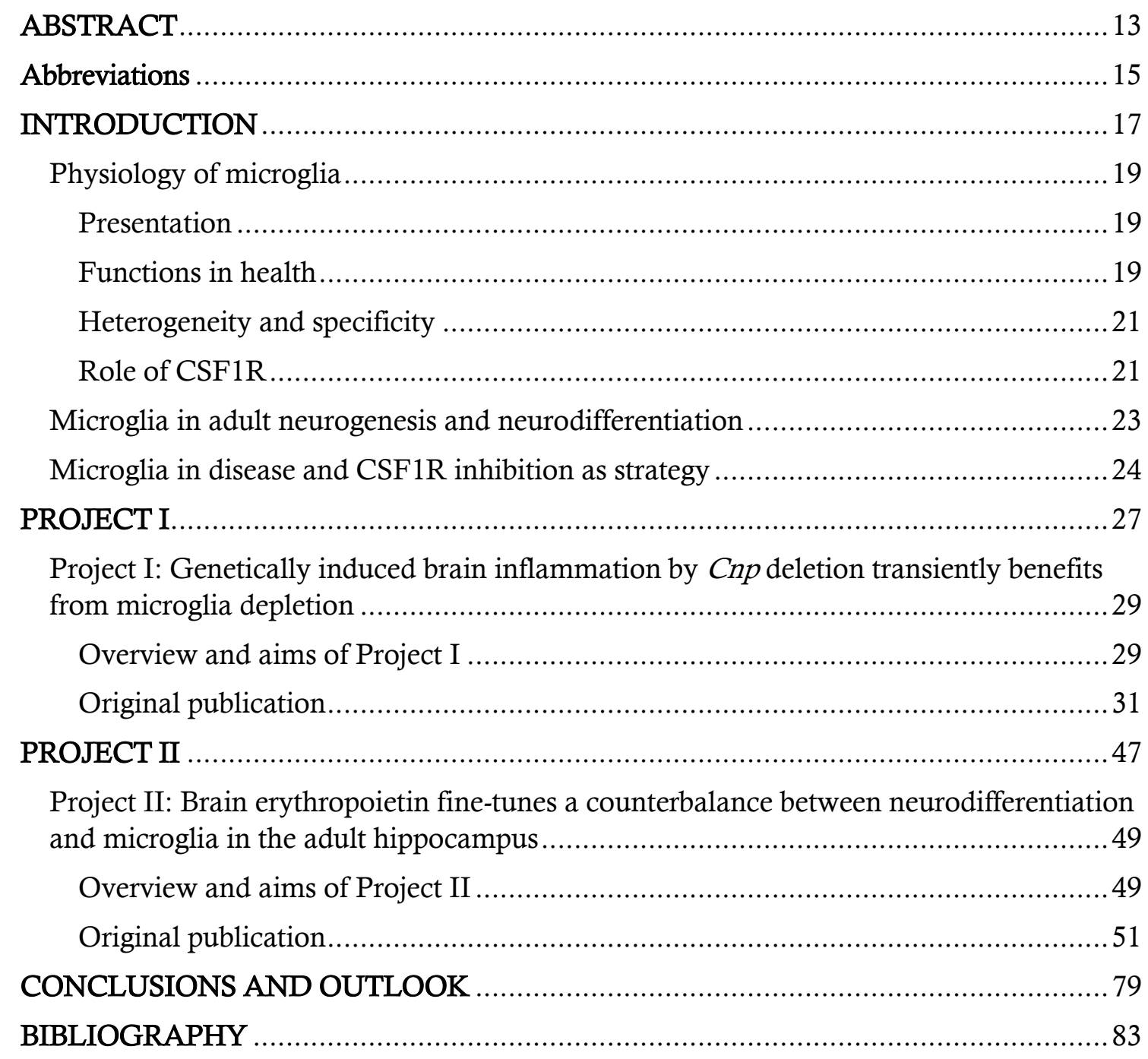




\begin{abstract}
The main effector functions of microglia are immune, synaptic network refinement, brain insult reaction, and neurogenesis regulation. This cumulative doctoral thesis focuses on the relevance of the colony-stimulating factor 1 receptor (CSF1R) signaling pathway of microglia in the context of the last two topics, specifically in [A] low-grade white matter inflammation and [B] hypoxia-induced neurogenesis.

Ad [A]: Our group previously detected that myelin structural protein cyclic nucleotide phosphodiesterase (CNP) deletion triggers low-grade white matter inflammation and causes a behavioral phenotype named catatonia. Treatment with the CSF1R inhibitor PLX5622 of $C n p^{-/}$mice leads to a strong reduction of neuroinflammation, i.e. microglial numbers and activation status, as well as a clear improvement of the catatonic signs. In my first paper, I systematically addressed aspects which are important for clinical translation. Amongst others, I found that microglia surviving PLX5622-induced depletion display a pro-inflammatory phenotype including targeted phagocytosis of oligodendrocyte precursor cells, and that two PLX5622 treatment cycles are not superior to one. These results may be helpful for guiding future use of CSF1R inhibitors in (pre)clinical studies.

Ad [B]: As work of our group has shown, exposure of mice to hypoxia, whether inspiratory or functional by motor-cognitive challenge, triggers the expression of brain erythropoietin (EPO). In my second paper, I found that treatment with exogenous EPO leads to not only increased hippocampal cornu ammonis 1 (CA1) pyramidal neuron numbers and dendritic spine densities, but most importantly it simultaneously decreases microglia proliferation, activity, and motility. Searching for mechanisms, I discovered a direct effect of EPO on microglia that acted in two phases: first EPO triggered immediate microglia apoptosis for just a limited time, leading to decreased microglia numbers. Subsequently, the reduction of the microglia population was maintained by decreased microglia proliferation. This was likely due to an EPO-induced decrease in the expression of interleukin 34, a neuronally expressed ligand of CSF1R. EPO also led to decreased microglia-neuron contacts and microglial metabolism in the CA1. Furthermore, this was paralleled by an increase in intermediate neuronal progenitors, which became mature by the end of a 3-week EPO treatment. Importantly, these effects are dependent on EPO receptor expression in microglia and neurons.
\end{abstract}




\section{Abbreviations of protein names}

\begin{tabular}{|c|c|}
\hline ATP & adenosine triphosphate \\
\hline CD11c & integrin alpha $X$ \\
\hline CD68 & CD68 antigen; macrosialin \\
\hline CTIP2 & B cell leukemia/lymphoma $11 B$ \\
\hline $\mathrm{CX}_{3} \mathrm{CR} 1$ & chemokine (C-X3-C motif) receptor 1 \\
\hline DAP12 & $T Y R O$ protein tyrosine kinase binding protein \\
\hline GSK3 $\beta$ & glycogen synthase kinase 3 beta \\
\hline IBA1 & allograft inflammatory factor 1 \\
\hline IGF1 & insulin-like growth factor 1 \\
\hline IRS1 & insulin receptor substrate 1 \\
\hline Mac2 & lectin, galactose binding, soluble 3 \\
\hline MHCII & major histocompatibility complex, class II \\
\hline P2RY12 & purinergic receptor $P 2 Y$, G-protein coupled 12 \\
\hline PDGFR $\alpha$ & platelet derived growth factor receptor, alpha polypeptide \\
\hline РTP-ろ & protein tyrosine phosphatase, receptor type $Z$ \\
\hline PU.1 & spleen focus forming virus proviral integration oncogene \\
\hline TBR1 & T-box brain transcription factor 1 \\
\hline TLE4 & transducin-like enhancer of split 4 \\
\hline TMEM119 & transmembrane protein 119 \\
\hline$\beta$-catenin & catenin (cadherin associated protein), beta 1 \\
\hline
\end{tabular}


INTRODUCTION 


\section{Physiology of microglia}

\section{Presentation}

Microglia were identified by Pío del Río-Hortega in 1919, who named them after the "extremely small" size of their soma. He noted that these cells emit, however, "long and tortuous processes", and are able to undergo a remarkable morphological change upon brain damage or infection. This pioneering series of studies also postulated that the ability of microglia to migrate to injury sites to perform phagocytosis could reflect a different embryonic origin than that of neurons and astrocytes: the mesoderm ${ }^{1,2}$.

The fact that microglia are immune cells and express monocyte/macrophage markers (importantly, IBA $1^{3}$ and PU. $1^{4}$ ) led to the belief that these cells would derive from mesodermal hematopoietic myeloid progenitors, recruited to and differentiated in the central nervous system $(\mathrm{CNS})^{5,6}$. It was later hypothesized that microglia would most probably migrate to the neural folds directly from the closely laying yolk sac, where extra-embryonic myeloid precursors can be found on embryonic day (E)7.5, since at this stage blood circulation in the mouse is not yet fully established ${ }^{7}$. This hypothesis was only confirmed in 2010: Yolk sac precursors migrate to the developing CNS between E8.5 and E9.5, where they proliferate until the second postnatal week in rodents, and disseminate throughout the parenchyma, colonizing the entire CNS at early developmental stages, and eventually mature to generate the adult microglia by postnatal day $(\mathrm{P}) 14^{8,9}$. This is the moment when microglia express TMEM119, one of the markers that differentiate them from the rest of the myeloid lineage cells ${ }^{10}$.

The adult microglia population is long-lived, with a self-renewal throughout life ${ }^{11,12}$ which is carefully maintained by a balanced coupled proliferation and apoptosis ${ }^{13}$. They account for around $10 \%$ of the total cell population in the brain ${ }^{12}$.

\section{Functions in health}

Although they are the principal innate immune cells of the CNS, the fact that microglia were discovered to have an active role in homeostasis, i.e. synaptic 
stripping $^{14}$ is what truly pushed the intensive research in this field. Via in vivo twophoton imaging in the cortex, it was revealed that microglia are highly motile cells which continuously scan their surroundings. While the cell body remains mostly still, it is the microglial processes which are remarkably dynamic under homeostatic conditions. They are under a permanent protrude-and-retract movement, where each microglial cell has its niche and avoids mutual contact to others. Under this characteristic technique, microglia have been estimated to scan the entire brain parenchyma just over the course of a few hours ${ }^{15}$. They contact several neural components including astrocytes, blood vessels, neuron somas, and synaptic structures $^{15-17}$.

Once a damage or infection is detected, microglia undergo a profound phenotype switch, which includes changes in their morphology, behavior, and gene expression. The ramified, homeostatic, or "resting" microglia enlarge the cell body, retract their processes, and develop a targeted movement towards the injured site. Like this, they become amoeboid or "activated" microglia, and can actively migrate, phagocytose, and release pro- or anti-inflammatory soluble factors ${ }^{15,16}$.

During embryonic and early postnatal development, microglia can be found nearby apoptotic neurons, removing debris, but also providing trophic support for developing neurons by secreting a variety of neurotrophic factors ${ }^{18,19}$. While performing synaptic pruning, microglia directly interact with pre- and post-synaptic terminals, removing less active dendritic spines and prolonging their contact with more active ones ${ }^{20-22}$.

One way microglia 'sense' the neuronal activity for this purpose is by soluble factors released by neurons for which microglia express specific receptors. For example, neuronal injury studies have identified that microglia respond to neuronal-activityassociated ATP with the purinergic receptor P2RY12 ${ }^{23-25}$. ATP would act as a localized signal for microglial recruitment to not only damaged, but also activated synapses in order to protect the brain from excessive neuronal activation ${ }^{26}$. Similarly, the neuronal chemokine fractalkine guides microglia via receptor $\mathrm{CX}_{3} \mathrm{CR} 1^{27}$ for correct development of synaptic networks. Knockout mice for $\mathrm{CX}_{3} \mathrm{CR} 1$ have less refined and mature synapses in the hippocampus by $\mathrm{P} 15^{28}$, and by adulthood they show behavioral, long-term potentiation, and synaptic plasticity impairments, along with decreased numbers of newly born neurons in the dentate gyrus ${ }^{29}$. Indeed, a 
healthy microglia population is absolutely required for correct brain wiring, development and neurogenesis. Precisely this last topic will be described with more insight later on in this introduction.

\section{Heterogeneity and specificity}

Amongst different brain regions, ages, and even genders, different microglial numbers, morphologies, and transcriptomes can be found under homeostatic conditions $^{30,31}$ as well as under disease ${ }^{32}$. It even has been postulated that the regional differences of microglia within the CNS are so varied that they mimic the macrophage tissue diversity ${ }^{33}$. Despite the fact that monocytes or tissue macrophages and microglia share the same embryonic origin, immune functions, and many surface markers ${ }^{34}$, microglia have a unique transcriptomic signature ${ }^{10,35}$. This allows the selective identification of microglia versus macrophages even in the diseased brain, when infiltration from monocytes takes place ${ }^{10,36}$, by markers like TMEM119 or P2RY12.

\section{Role of CSF1R}

The colony-stimulating factor 1 (CSF1), also known as macrophage-CSF (M-CSF), was the first growth factor identified and shown to stimulate the formation of macrophage colonies ${ }^{37,38}$. It only binds to CSF1 receptor (CSF1R), a member of the receptor tyrosine kinase class III family ${ }^{39,40}$, which is also bound by interleukin 34 $(\mathrm{IL}-34)^{41}$.

In the CNS, CSF1R is only expressed by microglia and meningeal macrophages ${ }^{42}$, and its signaling is proven to be essential for microglial cell survival. Knockout mice for CSF1 (Csf1 $\left.1^{o p / o p}\right)$ and IL-34 (I134 $\left.4^{\text {LacZ/LacZ }}\right)$ display a partial reduction of microglia, more notably in white matter areas in $C s f 1^{o p / o p}$ mice $^{43}$, or grey matter regions of II34 ${ }^{\mathrm{LacZ} / \mathrm{LacZ}}$ mice ${ }^{44}$, while CSF1R knockout mice ( $\left.C S f 1 r^{\circ}\right)$ are completely depleted of microglia and rarely survive to adulthood ${ }^{8,45}$. This shows a functional overlap by both ligands, but distinct expression patterns: CSF1 is largely expressed by glia and required for the maintenance of microglia in white matter tracts, and IL-34 is mostly expressed by neurons and required for microglia maintenance in grey matter regions $^{46-48}$. 
Downstream signaling from CSF1R includes modulation of GSK3 $\beta$ and $\beta$-catenin, both involved in the activation of cell cycle progression genes and cell survival ${ }^{49}$. Indeed, CSF1R inhibition with the tyrosine kinase inhibitors PLX3397 or PLX5622 in adult mice leads to approximately 99\% reduction of microglia within 3 weeks of treatment. Upon inhibitor withdrawal, microglia repopulate the brain reaching physiological levels in 14 days $^{50,51}$, exclusively via proliferation of those cells surviving depletion ${ }^{52}$. How a small population of microglia resists the application of CSF1R inhibitors is still not elucidated, but one study identified a Mac2 ${ }^{+}$microglial subpopulation that could explain this phenomenon, since the authors claim this microglia subset is CSF1R-signaling independent ${ }^{53}$.

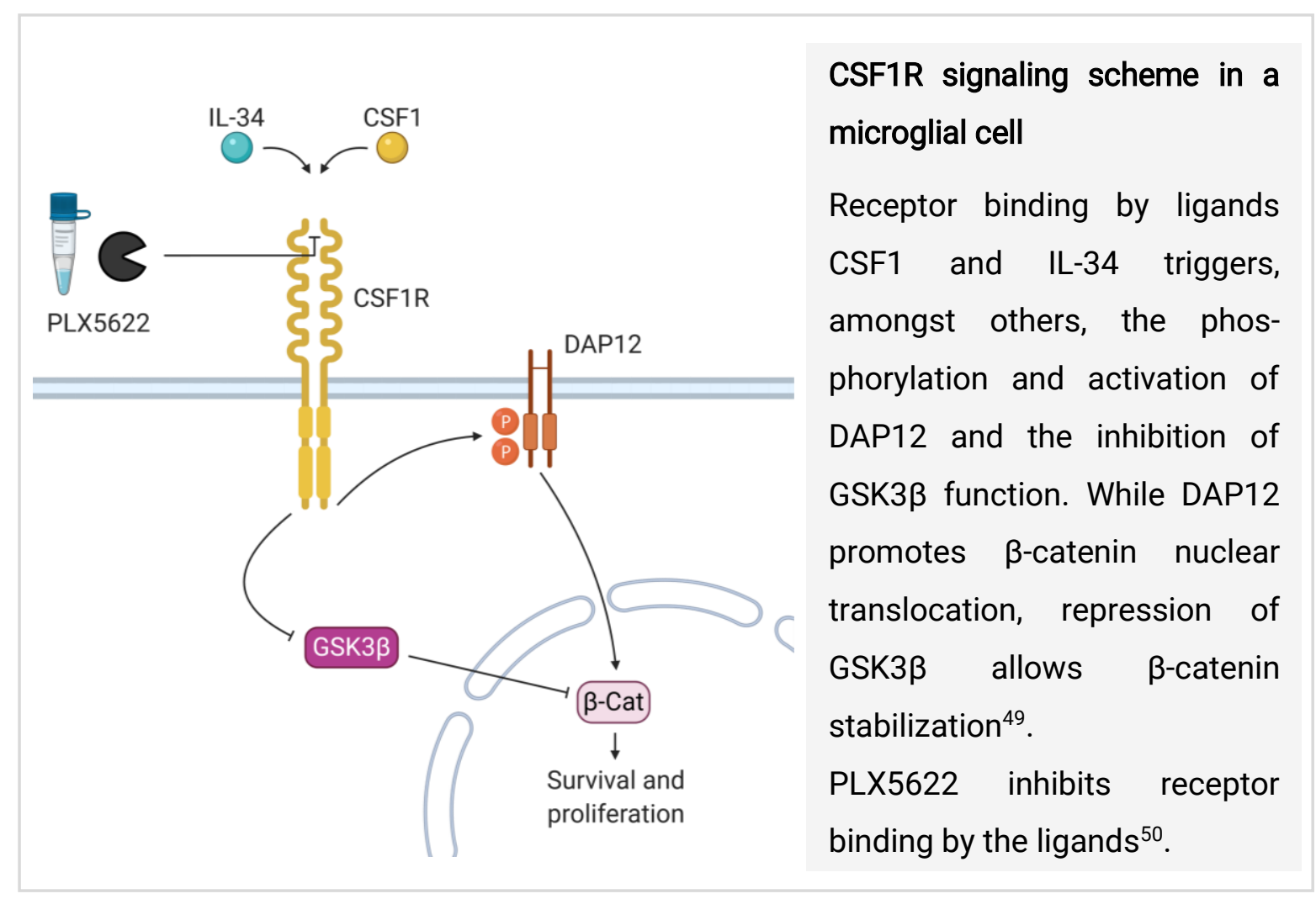

Apart from microglial proliferation, a novel role for the CSF1R axis was observed in neuronal development. During early postnatal development, CSF1 is co-expressed in $\mathrm{TBR}^{+}$neuronal precursor cells (NPC), and IL-34 is co-expressed by CTIP2 ${ }^{+}$ neurons, while CSF1R is expressed in NPC and microglia. By P20 the expression of CSF1R is largely limited to microglia. Importantly, it was shown in vitro and in vivo 
that CSF1 and more efficiently IL-34 could suppress NPC proliferation and enhance neuronal differentiation. Also, $C s f 1 r^{--}$mice and acutely microglia-depleted mice embryos have a significantly reduced number of TBR $1^{+}$and CTIP2 ${ }^{+}$neurons ${ }^{54}$ which persists throughout postnatal development ${ }^{55}$. This indicates a direct role of the CSF1R axis and microglia in promoting survival and maturation of neural progenitors, which might be further supported by the fact that IL-34 also binds receptor PTP- $\zeta$, expressed in NPC and glia, and its signaling triggers as well a decrease in NPC proliferation ${ }^{56}$.

\section{Microglia in adult neurogenesis and neurodifferentiation}

Adult neurogenesis was demonstrated to occur throughout life in the subgranular zone of the hippocampal dentate gyrus (DG) and the subventricular zone of the lateral ventricle in different species ${ }^{57}$. The current state of the art however shows that this is a difficult process to prove and understand, with the latest research in humans finding contradictory results ${ }^{58,59}$. It is nevertheless intensely studied, and plenty of evidence in the recent years point to microglia being essential regulators of the neurogenic niche in the adult DG.

From the many neurons that are born during neurogenesis, only a few survive to maturity and become integrated in the circuitry. Microglia perform steady-state phagocytosis of those newborn neurons which are apoptotic ${ }^{60}$. This phagocytosis is done by ramified microglia via a specific modification of their processes, and is in stark contrast to the phagocytosis triggered by brain insults or neurodegeneration, which microglia perform in their amoeboid phenotype ${ }^{60}$. Acutely blocking microglial phagocytosis, or directly depleting microglia from the adult brain, leads to a transient increase of neuroblasts. Restoring microglial phagocytosis, or allowing them to repopulate the brain, respectively, produces that the neurogenesis rate goes back to physiological levels ${ }^{61,62}$.

Whereas aging, inflammation, and brain disease have a negative impact on neurogenesis and its regulation by microglia ${ }^{63-65}$, physical exercise seems to boost NPC proliferation and prime microglia to support adult neurogenesis ${ }^{18,66,67}$. During exercise and motor-cognitive challenge, brain cells are susceptible to experience 
hypoxia and express hypoxia-inducible factor 1 (HIF 1$)^{68}$, a reportedly neurogenesisregulating agent ${ }^{69,70}$. Indeed, the hypoxia-induced hormone erythropoietin (EPO) is required for physiological NPC proliferation ${ }^{71}$ and responsible for the hypoxiaenhanced neurogenesis ${ }^{72}$. In adult mice, treatment with EPO acts as a neurodifferentiation booster by increasing the number and dendritic spine densities of CA1 neurons ${ }^{73,74}$, while it also prevents microglial proliferation, motility and $\operatorname{activity~}^{75,76}$.

Another molecule reported to increase neurogenesis is IGF1, a potent neurotrophic hormone often associated with exercise and needed for the exercise-induced increase of $\mathrm{NPC}^{77,78}$. After exercise, microglia increase their release of IGF1 $1^{79}$ and the insulin receptor IRS1 is upregulated in the $\mathrm{DG}^{80}$. This could promote the proliferation and differentiation of NPC via downstream signaling of the NPC-expressed IRS1 to GSK $3 \beta^{80,81}$. Of note, both HIF1 and IGF1 pathways seem to converge on $\beta$-catenin ${ }^{69}$, a well-known regulator of cell cycle genes with reported effects on neurogenesis ${ }^{82}$ as well as aforementioned microglial proliferation ${ }^{49}$.

\section{Microglia in disease and CSF1R inhibition as strategy}

Degeneration of the nervous tissue is a common feature of neurological and neuropsychiatric diseases. Chronic inflammation is often involved in it, with microglia displaying a recognizable phenotype clearly distinct from that of the healthy or acutely inflamed brain, but quite similar to that present in aged individuals ${ }^{83,84}$. This phenotype has been extensively characterized over the last few years by gene expression analysis, and the term 'disease-associated microglia' $(\mathrm{DAM})^{84}$ is now well accepted.

DAM (and aged microglia) are characterized by downregulation of the homeostatic microglia signature genes Tmem119and P2ry12, and upregulation of Itgax (CD11c), MHCII, Csf1 and Tyrobp (DAP12), amongst others ${ }^{83,84}$. In addition, the switch from homeostatic microglia to DAM is a dynamic process where intermediate states can be found ${ }^{84}$. This makes the final function of DAM somewhat obscure: they could be disease-inducing or therapeutical ${ }^{84-86}$. 
Since the regulatory protein DAP12 and the ligand CSF1 interact with CSF1R to induce microglial proliferation ${ }^{49}$, their upregulation in DAM might explain the commonly observed microgliosis (i.e. inflammation) across many brain diseases and aged individuals ${ }^{83-85,87}$. Modulating the microglial population and shifting it back to its homeostatic phenotype might be, thus, an interesting treatment approach. Therefore, inhibitors of CSF1R (like PLX5622) have recently become one of the most utilized tools in the research for potential therapies in CNS pathologies. With this pharmacological strategy, it was discovered that microglia can be acutely depleted from the adult brain without negatively affecting blood-brain-barrier integrity, general health, cognition, or behavior ${ }^{51}$. This is in contrast to genetic or toxin-based approaches, which would produce undesirable side effects like cytokine storm or synaptic spine alterations ${ }^{86,88}$, thus biasing the disease model and the effectivity of microglia depletion as treatment.

Pharmacological CSF1R inhibition has been tested in a variety of disease models, ranging from neurodegenerative $e^{50}$ to inflammatory conditions ${ }^{89,90}$. Many of these studies found an improvement of the disease course, but the doubt of whether DAM are detrimental or beneficial remains, since upon microglia depletion a worsening of the symptoms has also been reported, especially in models of CNS injury or ischemia ${ }^{85,86}$. Nevertheless, a very important, clear conclusion from studies with CSF1R inhibitors is that repopulating microglia, those which proliferated from the few cells enduring the treatment ${ }^{52}$, have a 'rejuvenated' phenotype. This is, microglial depletion with subsequent recovery promotes (at least transiently) the homeostatic microglia signature and has an overall anti-inflammatory, beneficial effect ${ }^{62,91}$. 


\section{PROJECT I}




\section{Project I: Genetically induced brain inflammation by Cnp deletion transiently benefits from microglia depletion}

\section{Overview and aims of Project I}

Several neuropsychiatric diseases have been reported to present with microgliosis and low-grade microglial activation, including schizophrenia ${ }^{92}$. The mechanism behind how microglia become over-reactive or chronically inflammatory in brain disease is still not fully described, but in the recent years some significant contributions have shed more light in the field.

Apart from the abnormal microglia population, clinical studies in schizophrenia, autism, depression, and dementia report changes in brain white matter tracts ${ }^{93}$. Thus, the involvement of another glial cell type seems undeniable: the oligodendrocytes. Postmortem human studies identified the myelin structural protein cyclic nucleotide phosphodiesterase (CNP) to be significantly reduced in the brains of schizophrenia, bipolar disorder, or major depression patients ${ }^{94}$. Furthermore, a partial loss-offunction $C N P$ allele has been identified to be strongly associated to the development of white matter hyperintensities and catatonia ${ }^{90,94}$.

In mice, heterozygosity for $C n p$ leads to a mild disease phenotype at old age with normal motor functions, but low-grade brain inflammation and catatonia are still present ${ }^{94}$. Catatonia is defined as a psychomotor syndrome that reflects a disruption of the executive control, and causes sudden immobility and stupor. Although classically linked to schizophrenia, it can also occur in major mood disorders and secondary to other pathologies ${ }^{95}$. In mice it can be experimentally measured by the bar test, where Cnp deficient mice are brought into an uncomfortable posture and, unlike healthy mice, remain in it for a prolonged period of time ${ }^{94}$.

The brains of Cnp null mutant mice show an age-related increase in astrogliosis, axonal degeneration and, importantly, in microglial numbers and activation. Catatonia can be observed in $C n p^{-1}$ animals from the early age of 8 weeks, together with neuroinflammatory signs ${ }^{90}$. When preventive CSF1R inhibitor PLX5622 treatment is applied from weeks 3 to 8 , an almost complete relief of the catatonic and inflammatory signs can be observed. The microglia that repopulate the brains of these animals remain at physiological levels for at least 4 weeks after inhibitor withdrawal, 
thus being most likely a cause for the reduced axonal degeneration and astrogliosis observed under PLX5622 treatment in the corpus callosum. As a grave catatonia and anti-inflammatory treatment strategy, $C n p^{-/}$mice received PLX5622 at the age of 27 weeks. This also led to a drastic improvement of the catatonic and inflammatory phenotypes in white matter regions, but the following observations remained unexplained: $C n p^{-/}$mice showed a lower rate of microglial depletion, with around $30 \%$ of 'leftover' cells surviving CSF1R inhibition in contrast to the $5 \%$ leftover in wild-type mice; and PDGFR $\alpha^{+}$oligodendrocyte precursor cells (OPCs) were decreased under PLX5622 treatment in both $C n p^{-/}$and wild-type mice ${ }^{90}$.

With those previous results in mind, the aims of Project $I$ were to study the characteristics of leftover microglia evading depletion and the intercellular interactions that might arise during CSF1R inhibition. Also, in order to address the best treatment plan for translation, this project was built as a comparison between one and two long-term PLX5622 applications.

We discovered that the phenotype of the leftover microglia in the corpus callosum was highly inflammatory, characterized by a decreased expression of homeostatic microglia marker TMEM119, but upregulation of DAM-associated CD68, MHCII, and CD11c. These microglia are located in white matter tracts, but they seem to expand to gray matter areas nearby. Very interestingly, PDGFR $\alpha^{+} \mathrm{OPCs}$ suffered from a targeted phagocytosis by these microglial cells which was documented both in vitro and in vivo. Mature oligodendrocytes and overall myelination, however, were not compromised by the treatment. In vitro studies were also helpful to establish a culture system for efficient microglia depletion with PLX5622, where astrocytesecreted factors are required, since pure cultured microglia did not show an accelerated death during CSF1R inhibition.

Although application of two long-term PLX5622 treatments did not provide a beneficial outcome with respect to one treatment alone, taking these results together deepens the knowledge of catatonia, and point at myelin structural abnormalities as the cause for a complex neuroinflammatory response that triggers catatonic signs in mice. 


\section{Original publication}

Fernandez Garcia-Agudo, L.*, Janova, H.*, Sendler, L. E.*, Arinrad, S., Steixner, A. A., Hassouna, I., Balmuth, E., Ronnenberg, A., Schopf, N., van der Flier, F. J., Begemann, M., Martens, H., Weber, M. S., Boretius, S., Nave, K. A. \& Ehrenreich, $\mathrm{H}$. Genetically induced brain inflammation by $\mathrm{Cnp}$ deletion transiently benefits from microglia depletion. FASEB J33, 8634-8647, doi:10.1096/fj.201900337R (2019).

*Equal contribution

\section{$\underline{\text { Personal contribution }}$}

I was personally responsible for the optimization and conduction of all in vitro experiments as well as the in vivo phagocytosis study. Together with the first coauthors, I performed microscopy imaging and triple-labeled cellular quantification. I was also involved in the experimental planning, discussion and interpretation of the results, and literature research. During the publishing process, I was involved in the manuscript and display items drafting, as well as later revision and pre-press proofing. 


\title{
Genetically induced brain inflammation by Cnp deletion transiently benefits from microglia depletion
}

\author{
Laura Fernandez Garcia-Agudo,* Hana Janova,, ${ }^{*}$ Lea E. Sendler,* Sahab Arinrad,* Agnes A. Steixner,* \\ Imam Hassouna, ${ }^{*}$ Evan Balmuth, ${ }^{*}$ Anja Ronnenberg, ${ }^{*}$ Nadine Schopf, ${ }^{*}$ Felicia J. van der Flier, ${ }^{*}$ \\ Martin Begemann, ${ }^{*,+, \neq}$ Henrik Martens, ${ }^{\S}$ Martin S. Weber, ${ }^{\mathbb{\top}}$ Susann Boretius, ${ }^{t, \|}$ Klaus-Armin Nave, ${ }^{+, \#, 1}$ \\ and Hannelore Ehrenreich ${ }^{*, t, 2}$ \\ ${ }^{*}$ Clinical Neuroscience and "Department of Neurogenetics, Max Planck Institute of Experimental Medicine, Göttingen, Germany; ${ }^{\dagger}$ Deutsche \\ Forschungsgemeinschaft (DFG) Center for Nanoscale Microscopy and Molecular Physiology of the Brain (CNMPB), Göttingen, Germany; \\ ${ }^{\ddagger}$ Department of Psychiatry and Psychotherapy and ${ }^{\top}$ Institute of Neuropathology and Department of Neurology, Universitätsmedizin \\ Göttingen (UMG), Georg-August-University, Göttingen, Germany; ${ }^{\S}$ Synaptic Systems GmbH, Göttingen, Germany; and "Functional Imaging \\ Laboratory, Leibniz Institute for Primate Research, Göttingen, Germany
}

\begin{abstract}
Reduced expression of 2'-3'-cyclic nucleotide 3 '-phosphodiesterase (Cnp) in humans and mice causes white matter inflammation and catatonic signs. These consequences are experimentally alleviated by microglia ablation via colony-stimulating factor 1 receptor (CSF1R) inhibition using PLX5622. Here we address for the first time preclinical topics crucial for translation, most importantly 1) the comparison of 2 long-term PLX5622 applications (prevention and treatment) $v s .1$ treatment alone, 2) the correlation of catatonic signs and executive dysfunction, 3) the phenotype of leftover microglia evading depletion, and 4) the role of intercellular interactions for efficient CSF1R inhibition. Based on our $\mathrm{Cnp}^{-1-}$ mouse model and in vitro time-lapse imaging, we report the unexpected discovery that microglia surviving under PLX5622 display a highly inflammatory phenotype including aggressive premortal phagocytosis of oligodendrocyte precursor cells. Interestingly, ablating microglia in vitro requires mixed glial cultures, whereas cultured pure microglia withstand PLX5622 application. Importantly, 2 extended rounds of CSF1R inhibition are not superior to 1 treatment regarding any readout investigated (magnetic resonance imaging and magnetic resonance spectroscopy, behavior, immunohistochemistry). Catatonia-related executive dysfunction and brain atrophy of $\mathrm{Cnp}^{-1-}$ mice fail to improve under PLX5622. To conclude, even though microglia depletion is temporarily beneficial and worth pursuing, complementary treatment strategies are needed for full and lasting recovery.-Fernandez Garcia-Agudo, L., Janova, H., Sendler, L. E., Arinrad, S., Steixner, A. A., Hassouna, I., Balmuth, E., Ronnenberg, A., Schopf, N., van derFlier, F. J., Begemann, M., Martens, H., Weber, M. S., Boretius, S., Nave, K.-A., Ehrenreich, H. Genetically induced brain inflammation by $\mathrm{Cnp}$ deletion transiently benefits from microglia depletion. FASEB J. 33, 8634-8647 (2019). www.fasebj.org
\end{abstract}

KEY WORDS: CSF1R inhibitor PLX5622 - catatonic signs $\cdot$ executive function $\cdot$ hurdle test $\cdot$ phagocytosis

2'-3'-Cyclic nucleotide $3^{\prime}$-phosphodiesterase $(\mathrm{Cnp})$ is a structural protein present in noncompacted myelin and accounting for about $4 \%$ of total CNS myelin proteins (1). Null $\left(\mathrm{Cnp}^{-/-}\right)$mutant mice constitute a translationally interesting model of genetically induced, progressive brain inflammation (2). Starting already at $8 \mathrm{wk}$ of age, these animals develop white matter inflammation and catatonic signs. Analogously, in schizophrenia, severe catatonia and progressed

ABBREVIATIONS: CAII, carbonic anhydrase II; CC, corpus callosum; CC1, adenomatous polyposis coli clone CC1; CD11c, integrin- $\alpha$ X; CD13, alanyl aminopeptidase membrane; CD3, cluster of differentiation 3; CD68, macrosialin; CG, cingulate cortex; CNI, Cambridge Neurologic Inventory; Cnp, 2'$3^{\prime}$-cyclic nucleotide $3^{\prime}$-phosphodiesterase; $\mathrm{Cnp}^{-1-}, \mathrm{Cnp}$ null; CSF1, colony-stimulating factor 1; CSF1R, CSF1 receptor; CX $\mathrm{CR}_{3}$, C-X3-C motif chemokine receptor 1; FACS, fluorescence-activated cell sorting; FCS, fetal calf serum; GFAP, glial fibrillary acidic protein; GRAS, Göttingen Research Association for Schizophrenia; Iba1, ionized calcium-binding adapter molecule 1; IHC, immunohistochemistry; MBP, myelin basic protein; MHCII, major histocompatibility complex class II; MRI, magnetic resonance imaging; MRS, magnetic resonance spectroscopy; NHS, normal horse serum; OF, open field; OPC, oligodendrocyte precursor cell; PDGFR- $\alpha$, platelet-derived growth factor receptor- $\alpha$; PDL, poly-D-lysine; PU.1, Spi-1 proto-oncogene; ROI, region of interest; Tmem119, transmembrane protein 119; WT, wild type

${ }^{1}$ Correspondence: Department of Neurogenetics, Max Planck Institute of Experimental Medicine, Hermann-Rein-Str.3, 37075 Göttingen, Germany. E-mail: nave@em.mpg.de

${ }^{2}$ Correspondence: Clinical Neuroscience, Max Planck Institute of Experimental Medicine, Hermann-Rein-Str.3, 37075 Göttingen, Germany. E-mail: ehrenreich@em.mpg.de

doi: $10.1096 /$ fj.201900337R

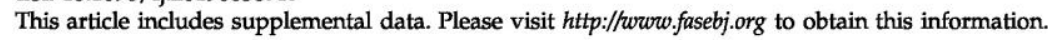


axonal degeneration in the frontal corpus callosum (CC), identified by diffusion tensor imaging, are associated with the Cnp partial loss-of-function genotype rs2070106-AA (3, 4). Even in the general population, carriers of the AA genotypeare more likely than $\mathrm{G}$ carriers to display frontotemporal white matter hyperintensities on T2-weighted magnetic resonance images (4). Such hyperintensities are interpreted as subclinical signs of vascular changes, neuroinflammation, and demyelination (5-7). In young $\mathrm{Cnp}^{-1-}$ mutants, experimental depletion of microglia with the colony-stimulating factor 1 (CSF1) receptor (CSF1R) inhibitor PLX5622 $(8,9)$, which blocks a critical microglial survival pathway, prevents catatonia onset and ameliorates existing catatonic signs in adult $\mathrm{Cnp}^{-/-}$mice (4). Therefore, targeting microglial cells by CSF1R inhibition arose as a potential new therapy for this still enigmatic neuropsychiatric syndrome.

In these previous studies, several fundamental questions critical for the potential translation to patients had to remain open and are now addressed for the first time in the present preclinical work. 1) We explored in $\mathrm{Cnp}^{-/-}$mice a potential additional benefit of 2 long-term PLX5622 applications $v s$. a single one. Surprisingly, the 2 extended CSF1R inhibition periods were not superior to only one regarding any outcome measure [magnetic resonanceimaging (MRI), magnetic resonance spectroscopy (MRS), behavior, immunohistochemistry (IHC)]. 2) As a result of our screening for additional catatonia tests, we introduce here the hurdle test, a new instrument measuring features of catatoniarelated executive dysfunction in mice. Hurdle and bar test results were cross-validated in several mouse cohorts, ultimately leading to a first catatonia severity composite score. As a supporting translational step, the correlation of catatonic signs with executive dysfunction was confirmed in human patients. However, unexpectedly, catatoniarelated executive dysfunction of $\mathrm{Cn}^{-1-}$ mice failed to improve under PLX5622, as did the progressive brain atrophy reported here in $\mathrm{Cnp}^{-1-}$ mice. 3) CSF1 R inhibition in adult $\mathrm{Cnp}^{-1}$ mice was previously found less effective in eliminating microglia (4). We speculated at the time that this could reflect their activation status but also a reduced responsiveness to PLX5622 in conditions of neuroinflammation. Starting to define the phenotype of apparently PLX5622 resistant (i.e., leftover) microglia in $\mathrm{Cnp}^{-1-}$ mice under depletion as well as the role of intercellular interactions for efficient CSF1R inhibition, we report here that microglia surviving PLX5622 display a highly inflammatory phenotype with aggressive premortal phagocytosis of oligodendrocyte precursor cells (OPCs). Taken together, these novel preclinical findings will contribute in an essential way to further planning of therapeutic approaches based on CSF1R inhibition.

\section{MATERIALS AND METHODS}

\section{Human studies on catatonic signs and executive function}

The present study complies with the Helsinki Declaration and was approved by the Ethics Committees of the University of Göttingen and of collaborating centers. All subjects, or their legal representatives, or both, gave written informed consent. The Göttingen Research Association for Schizophrenia (GRAS) Data Collection $(10,11)$ comprises deep phenotyping information on $>1700$ patients diagnosed with schizophrenia or schizoaffective disorder according to Diagnostic and Statistical Manual of Mental Disorders, Fourth Edition, Text Revision (12).Complete information on catatonic signs and Luria test [subscales of the Cambridge Neurologic Inventory (CNI) (13), the latter measuring executive motor function] or Trail Making Test B (14) was available in $n=$ 1287 (age $39.1 \pm 12.6,68.7 \%$ males) and $n=1382$ (age $39.7 \pm 12.9$, $69.1 \%$ males) patients, respectively.

\section{Mouse studies}

Behavioral experiments were conducted in accordance with the German Animal Protection Law and approved by the local Animal Care and Use Committee (LAVES, Niedersächsisches Landesamt für Verbraucherschutz und Lebensmittelsicherheit, ldenburg, Germany). All experiments were performed by investigators unaware of group assignment or genotype and treatment (i.e., fully blind).

\section{Mice}

Behavioral experiments were conducted using wild-type (WT) and $\mathrm{Cnp^{-/- }}$ mice of a C57Bl/6N background. Genotyping was previously described $(2,3)$. Mice weregroup housed in ventilated cabinets, gender separated (Scantainers; Scanbur, Karlslunde, Denmark), and maintained under standard conditions, including 12-h light/dark cycle (lights off at $7 \mathrm{PM}$ ) at $20-22^{\circ} \mathrm{C}$, with access to food and water ad libitum.

\section{Treatment}

Mice were assigned to groups as described in the Results and Figures, receiving either the CSF1R inhibitor PLX5622(1200 ppm, formulated in AIN-76A standard chow by Research Diets, New Brunswick, NJ, USA) or control food (AIN-76A) provided by Plexxikon (Berkeley, CA, USA) $(8,9)$. PLX5622 batches used were 16010809A9TT1.0i, 16092608A1TT1.0i, 17010309A7TT1.0i, 17032710A5TT1.0i, 18030908A9TT1.0i, and 17121308A1TT1.0i.

\section{Bar test}

The bar test was performed as previously described by Janova et al. (4). Briefly, following 30 min habituation to the experimental room, mice were gently carried by the tail and brought into proximity of a horizontal bar made of stainless steel. Mice were allowed to grasp the bar with both forepaws and stand upright before the tail was released. Each mouse was tested in 2 consecutive trials. Trials were recorded with a high-resolution camcorder (Sony HDR-CX405; Sony, Tokyo, Japan) for subsequent manual scoring of time spent immobile at the bar.

\section{Hurdle test}

This test was developed to measure the executive psychomotor dysfunction aspect of catatonia (Fig. 1 and Supplemental Videos S1 and S2). Prior to testing, mice were transferred to the experimental room to habituate for $30 \mathrm{~min}$. The experimentcomprised 2 consecutive trials with an intertrial interval of $\leq 5 \mathrm{~min}$. The first trial assesses disturbances in executive function, whereas the second trial can be used as a control for motor function deficits. The test was performed within a circular open field (OF) arena 
(119 $\mathrm{cm}$ diameter) containing an in-house-made polyvinylchloride comb inset $(95 \mathrm{~cm}$ diameter, $2.7 \mathrm{~cm}$ height) made of equally built $(10 \times 10 \mathrm{~cm})$ connected combs. The light intensity (140 lux) in the OF center motivated mice to move to the periphery. At the beginning of each trial, a mouse was placed into the comb center and its performance video recorded and tracked using Viewer 3 Tracking Software (Biobserve, Bonn, Germany). A trial ended as soon as a mouse reached the periphery or after a cutoff time of $5 \mathrm{~min}$. The entire arena including the inset was cleaned with $70 \%$ ethanol and tap water after each trial. The challenge in this test was to reach the periphery as fast as possible by climbing over the hurdles using the shortest possible way. Executive performance was assessed by calculating the ratio of latency to periphery (s) divided by the number of crossed hurdles (\#). To account for animals that did not overcome any hurdle, we calculated the ratio as $[(\mathrm{s}) /(\#+1)]$.

IHC

Anesthetized mice were perfused via the left cardiac ventricle with Ringer's solution (B. Braun Medical, Bethlehem, PA, USA) followed by $4 \%$ formaldehyde. Brains were dissected, postfixed overnight in $4 \%$ formaldehyde, dehydrated in $30 \%$ sucrose, and stored at $-80^{\circ} \mathrm{C}$. Coronal sections of $30 \mu \mathrm{m}$ were obtained by cutting on a cryostat (Leica-CM1950; Leica Microsystems, Buffalo Grove, IL, USA) and stored at $-20^{\circ} \mathrm{C}$ in $25 \%$ ethylene glycol and $25 \%$ glycerol in PBS. For cluster of differentiation 3 (CD3) staining, sections were microwaved in citrate buffer $(1 \mathrm{mM}, \mathrm{pH} 6.0)$ and for integrin- $\alpha \mathrm{X}$ (CD11c) detection additionally pretreated with $0.5 \% \mathrm{H}_{2} \mathrm{O}_{2}$, respectively. Sections were permeabilized and blocked with $5 \%$ normal horse serum (NHS) and $0.5 \%$ Triton $\mathrm{X}-100$ in PBS. Sections at a bregma level between +1.15 and $+0.5 \mathrm{~mm}$ were immunostained for ionized calcium-binding adapter molecule 1 (Iba1) (rabbit, 1:1000, ab178846; Abcam, Cambridge, MA, USA), Iba1 (chicken, 1:1000, 234006; Synaptic Systems, Göttingen, Germany), glial fibrillary acidic protein (GFAP) (mouse, 1:500, NCL-GFAP-GA5, Leica Microsystems), CD3 (rat, 1:100, MCA1477; Bio-Rad, Hercules, CA, USA), macrosialin (CD68) (rat, 1:400, MCA1957GA; Bio-Rad), plateletderived growth factor receptor $-\alpha$ (PDGFR- $\alpha$ ) (rabbit, 1:300,3174; CellSignaling Technology, Danvers, MA, USA), transmembrane protein 119 (Tmem119) (rabbit, 1:1000, 400002; Synaptic Systems), alanyl aminopeptidase membrane (CD13)-AF647 (rat, 1:200, 564352; BD Biosciences, San Jose, CA, USA), Spi-1 protooncogene (PU.1) (rabbit, 1:500, A13971; Thermo Fisher Scientific, Waltham, MA, USA), major histocompatibility complex class II (MHCII) (rat, 1:100, 14-5321; Thermo Fisher Scientific), myelin basic protein (MBP; rabbit, 1:500, A0632; Agilent Technologies, Santa Clara, CA, USA), adenomatous polyposis coli clone CC1 (CC1) (mouse, 1:100, OP80-100UG; Calbiochem, San Diego, CA, USA), carbonic anhydrase II (CAII) (rabbit, 1:150, gift from Said Ghandour, Université de Strasbourg, Strasbourg, France) and CD11c (Armenian hamster, 1:50, NB110-97871; Novus Biologicals, Centennial, CO, USA) in 3\% NHS and $0.5 \%$ Triton X-100 in PBS. The following secondary antibodies were used for fluorescent microscopy: donkey anti-rabbit Alexa Fluor 647 (A-31573), donkey anti-rabbit Alexa Fluor 488 (A-21206), donkey antimouse Alexa Fluor 488 (A-21202), goat anti-rabbit Alexa Fluor 555 (A-21428), goat anti-rat Alexa Fluor 647 (A-21247; 1:1000; Thermo Fisher Scientific), donkey anti-chicken Alexa Fluor 488 (703-546-155), and donkey anti-chicken Alexa Fluor 647 (703-605155; 1:1000; Jackson ImmunoResearch Laboratories, West Grove, PA, USA) in 3\% NHS and 0.5\% Triton X-100 in PBS. For CD11c staining, goat anti-Armenian hamster Biotin-SP (long spacer)conjugated antibody (1:300, 127-065-160; Jackson ImmunoResearch Laboratories) was used, followed by signal amplification by a TSA Biotin kit according to the manufacturer's instructions (NEL700A001KT; PerkinElmer, Waltham, MA, USA). For CC1, biotinylated horse anti-mouse (1:250, CI-1000;
Vector Laboratories, Burlingame, CA, USA) was used. CD11c and CC1 stainings were incubated with Streptavidin Alexa Fluor 633 antibody (1:500, S-21375; Thermo Fisher Scientific). Cell nuclei were counterstained with DAPI (1:5000; MilliporeSigma, Burlington, MA, USA).

\section{Morphometry}

For analysis of Iba1, Tmem119, CD68, MHCII, CD11c, PDGFR- $\alpha$, $\mathrm{MBP}$, GFAP, CD3, and CD13 fluorescent staining, sections were scanned using inverted epifluorescent microscopes: Leica DM16000B with an air $\times 20$ /NA0.4 objective lens or Nikon Ti2 Eclipse (Nikon, Tokyo, Japan) with an S Plan Fluor $\times 40 / N A$ $0.6 E L$ WD objective lens. The scanned images were processed and analyzed by Fiji software ( $h$ ttp://fiji.sc/Fiji). Using the DAPI channel, the CC and cingulate cortex (CG) were defined as regions of interest (ROI). Cell density expressed as cells per square millimeter was obtained after manual counting and normalization to ROI. Quantification in 1 section/brain of positive areas was performed upon uniform thresholding and expressed as a percentage of CC. For quantification of $\mathrm{Iba} 1^{+} \mathrm{PU} .1^{+} \mathrm{CD} 13^{+}$cells, $\mathrm{CC}^{+}$cells, and CAII ${ }^{+}$cells, images of $1-3$ sections/brain covering the rostral part of the CC were taken using a Leica TCS-SP5 (Leica Microsystems) inverted confocal setup equipped with 405-, 561-, and 633-nm excitation laser beams. Images in $1024 \times 1024$ format were collected at $2 \mu \mathrm{m}$ for Iba $1^{+} \mathrm{PU} .1^{+} \mathrm{CD} 13^{+}$cells and at $0.5 \mu \mathrm{m}$ for $\mathrm{CC}^{+}{ }^{+}$cells and $\mathrm{CA} \Pi^{+}$cells intervals using a Plan-Apo $\times 20$ /NA0.7 glycerol-immersion objective lens. Representative confocal images in $1024 \times 1024$ or $2048 \times 2048$ formats were taken with a Plan-Apo $\times 63$ /NA1.3 glycerol-immersion objective lens at intervals between 0.5 and $2 \mu \mathrm{m}$. Processing and manual quantification were done in Fiji or Imaris v9.1.0 (Oxford Instruments, Abingdon, United Kingdom).

\section{Flow cytometry}

For analysis of brains by flow cytometry, anesthetized mice were transcardially perfused with Ringer's solution and dissected brains mechanically dissociated by dounce homogenization in HBSS supplemented with $15 \mathrm{mM}$ HEPES, 0.5\% glucose, and $2000 \mathrm{KU}$ of DNaseI (Worthington Biochemical, Lakewood, NJ, USA). To remove the myelin, cells were resuspended in 37\% Percoll (GE Healthcare, Waukesha, WA USA) in DMEM supplemented with $10 \%$ fetal calf serum (FCS) layered over with HBSS and centrifuged without brakes. The cells pelleted were washed with HBSS and stained with viability dye (Zombie NIR, 1:100, 429105; BioLegend, San Diego, CA, USA). After washing in fluorescenceactivated cell sorting (FACS) buffer (PBS supplemented with $2 \%$ FCS, $0.01 \mathrm{M}$ EDTA pH 8.0 , and $\left.0.01 \% \mathrm{NaN}_{3}\right), \mathrm{FcR}$ were blocked by anti-CD16/32 antibody (1:100, 14-0161-85 Thermo Fisher Scientific), cells were stained with antibodies for CD45 PerCP Cy5.5 (1:100, 103132), CSF1R PE (CD115) (1:100, 135505; both by BioLegend), CD11b AF488 (1:100 53-0112-82), CD11c PE (1:100, 12-0114-81; Thermo Fisher Scientific), and nuclei with Hoechst3352 (1:500, H1399. Thermo Fisher Scientific). Fluorescence minus one controls for CD11c and CSF1R were processed in parallel. Filtered samples were acquired on a FACSAria I (BD Biosciences, San Jose, CA, USA) and data analyzed by FlowJo software (BD Biosciences). For analysis of mixed glial cultures, cells seeded at a density of $1 \times 10^{6}$ cells/well into 6-well plates were trypsinized (see Glial cultures preparation and PLX5622 stimulation) and washed 2 times with PBS. Zombie Aqua (1:100, 77143 BioLegend) was used as a viability dye. Blocking of $\mathrm{FCR}$ was done with anti-mouse CD16/32 (1:100, 14-0161-85; Thermo Fisher Scientific) in FACS buffer. OPCs were immunostained 
A Hurdle test

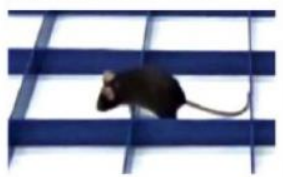

B Bartest

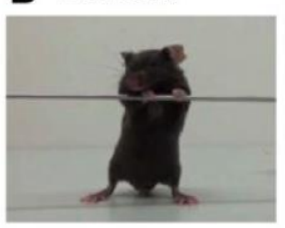

C Bar:Hurdle-intercorrelation

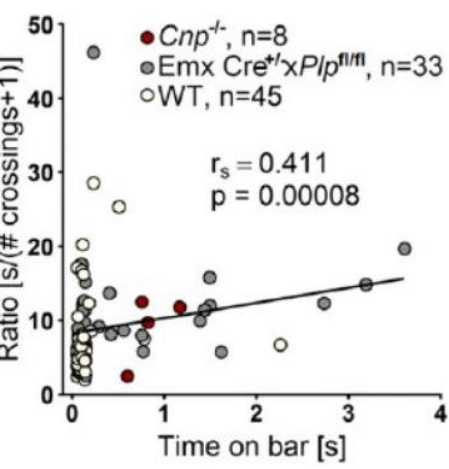

D Catatonia - executive function

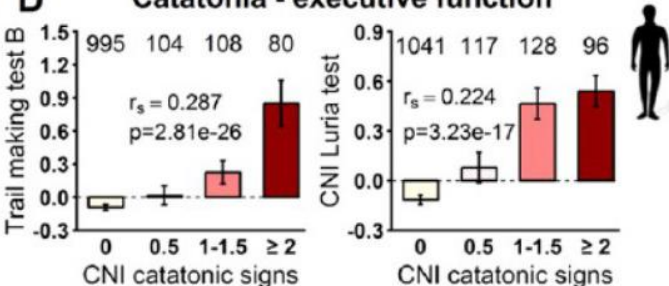

E Study design MRI/MRS measurements

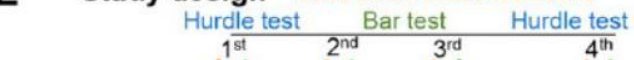
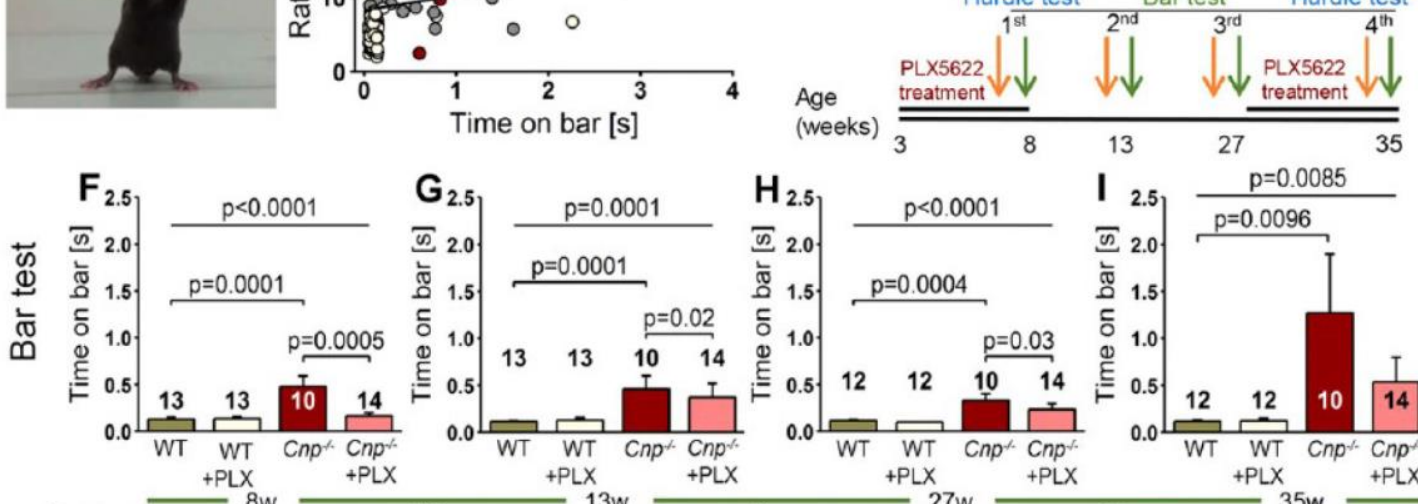

$\mathbf{H}_{2.5} \quad \mathrm{p}<0.0001 \quad$ I $2.5 \mathrm{p}=0.0085$
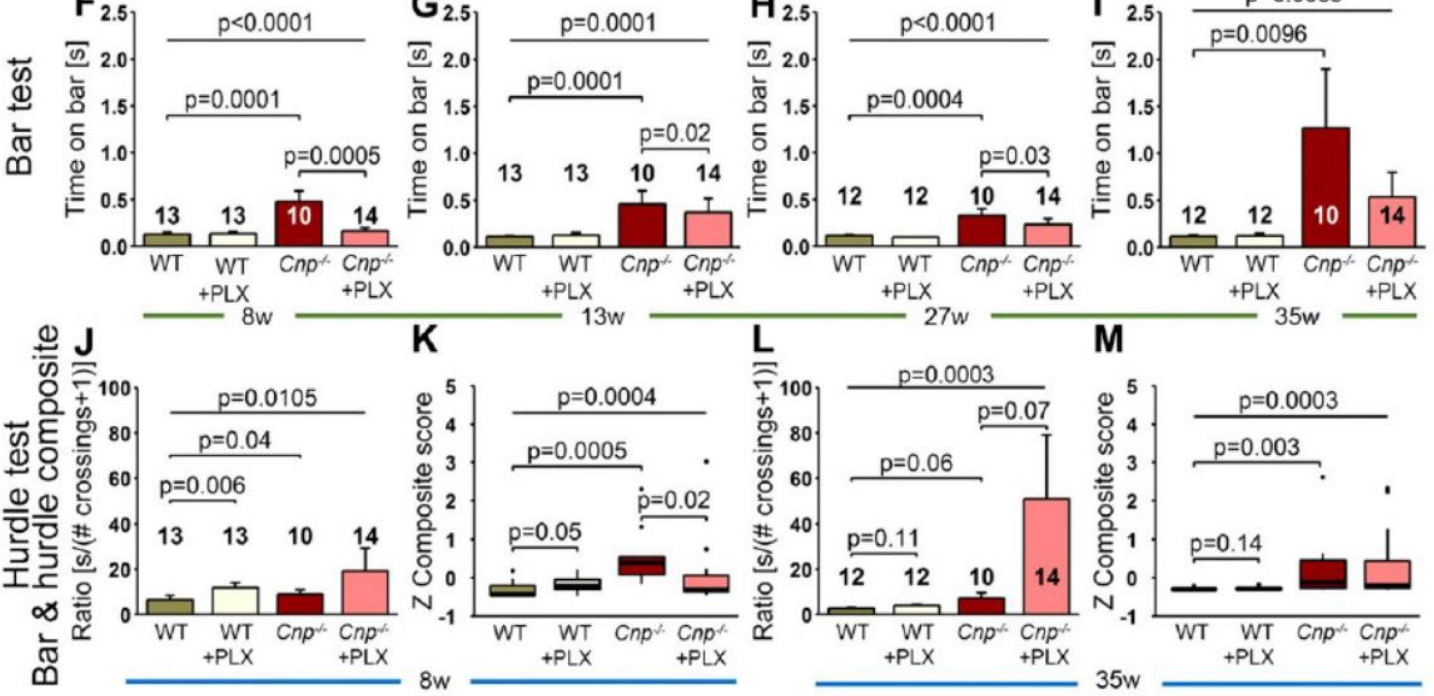

N Control food

O PLX5622

$\mathbf{P}$

Control food PLX5622

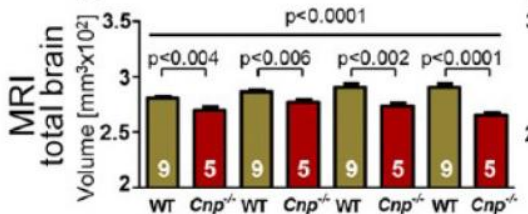

$p<0.0001$

대제

$\mathrm{p}=0.009$
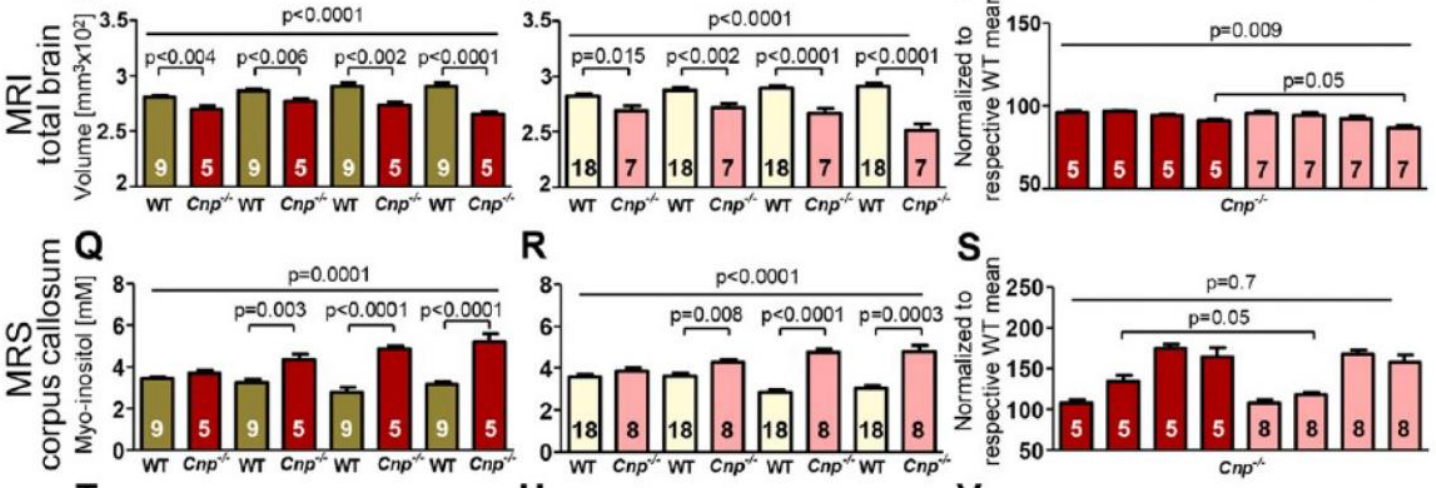

$\mathbf{R}$

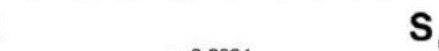

$\mathbf{S}_{5}$

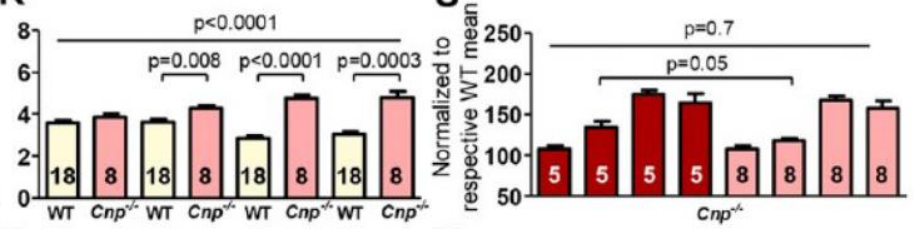

$T$
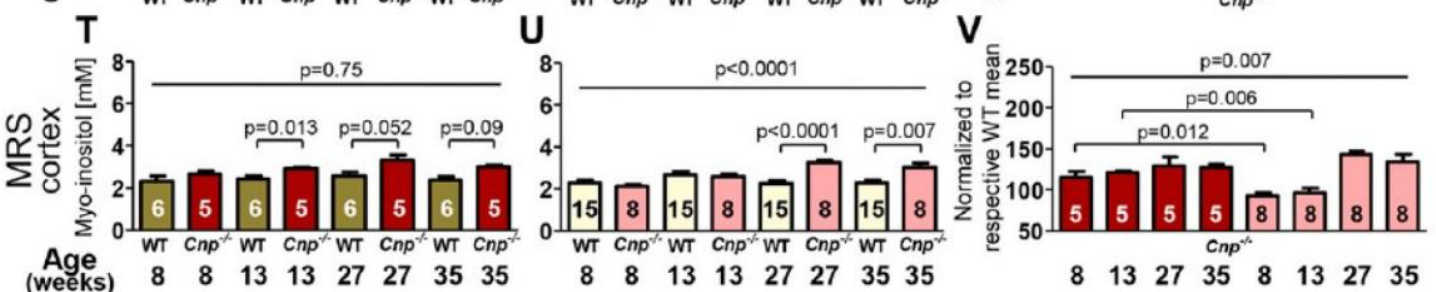

Figure 1. Behavioral and MRI or MRS readouts associated with Cnp deletion; influence of CSF1R inhibition using PLX5622. A) Image of the newly developed hurdle test: mouse climbing over a hurdle on its way to the OF periphery (see also Supplemental (continued on next page) 
for PDGFR- $\alpha$ PE (1:100, 12-1401-81; Thermo Fisher Scientific). For intracellular staining of astrocytes, cells were fixed and permeabilized with Cytofix and Cytoperm (BD Biosciences, Allschwil, Switzerland) and then immunostained for GFAPAF647 (1:100,561470; BD Pharmingen, Allschwil, Switzerland) in saponin block buffer $(0.1 \%$ saponin, $1 \%$ bovine serum albumin and $5 \%$ NHS in PBS). Fluorescence minus one controls were processed in parallel.

\section{Glial culture preparation and PLX5622 stimulation}

Brains from postnatal day 0 or $1 \mathrm{C}-\mathrm{X} 3-\mathrm{C}$ motif chemokine receptor 1 green fluorescence protein $\left(C X_{3} C R 1\right)^{+/ G F P}$ mice were freed from meninges before digestion with trypsin and EDTA $0.05 \%$ for $10 \mathrm{~min}$ at $37^{\circ} \mathrm{C}$. The enzymatic reaction was stopped by adding microglia medium ( $10 \%$ horse serum and $0.5 \%$ penicillin-streptomycin in DMEM, all from Thermo Fisher Scientific) supplemented with $400 \mathrm{IU} /$ brain of DNase I. After mechanical trituration, cells were centrifuged $(10 \mathrm{~min}, 150 \mathrm{~g}$, $\mathrm{RT}$ ) and added to $10 \mathrm{ml}$ prewarmed microglia medium into a poly-D-lysine (PDL)-coated $(50 \mu \mathrm{g} / \mathrm{ml}) 75-\mathrm{cm}^{2}$ cell culture flask. Cells were incubated at $37^{\circ} \mathrm{C}$ and $5 \% \mathrm{CO}_{2}$. Medium changes were performed on $\mathrm{d} 2$ and 3 . On d 5 and 7 , cultures were stimulated with L929-conditioned medium (1:3). Pure microglial cells were harvested ond 7 and 9 by manual shaking of cell culture flasks and seeded at densities of 20,000 cells / well on PDL-coated 24-well plates for IncuCyte Zoom (Sartorius, Ann Arbor, MI, USA) experiments. After $24 \mathrm{~h}$, cells were stimulated with 10,1 , and $0.1 \mu \mathrm{M}$ PLX5622 (kindly provided by Plexxikon) or $0.05 \%$ DMSO as control. Single cells of mixed glial cultures were obtained by trypsination (trypsin and EDTA $0.05 \%$, $10 \mathrm{~min}, 37^{\circ} \mathrm{C}$ ) of the above-mentioned flasks. Cells were washed, centrifuged, and seeded at densities of 350,000 cells / well on PDLcoated 24-well plates or $1 \times 10^{6}$ cells/well on PDL-coated 6-well plates. After 48-72 h, PLX5622 or DMSO at the mentioned concentrations was added to the cells. In the specified IncuCyteZoom experiments, recovery medium consisted of microglia medium with L929-conditioned medium (1:3). Astrocyte-conditioned medium was obtained from mixed glial cultures grown in microglia medium for $7 \mathrm{~d}$. Pure CSF1 was used at a concentration of $10 \mathrm{ng} / \mathrm{ml}$ (PAN-Biotech, Aidenbach, Germany).

\section{Generation of L929-conditioned medium}

L929 mouse fibroblast cultures at a density of 500,000 cells were seeded in $75-\mathrm{cm}^{2}$ cell culture flasks with 55 ml of $\mathrm{L} 929$ medium $(10 \%$ FCS and 1\% penicillin-streptomycin in DMEM). After $7 \mathrm{~d}$ of incubation $\left(37^{\circ} \mathrm{C}, 5 \% \mathrm{CO}_{2}\right)$, $\mathrm{L} 929$-conditioned medium was collected, filtered through a $0.22-\mu \mathrm{m}$ filter, and stored at $-20^{\circ} \mathrm{C}$ until used.

\section{Immunocytochemistry}

Mixed glial cultures were fixed with $2 \%$ acrolein and $3 \%$ formaldehyde in PBS. Cells were permeabilized and blocked with $5 \%$ NHS and $0.5 \%$ Triton X-100 in PBS and immunostained for GFP (goat, 1:500, 600101215; Rockland, Limerick, PA, USA) and PDGFR- $\alpha$ (rabbit, 1:500, 3174; Cell Signaling Technology) in $1 \%$ NHS and $3 \%$ bovine serum albumin and $0.05 \%$ Triton X-100 in PBS overnight. As secondary antibodies, donkey anti-goat Alexa Fluor 488 (A11055) and donkey anti-rabbit Alexa Fluor 647 (A31573) antibodies (1:1000; Thermo Fisher Scientific) were used in $1 \%$ NHS and $3 \%$ bovine serum albumin and $0.05 \%$ Triton X-100 in PBS. Cell nuclei were counterstained with DAPI (1:5000; MilliporeSigma).

\section{Image acquisition and processing of glial cultures}

IncuCyteZoom images $(1400 \times 1040 \mu \mathrm{m})$ were taken with $\mathrm{x} \times 10$ objective once every $2 \mathrm{~h}$ using a green fluorescent channel and bright field. Microglial cell quantification was performed in IncuCyte Zoom software via processing definition with TopHat (The Center for Computational Biology at Johns Hopkins University, Baltimore, MD, USA) parameter (radius $=100 \mu \mathrm{m}$, threshold green calibrated unit $=2$ ) and edge split. Obtained graphs were processed in Prism5 software (GraphPad Software, La Jolla, CA, USA) with approximate Savistsky-Golay smoothing (second order, 13 neighbors). Confocal images were acquired with a Leica TCS-SP5 inverted confocal setup equipped with 405-, 488-, and 633-nm excitation laser beams using an Apo $\times 63 /$ NA1.3 glycerol-immersion objective lens. Images in $2048 \times 2048$ were imaged in stacks with a $z$ step size of $1 \mu \mathrm{m}$ and line mean of 2 . Stacks were analyzed using Fiji

Videos S1 and S2). B) Image of the bar test: mouse exhibiting a typical catatonic posture. $C$ ) Intercorrelation of bar and hurdle test using mice from 3 different test validation cohorts. $X$ axis: time spent on the bar (s). $Y$ axis: hurdle test measured as time (s) per number of crossings (\#) + 1 [s/(\#+1)]. Data points were jittered for better visual representation. Spearman rank correlation with 2-sided significance testing indicates a positive correlation between the 2 catatonia tests. $D$ ) Correlation supporting translational data: relationship between severity of catatonic signs as determined by the CNI and 2 independent readouts of executive function in human schizophrenic subjects of the GRAS Data Collection. Scale bars represent means \pm sEM of Trail Making Test B and Luria test (standardized linear regression residuals after correction for age and medication using chlorpromazine equivalents, sorted by severity of CNI catatonic signs). Spearman rank correlation (2-sided significance testing) indicates a positive relationship between executive function and catatonic signs. $E$ ) Schematic overview of longitudinal study design with PLX5622 (or control diet) phases (black bars), time points of behavioral experiments, or MRI and MRS measurements (arrows). $F-I$ ) Catatonic signs in WT and $C n p^{-1-}$ mice measured by the bar test. Mice were tested after a 5-wk PLX5622 or control-food diet (age $8 \mathrm{wk})(F)$, after 5 and $19 \mathrm{wk}$ of microglial repopulation (age 13 or $27 \mathrm{wk}$, respectively) $(G, H)$ and at the end of another 8-wk diet with PLX5622 or control food (age $35 \mathrm{wk})(I) . J M$ ) Executive function of WT and $C n p^{-/}$ mice in hurdle test and composite score of hurdle and bar tests: mice were hurdle-tested twice after a 5-wk PLX5622 or control diet (age $8 \mathrm{wk})(/)$ and after an 8-wk diet (age $35 \mathrm{wk})(L)$; composite score of catatonic signs $(K, M)$ shown as means of $Z$ standardized bar and hurdle test results in WT and $\mathrm{Cnp}^{-1-}$ mice; data presented as Tukey's boxplots; $n$ numbers are equivalent to $(J, L)$, respectively. $N, O)$ MRI of total brain: longitudinal volumetric analysis in WT and $\mathrm{Cnp}^{-/-}$mice without and with PLX5622 treatment (design shown in $E$ ). $P$ ) Data of $\mathrm{Cnp}^{-/-}$mice normalized to respective WT means. Note reduced total brain volume in PLX5622-treated mice at 35 wk. $Q R$ ) MRS CC: myo-inositol in WT and $C n p^{-1-}$ mice without $(Q)$ and with $(R)$ PLX5622 treatment; MRS performed along with MRI. S) Data of $\mathrm{Cnp}^{-1-}$ mice normalized to respective WT means. Note the reduction of myo-inositol in PLX5622-treated $C n p^{-1-}$ mice only at $13 \mathrm{wk}$. $T-U$ ) MRS cortex: myo-inositol in WT and $C n p^{-/-}$mice without (T) and with $(U)$ PLX5622 treatment. MRS performed along with MRI. $V$ ) Note the reduction of myo-inositol in PLX5622-treated $C n p^{-1-}$ mice only up to $13 \mathrm{wk}$. All data $(F-V)$ were individually tested for Gaussian distribution using the Kolmogorov-Smirnov test. Nonparametric Kruskal-Wallis test was performed $(F M, R)$ for multiple group comparisons, followed by post hoc 2-tailed Mann-Whitney $U$ tests. Two-way ANOVA was performed $(N-Q S-V)$ followed by post hoc 2-tailed unpaired $t$ tests. Numbers $(n)$ indicated above or within bars; w, week. 
software, and colocalization of fluorescent labels was shown via orthogonal views.

\section{MRI and ${ }^{1} \mathrm{H}-\mathrm{MRS}$}

Mice were anesthetized with $5 \%$ isoflurane, intubated, and kept at $1.75 \%$ isoflurane by active ventilation with a constant respiratory frequency of 85 breaths/min (Animal Respirator Advanced; TSE Systems, Bad Homburg, Germany). MRI and localized ${ }^{1} \mathrm{H}-\mathrm{MRS}$ were performed at a magnetic field strength of 9.4T (Bruker, Billerica, MA, USA). MRI consisted of T2-weighted images (2-dimensional fast spin echo, repetition time/echo time = $2800 / 11 \mathrm{~ms}, 100 \times 100 \times 300 \mu^{3}$ ) based on which respective volumes of interest for localized proton magnetic resonance $(M R)$ spectra were positioned. MR spectra (stimulated echo acquisition mode, TR/TE/mixing time $=6000 / 10 / 10 \mathrm{~ms}$ ) were obtained from a volume of interest in the cortex $\left(3.9 \times 0.7 \times 3.2 \mathrm{~mm}^{3}\right)$ and CC $\left(3.9 \times 0.7 \times 1.7 \mathrm{~mm}^{3}\right)$. Metabolite quantification was completed with spectral evaluation by LCModel (v.6.3-1L). Results with Cramer-Rao lower bounds $>\mathbf{2 0} \%$ were excluded from further analysis. Volumes of total brain, $\mathrm{CC}$, and cortex were determined using MT-weighted 3-dimensional MRI (100 $\mu \mathrm{m}$ isotropic resolution) and manual segmentation of respective areas (Amira Software v.5.4.5; Visage Imaging, Richmond, VIC, Australia).

\section{Statistics}

For human studies, Spearman rank correlations were performed on standardized linear regression residuals after correction for age and medication (chlorpromazine equivalents). For mouse studies, Gaussian distribution was determined by KolmogorovSmirnov tests. Two-way ANOVA with or without repeated measures was used for normally distributed data and KruskalWallis test for data without normal distribution. Between-group comparisons were performed by Student's $t$ test or MannWhitney $U$ test. Mann-Whitney $U$ tests (as denoted by $\$$ ) were performed on the proportion of Tmem $119^{-}$cells (green) among Tmem $119^{-}$and Tmem $119^{+}$cells (green and gray), [i.e., Tmem $119^{-} /\left(\right.$Tmem $119^{-}+$Tmem $\left.\left.119^{+}\right)\right]$. To assess the correlation between hurdle and bar tests, a Spearman rank correlation was performed. One outlier (WT) was identified and excluded from correlation analyses. A value of $P \leq 0.05$ was considered significant. All statistical analyses were performed using Prism5 software or R v.5.0 (R Foundation for Statistical Computing, Vienna, Austria).

\section{RESULTS}

\section{Executive dysfunction and catatonia: development of the hurdle test for mice}

In need of a simple test to specifically measure the executive dysfunction aspect of catatonia, we developed the hurdle test for mice (Fig. $1 A$ and Supplemental Videos S1 and S2). This new executive behavioral tool allows the rating of catatonia-related psychomotor dysfunction. It displays high intercorrelation with the bar test (Fig. 1B,C), the thus far only available instrument for assessing catatonic signs in mice $(3,4,15)$. The hurdle test is performed in an OF arena equipped with an in-house, selfmanufactured, comb-like grid of $2.7 \mathrm{~cm}$ height. Animals started the first trial in the center. NormalWT mice, feeling uncomfortable in the illuminated center, pushed to reach the periphery as fast as possible by climbing over the hurdles. Catatonic mice, however, remained somewhat perplexed and indecisive in the starting comb, moving around planlessly. After some delay compared with WT mice, they also crossed hurdles and reached the wall. The ratio of time to periphery and number of hurdle crossings is used as readout of performance. As an ideal add-on of this test, any underlying deficits in motor function or learning capability are easily coevaluated or excluded because $\mathrm{Cnp}^{-1-}$ mice (as well as other myelin mutants with catatonic signs; unpublished results) usually perform normally in the second trial. Thus, complementing the bar test, the hurdle test provides a robust measure of catatoniarelated executive dysfunction, allowing us to create a catatonia severity composite score together with the bar test (standard operating procedure in analogy to our autism severity composite score for mice found in ref. 16; manuscript on comprehensive hurdle test description in preparation).

\section{Executive dysfunction and catatonia: correlation in patients with schizophrenia}

To directly explore also in humans the relation of catatonia and executive function, we employed our GRAS Data Collection of deeply phenotyped schizophrenic subjects $(10,11)$. Indeed, the severity of catatonic signs correlated highly significantly with 2 different executive tests: the Trail Making Test B (14), assessing executive function via visual search, processing speed, and mental flexibility, and the Luria test (subscale of CNI) (13), evaluating executive motor function and motor learning and memory (Fig. 1D).

\section{Differential response of pathologic bar and hurdle test performance of $\mathrm{Cnp}^{-7-}$ mice to CSF1R inhibition by PLX5622}

In the 2-treatment study, bar and hurdle tests were conducted regularly from 8 to 35 wk of age (design Fig. $1 E$ ). In both tests, $\mathrm{Cnp}^{-1-}$ mice continuously performed worse compared with WT mice (Fig. $1 F-M$ ). Strikingly, however, hurdle test performance appeared even poorer under PLX5622 in both $\mathrm{Cnp}^{-/-}$and WT littermates, whereas the bar test performance of $\mathrm{Cnp}^{-/-}$mice improved (Fig. $1 F-I$ ), as previously reported by Janova et al. (4). Thus, the catatonia composite score, based on these 2 measures, integrates overall catatonia severity, including executive performance in $\mathrm{Cnp}^{-1-}$ mice, but also clearly reflects the incomplete relief of symptoms by PLX5622 (Fig. $1 J-M$ ).

\section{Repeated MRI and MRS in Cnp ${ }^{-1-}$ mice failed to document a lasting benefit of CSF1R inhibition by PLX5622}

Comparative morphometrical analysis of total brain volume revealed an overall reduction in $\mathrm{Cnp}^{-1-} \mathrm{com}-$ pared with WT mice (Fig. $1 N-P$ ). This progressive brain atrophy was not alleviated by PLX5622 at any time and 
A

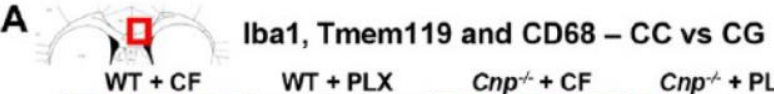

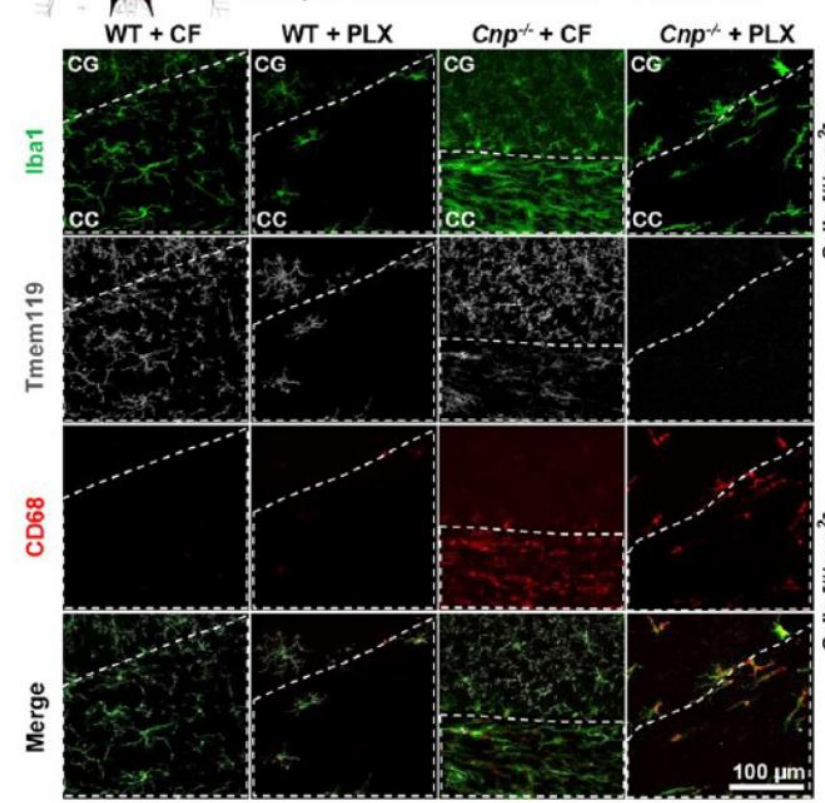

D

Inflammation progression to prefrontal cortex

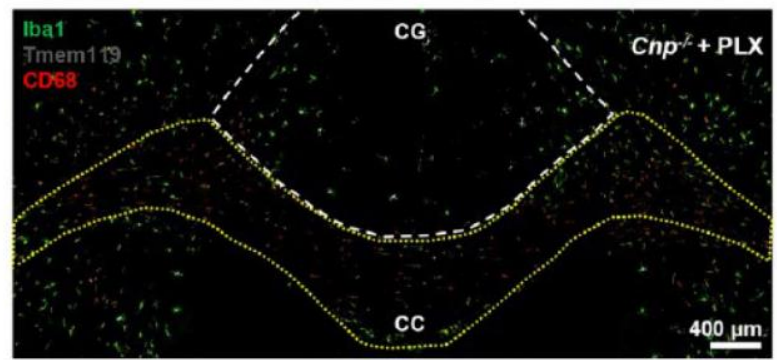

B Iba1 vs Tmem119 - corpus callosum

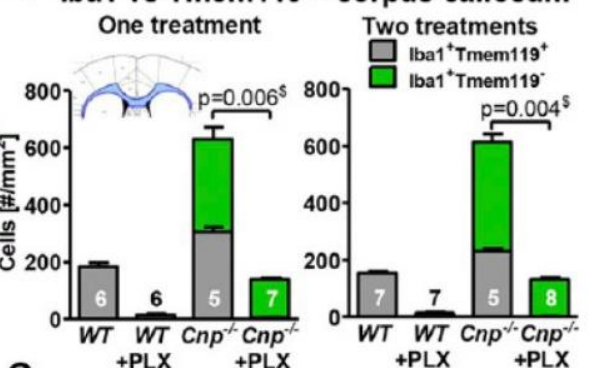

C

Iba1 vs Tmem119 - cingulate cortex

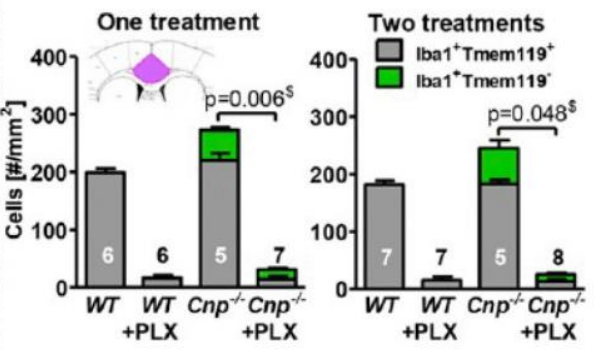

CD68 - corpus callosum

E One treatment Two treatments

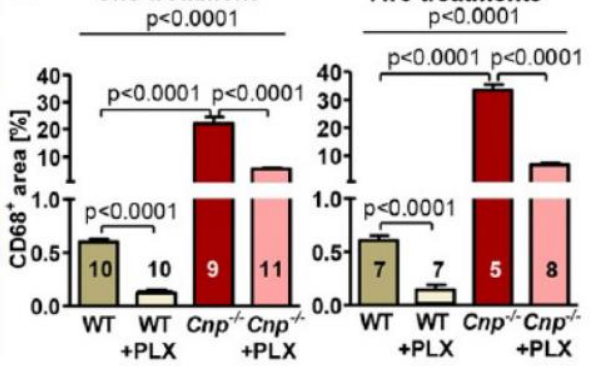

$\mathbf{F}$

Iba1, MHCII, Tmem119 - corpus callosum
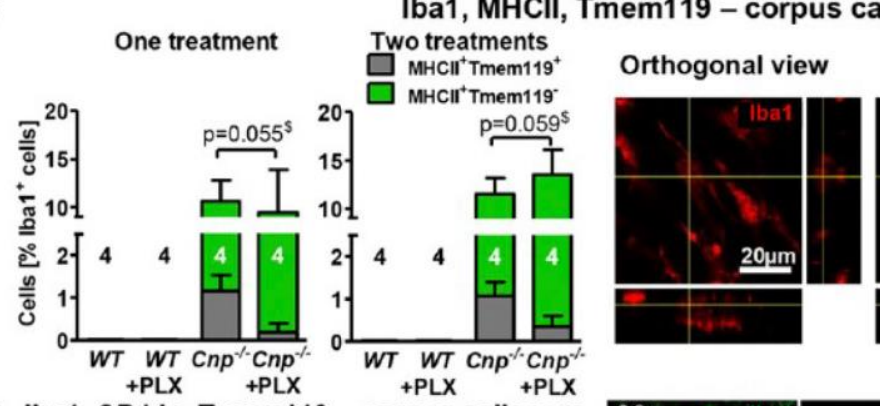

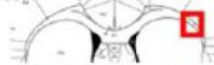

$\mathrm{Cnp}^{\%}+\mathrm{CF}$

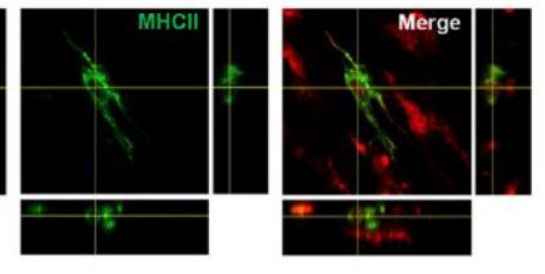

G Iba1, CD11c, Tmem119-corpus callosum
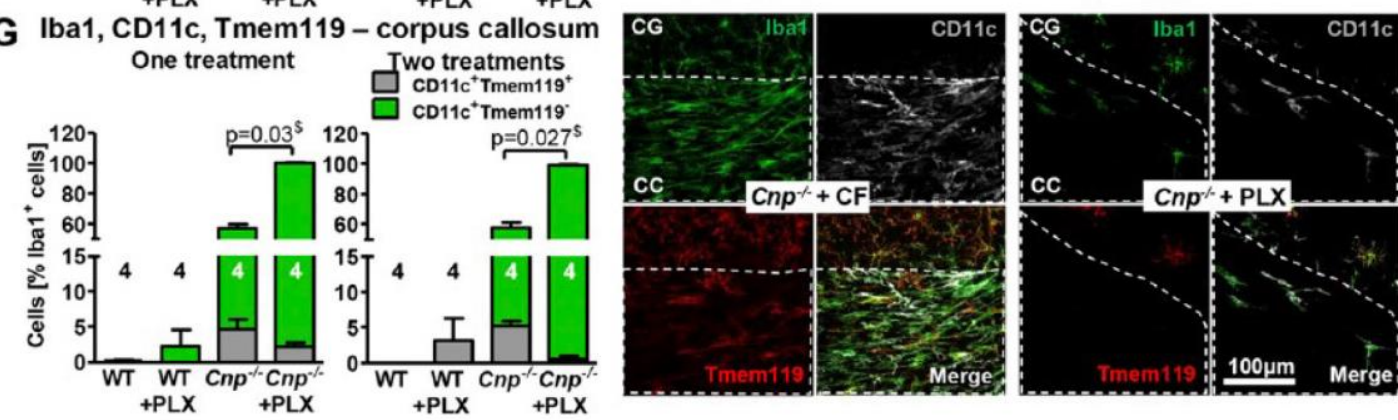

Figure 2. Microglial characterization under inflammation in $\mathrm{Cnp}^{-/-}$mice and upon CSF1R inhibition treatment either once, starting at age $27 \mathrm{wk}$ for $8 \mathrm{wk}$, or twice, starting additionally at age $3 \mathrm{wk}$ for $5 \mathrm{wk}$ (compare design in Fig. 1E). A) Representative (continued on next page) 
even tended to be inferior at the last time point. Myoinositol as the MRS readout of (micro)gliosis benefitted just at the beginning of the measurement series from CSF1R inhibition in both CC and cortex (Fig. 1Q-V).

\section{Microglial phenotype in the genetic neuroinflammatory condition of $\mathrm{Cnp}^{-1-}$ mice: effect of CSF1R inhibition}

CSF1R inhibition in adult $\mathrm{Cnp}^{-/-}$mice results in a considerable amount of leftover microglia after $8 \mathrm{wk}$ of treatment (4), possibly related to their activation status or reduced responsiveness in neuroinflammatory conditions. To start to define their phenotype under depletion, we evaluated the number of $\mathrm{Iba1}{ }^{+} \mathrm{Tmem} 119^{+}$vs. Iba1 ${ }^{+} \mathrm{Tmem} 119^{-}$ cells. Tmem119 is a microglial signature gene not expressed by monocyte-derived or other brain macrophages (17), and decreased under inflammatory conditions (18). Since we did not find appreciable numbers of monocytes or monocyte-derived macrophages in the brains of $\mathrm{Cnp}^{-/-}$mice (brain FACS analysis, data not shown), we considered all $\mathrm{Iba1}^{+}$cells to be microglia. We found Tmem 119 coexpressed in basically all $\mathrm{Iba}^{+}$WT cells but reduced to $\leq 50 \%$ in $\mathrm{Iba1}^{+}$cells of the $\mathrm{Cnp}^{-/-} \mathrm{CC}$. All leftover microglia of $\mathrm{Cnp}^{-/-}$mice have lost Tmem119 expression (Fig. 2A, B). In the CG with its lower spread-over inflammation, the results look similar but less pronounced (Fig. 2A, $C, D$ ).

Another microglial inflammation or phagocytosis marker, CD68, expressed by macrophages in late endosomes and lysosomes (19), is highly increased in $\mathrm{Cnp}^{-1-}$ CC and markedly reduced under PLX5622 (Fig. $2 A, D$, $E)$. As poor antigen-presenting cells with low levels of costimulatory receptors, microglia express $\mathrm{MHCII}$ only upon activation in inflammatory conditions to interact with brain-invading $\mathrm{CD} 4^{+} \mathrm{T}$ cells $(20,21)$. Hence, we find $\mathrm{Iba}^{+} \mathrm{MHCII}^{+}$cells exclusively in inflammation and mostly devoid of Tmem119 expression (Fig. 2F). Similarly, CD11c is barely found in normal WT microglia but augmented under inflammation. Upon PLX5622, its expression in leftover microglia is even further enhanced as demonstrated by IHC as well as whole-brain FACS (Figs.
$2 \mathrm{G}$ and Fig. 3A, B). The integrin CD11c (Itgax gene) binds fibrinogen and is highly expressed by dendritic cells, monocytes, macrophages, and neutrophils. During developmental myelogenesis, microglia express CD11c (22), and a small subpopulation retains this marker in adulthood (23). It is increased in neurodegenerative disease with simultaneous up-regulation of microglial phagocytosisrelated genes and down-regulation of signature genes (18), as shown here also with Tmem119. Astoundingly, there was no appreciable difference between 1 and 2 PLX5622 treatments regarding any of these readouts (Fig. $2 A-G$ ). Interestingly, CSF1R is equally expressed and also upregulated under inhibition by PLX5622 in both WT and $\mathrm{Cnp}^{-/-}$microglia in the sense of a compensatory mechanism (Fig. 3C).

\section{Microglia exposed to CSF1R inhibition affect OPCs and oligodendrocytes}

To study the effects of CSF1R inhibition on different glial cell types, we performed a FACS analysis of mixed glial cultures from $C X_{3} C R 1^{+/ G F P}$ mice after $7 \mathrm{~d}$ in vitro. Whereas microglial numbers show a dose-dependent decline under PLX5622, we see no reduction but a stepwise increase in $\mathrm{GFAP}^{+}$astrocytes, together with a decrease in PDGFR- $\alpha^{+}$OPCs, particularly strong under $10 \mu \mathrm{M}$ PLX5622 (Fig. 3D). The mechanism of disappearance of OPCs under PLX5622, namely a highly aggressive phagocytosis by microglia before they undergo cell death (premortal phagocytosis), is revealed in vitro by time-lapse imaging and immunocytochemistry (Fig. 3E and Supplemental Video S3). We note that neither astrocytes nor fibroblasts (added to mixed glial cultures) are a target of microglial phagocytosis (unpublished results). Searching in brain sections from PLX5622 treated mice for an indication of OPC phagocytosis by microglia also in vivo, we found scattered Iba $1^{+}$cells with engulfment of PDGFR- $\alpha^{+}$material (Fig. $3 F$ ), a feature not seen in untreated mice. Thus, phagocytosis by microglia may at least partly account for the decrease in PDGFR- $\alpha^{+}$OPCs under PLX5622 (Fig. 3G). Still unexplained is the rise of PDGFR- $\alpha^{+}$OPCs in the

IHC images of Iba1, Tmem119, and CD68 staining in CC and CG area in WT or Cnp ${ }^{-/-}$mice (age 35 wk) after 8 wk of PLX5622 or control food. Red box in the schematic overview on top is indicating the approximate area of shown images. The white dashed line shows border of CC. B, C) IHC quantification of $\mathrm{Ibal}^{+}$and Tmem $119^{+}$cells within CC $(B)$ or CG $(C)$ in WT or Cnp ${ }^{-/-}$mice (age $35 \mathrm{wk}$ ) after $8 \mathrm{wk}$ of PLX5622 or control food (1 treatment, started at $27 \mathrm{wk}$; left) or in WT or $\mathrm{Cnp}{ }^{-/-}$mice (age $35 \mathrm{wk}$ ) treated for $5 \mathrm{wk}$ (starting at age $3 \mathrm{wk}$ ) and, after $19 \mathrm{wk}$ of repopulation, treated again for 8 wk with PLX5622 or control food (2 treatments; right). Compare treatment design shown in Fig. 1E; schematic overviews on top of the bar graphs are indicating ROIs used for quantification. D) Representative IHC image of a Cnp I $^{-1-}$ mouse (age 35 wk) treated twice with PLX5622 Inflammation from the CC (yellow dotted line) is progressing into the CG (white dashed line). E) IHC quantification of CD68 area within CC of WT or $\mathrm{Cn} p^{-1-}$ mice (age $35 \mathrm{wk}$ ) after 1 or 2 PLX5622 treatments; quantified ROI from B. F) Percentages of

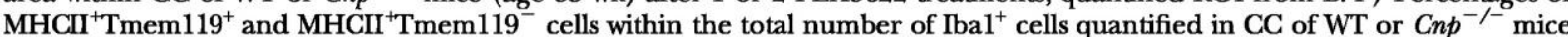
(age 35 wk) after 1 or 2 PLX5622 treatments; quantified ROI from $B$. Right panel gives orthogonal views of representative $\mathrm{Iba}^{+} \mathrm{MHCII}^{+}$cells in a $\mathrm{Cnp}{ }^{-1-}$ mouse treated with control food. Approximate area of shown image is indicated by the red box in the schematic overview on top. $G$ ) Percentages of CD11c ${ }^{+} T_{m e m} 119^{+}$and CD11c ${ }^{+}$Tmem $119^{-}$cells within the total number of $\mathrm{Iba}^{+}$cells quantified in CC of WT or $\mathrm{Cnp}^{-/-}$mice (age $35 \mathrm{wk}$ ) after 1 or 2 PLX5622 treatments; quantified ROI from B. Right panel shows representative images of Iba1, CD11c, and Tmem119 staining in $\mathrm{Cnp}^{-/-}$mice treated with PLX5622 or control food. All data $(B, C, E-G)$ were individually tested for Gaussian distribution using the Kolmogorov-Smirnov test. Two-tailed Mann-Whitney $U$ tests (as denoted by $\$$ ) were performed on the proportion of Tmem119 ${ }^{-}$(green bar) vs. Tmem119 (gray bar) $(B, C, F, G)$. Two-way ANOVA was performed $(E)$, followed by post hoc 2-tailed $t$ tests. CF, control food. All data are shown as means \pm SEM; $n$ indicated within bars. 


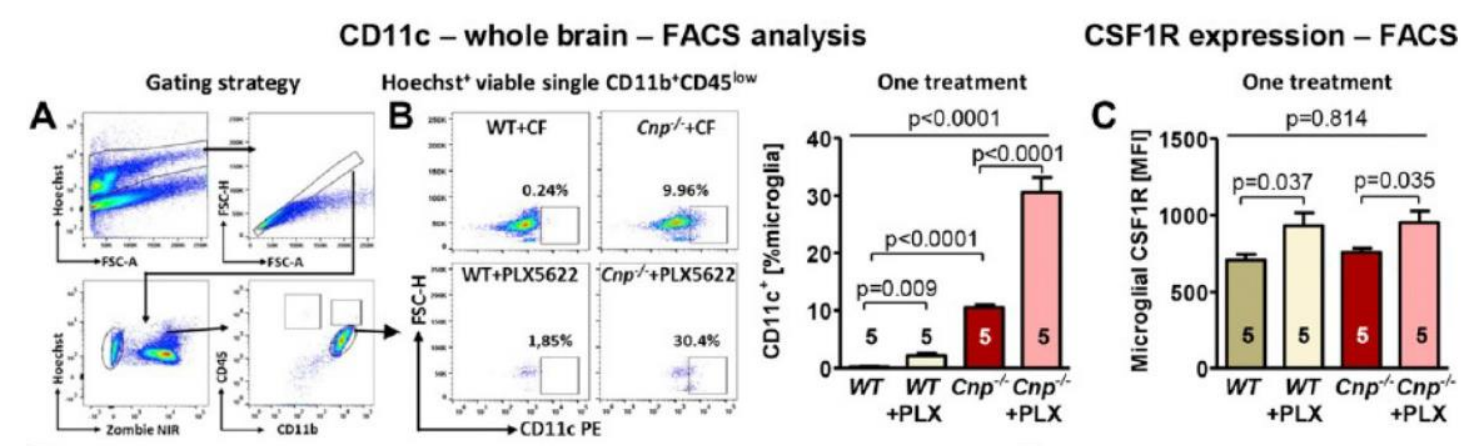

D

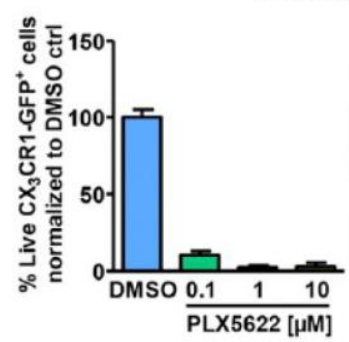

F Phagocytosis in vivo

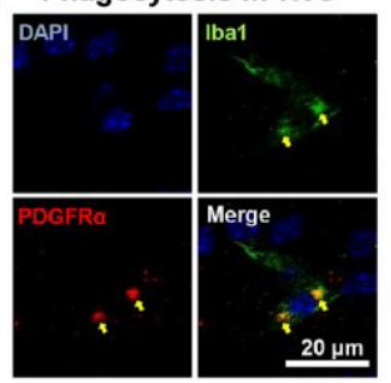

H CC1 - corpus callosum
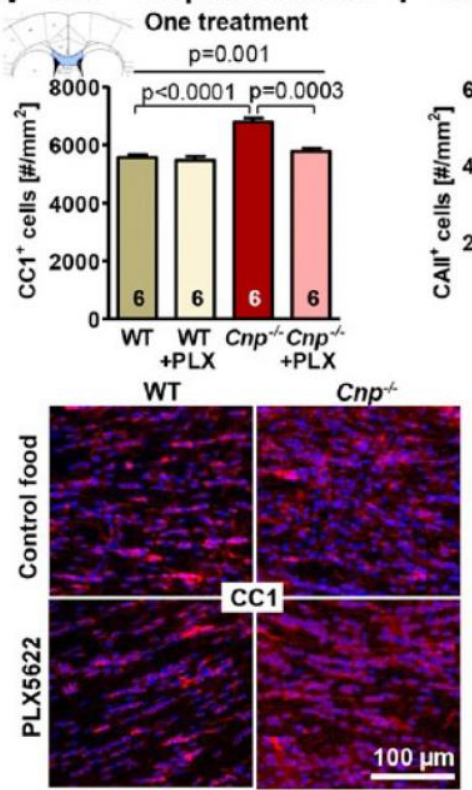

$\rightarrow \mathrm{CD} 11 \mathrm{CP}$

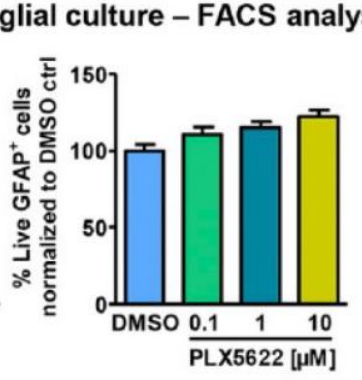

Orthogonal view

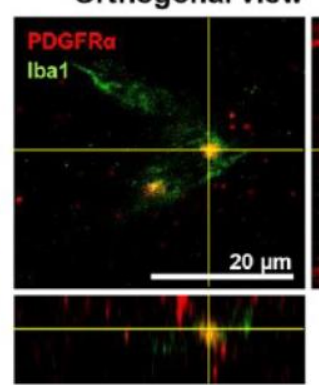

CAll - corpus callosum One treatment

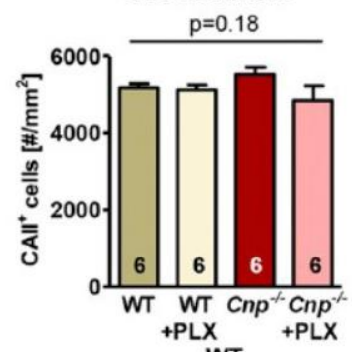

WT

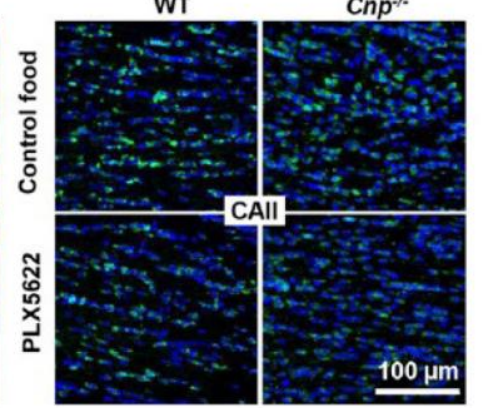

J

E Phagocytosis in vitro (DIV5)
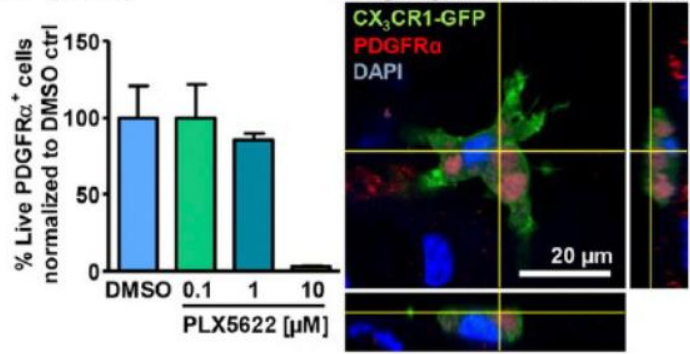

PDGFR $\alpha$ - corpus callosum

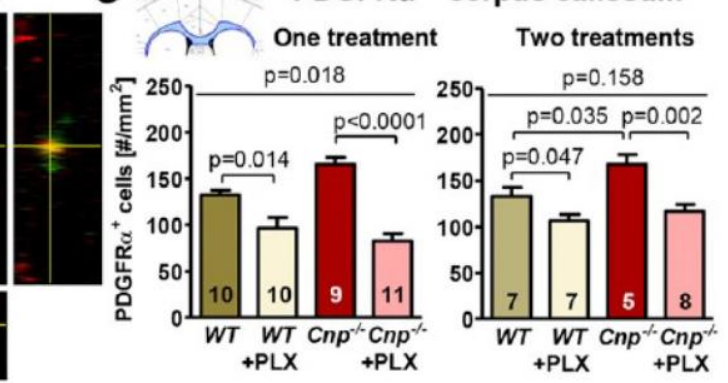

MBP - corpus callosum

One treatment Two treatments
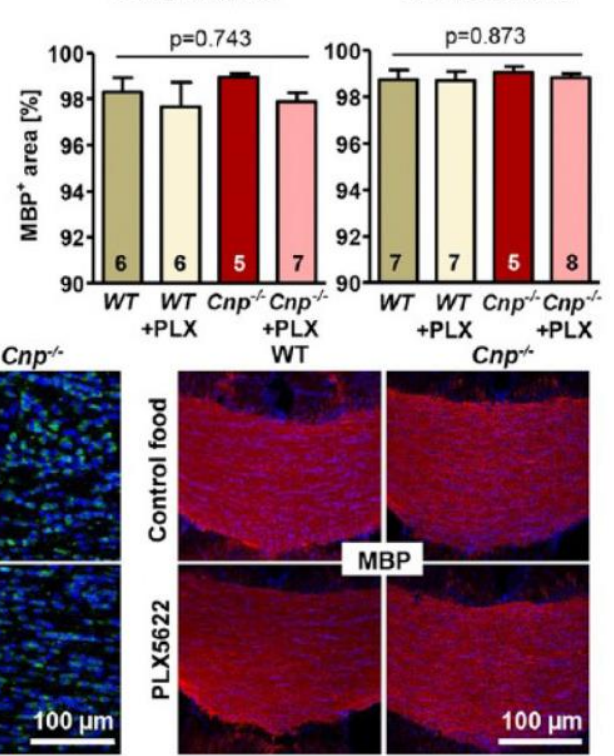

Figure 3. Microglia under CSF1R inhibition phagocytose OPCs (see also Supplemental Video S3) before they are eliminated. A) Gating strategy used for identification of microglia by flow cytometry. Only viable, nucleated (Hoechst $\left.{ }^{+}\right)$, single, $\mathrm{CD} 11 \mathrm{~b}^{+}, \mathrm{CD}^{4} 5^{\text {low }}$ (continued on next page) 
inflammatory condition of $\mathrm{Cnp}^{-/-}$mice (Fig. 3G). Assessing oligodendrocyte numbers by $\mathrm{CC} 1$ staining, we found in $\mathrm{Cnp}^{-1-}$ mice a similar increase and a reduction to WT levels by PLX5622. However, in contrast to PDGFR $\alpha^{+}$OPC, no effect was seen on $\mathrm{CC} 1$ stained oligodendrocytes in WT (Fig. $3 H$ ). This pattern is essentially confirmed (even though not significant; $P=$ 0.18 ) using CAII as another oligodendrocyte marker (Fig. 3I). Determining the $\mathrm{MBP}^{+}$area did not yield differences, confirming that myelination is not visibly affected (Fig. 3J). Once more, no obvious difference was found between 1 and 2 PLX5622 treatments wherever compared (Fig. 3).

\section{Cellular interplay determines microglial death under PLX5622}

To better understand the role of cellular interactions for microglial death under CSF1R inhibition, we performed a series of studies comparing pure microglial with mixed glial cultures (Fig. 4A). Surprisingly, pure microglial cultures, altogether showing decreased survival when remaining in their medium over $1 \mathrm{wk}$, did not respond to PLX5622 with enhanced cell death compared with DMSO control. In contrast, in a mixed glial culture, microglial death under CSF1R inhibition is nearly complete after $1 \mathrm{wk}$, with survival of cells in the DMSO control condition and even recovery of the condition with the lowest PLX5622 concentration $(0.1 \mu \mathrm{M})$ upon termination of PLX5622 exposure and addition of fresh medium. A very similar pattern is observed in pure microglial cultures if astrocyte-conditioned medium is added, underlining the importance of astrocytic contribution to both PLX5622 induced death and recovery thereafter. Adding CSF1 to pure microglial cultures increased survival and proliferation just of the DMSO control cultures. Under these conditions, cultures with any PLX5622 dose with or without CSF1 behaved similarly and all dissociated from this control curve. Inflammatory gliosis, measured by the $\mathrm{GFAP}^{+}$area, and invasion of $\mathrm{T}$ cells, determined by $\mathrm{CD}^{+}$cell counts, are enhanced in $\mathrm{Cnp}^{-1}$ mice and alleviated by PLX5622 (Fig.
4B). In WT mice, PLX5622 tends to increase the GFAP ${ }^{+}$area, a finding in good agreement with our in vitro data (Fig. $3 D$ ).

\section{Appearance of $\mathrm{CD}^{2} 3^{+} \mathrm{Iba1}{ }^{+} \mathrm{PU} .1^{+}$cells under PLX5622 in Cnp ${ }^{-1-}$ associated neuroinflammation suggests a role of pericytes for microglial repopulation}

CD13 (ANPEP gene; aminopeptidase $\mathrm{N}$ ) marks pericytes in the brain (24) and after injury (i.e., stroke) is coexpressed by $\mathrm{Iba}^{+}$cells with myeloid characteristics. We find the $\mathrm{CD}^{+} 3^{+}$area in the $\mathrm{CC}$ increased in size upon inflammation $\left(\mathrm{Cnp}^{-/}\right)$and further increased under PLX5622, by tendency even in the WT condition (Fig. 4C). In CC of $\mathrm{Cnp}^{-/-}$ mice, we note $\mathrm{CD} 13^{+}$cells that are triple labeled with Iba1 and PU.1 (as microglia and myeloid markers) and not seen in WT mice. These cells, which strongly resemble microglia by morphology, were more abundant under PLX5622 (Fig. 4D, E). It appears that the cessation of PLX5622 treatment could cause these cells to give rise to microglia. Indeed, as a first slight hint in this direction, we saw a decrease of these triple-labeled cells paralleling the increase in repopulating microglia (Fig. $4 F, G$ ).

\section{DISCUSSION}

The current preclinical study was initiated in preparation of potential human treatment trials for catatonia and builds on and extends our previous work on genetically induced white matter inflammation therewith associated catatonia and the impact of microglia ablation by CSF1R inhibition using PLX5622 $(3,4,25)$. CSF1R is expressed in the brain mostly by microglia, and its genetic deletion or pharmacological inhibition leads to their depletion, pointing to the importance of CSF1 and CSF1R in microglial survival and proliferation (26). Using our $\mathrm{Cnp}^{-1-}$ mouse model, we made several key observations. Perhaps the most surprising and clinically most important message regarding CSF1R inhibition is that $5 \mathrm{wk}$ of prevention, from age 3 to $8 \mathrm{wk}$, plus an additional $8 \mathrm{wk}$ of treatment,

cells were considered as microglia. B) Representative dot plots and quantification of CD11c microglia in whole brains of WT or $C n p^{-1-}$ mice (age $23 \mathrm{wk}$ ) after $8 \mathrm{wk}$ of PLX5622 or control food. $C$ ) Quantification of CSF1R levels on microglia in $A$ by flow cytometry in $B$. $D$ ) Flow cytometry analysis of $\mathrm{CX}_{3}$ CR1-GFP ${ }^{+}$mixed glial cultures stimulated with different PLX5622 concentrations or DMSO control for $7 \mathrm{~d}$ in vitro. Quantifications (percentage of live cells) shown for microglia $\left(\mathrm{CX}_{3} \mathrm{CR}_{1-\mathrm{GFP}^{+}}\right.$), astrocytes $\left(\mathrm{GFAP}^{+}\right)$, and OPCs (PDGFR- $\left.\alpha^{+}\right)$. E) Orthogonal views illustrate a representative microglial phagocytosis of OPCs in mixed glial cultures kept under $10 \mu \mathrm{M}$ PLX5622 stimulation until DIV5. F) Translation to in vivo: left panel shows representative IHC images of Ibal and PDGFR- $\alpha$ staining in CC area of a $\mathrm{Cnp}^{-1-}$ mouse (age $23 \mathrm{wk}$ ) after 8 wk of PLX5622. Yellow arrows indicate phagocytosed particles. Right panel gives orthogonal views of microglial phagocytosis of OPCs in vivo. $G$ ) IHC quantification of PDGFR- $\alpha^{+}$cells in CC of WT or $C n p^{-/-}$mice (age $35 \mathrm{wk}$ ) after 1 or 2 treatments with PLX5622 or control food (see design in Fig. $1 E$ ). Schematic overview is indicating ROI. $H$ ) IHC quantification and underneath representative images of $\mathrm{CCl}^{+}$cells within CC of WT or $\mathrm{Cnp} p^{-/-}$mice (age $35 \mathrm{wk}$ ) after 1 treatment with PLX5622 or control food (see design in Fig. $1 E$ ); schematic overview is indicating ROI. $I$ IHC quantification and underneath representative images of CAII in CC of WT or Cn $p^{-/ 2}$ mice (age $35 \mathrm{wk}$ ) after 1 treatment with PLX5622 or control food (see design in Fig. 1E); ROI used for quantification in $H$. $J$ ) IHC quantification of $\mathrm{MBP}^{+}$area as indicator of intact myelin sheath in CC of WT or $\mathrm{Cnp}^{-1-}$ mice (age 35 wk) after 1 or 2 treatments with PLX5622 or control food (see design in Fig. 1E); representative images are shown underneath; quantified ROI from G. All data $(B, C, G-J)$ were individually tested for Gaussian distribution using the Kolmogorov-Smirnov test. Two-way ANOVA was performed for $B, C, G-I$, and left graph in $J$, followed by post hoc 2-tailed $t$ tests in $B, C, G, H$. Nonparametric Kruskal-Wallis test was used for multiple group comparisons in right graph in J. CF, control food; DIV, $\mathrm{d}$ in vitro; MFI, mean fluorescence intensity. In vitro data were obtained from at least 3 independent biologic replicates. All data are shown as means \pm SEM; $n$ indicated within bars. 
A Pure microglia culture Mixed glial culture

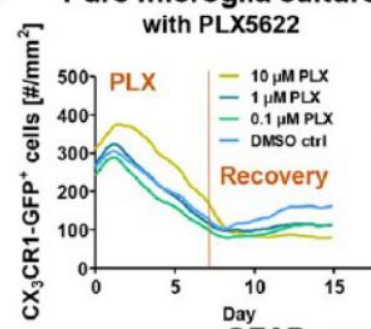

B

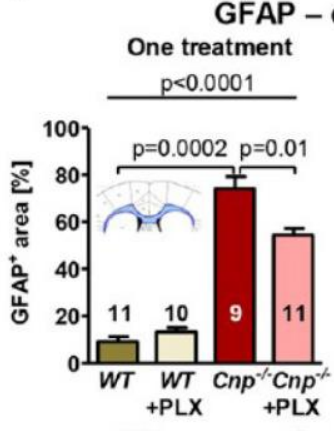

C
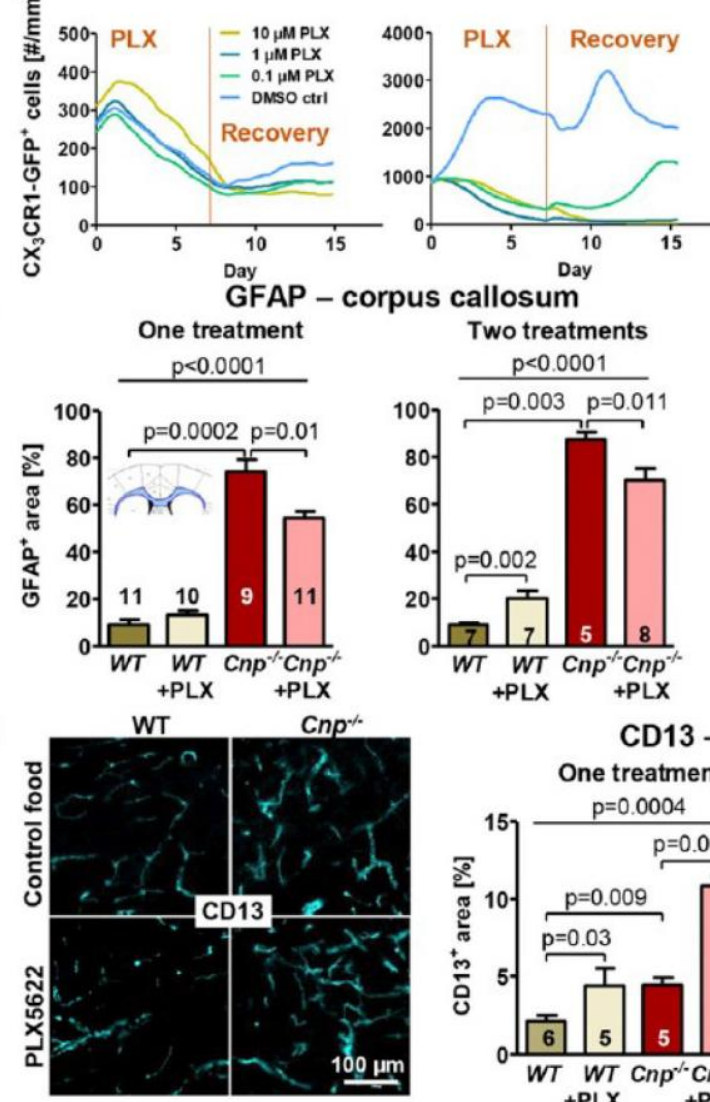

Day

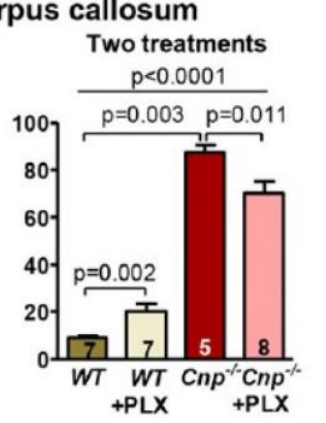

Pure microglia culture with astrocyte-conditioned medium CSF1 addition

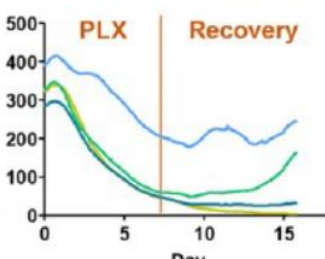

Day

CD3 - corpus

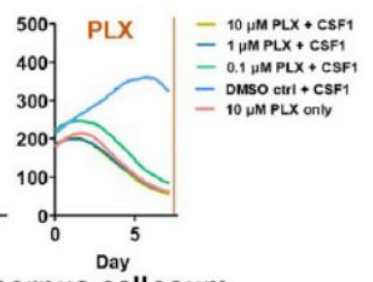

callosum

One treatment

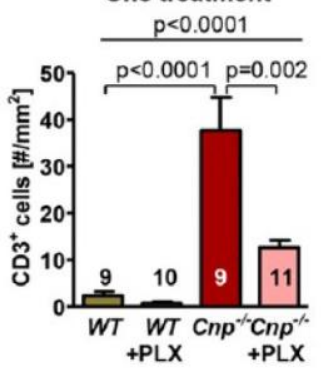

Two treatments

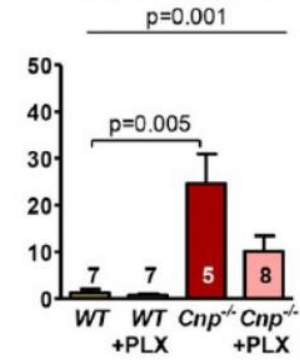

D

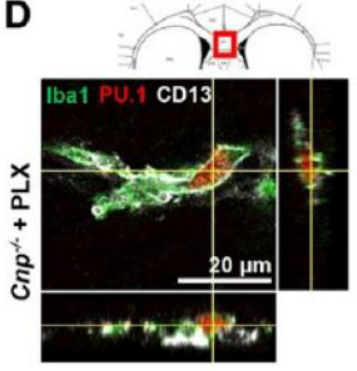

E

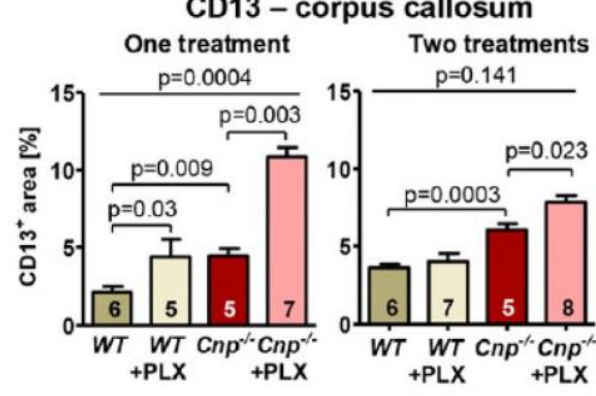

Iba1, PU.1, CD13 - corpus callosum
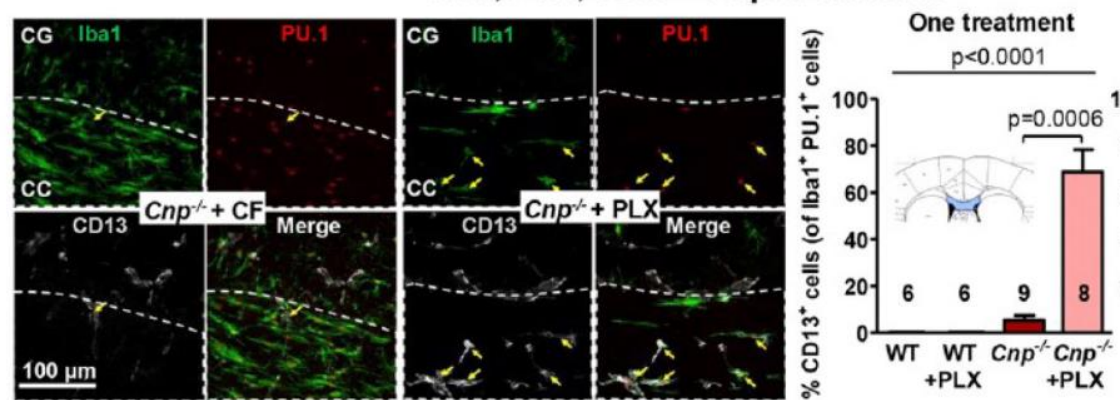

Two treatments

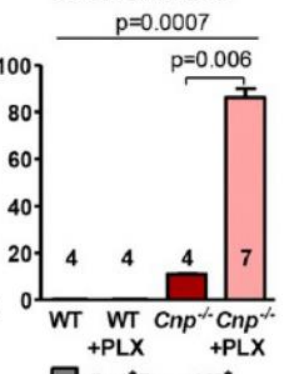

$\mathbf{F}$

Microglia repopulation after

G
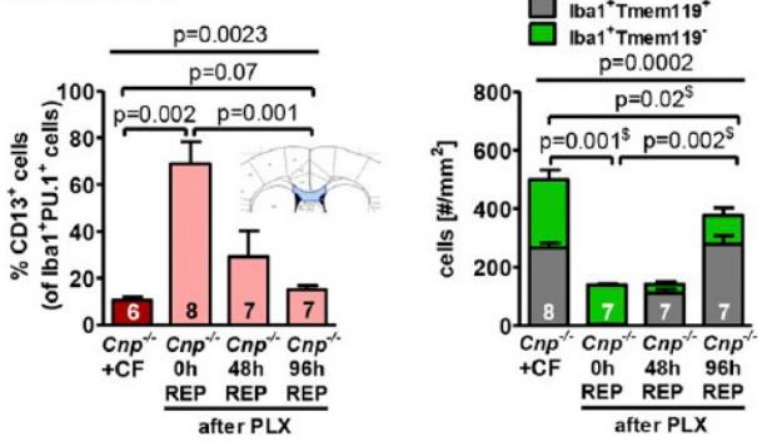

Figure 4. Studies on cellular interplay, coreaction, and inflammation markers before and after microglial repopulation. A) Dynamics of $\mathrm{CX}_{3} \mathrm{CR} 1-\mathrm{GFP}^{+}$microglia survival in different culture compositions (pure microglial or mixed glial cultures) during (continued on next page) 
from age 27 to $35 \mathrm{wk}$, did not yield a noticeable difference in any outcome measure, and that clear benefit appeared to be just transient. For clinical considerations concerning white matter inflammation and catatonia, this unexpected result implies that the transitorily advantageous microglial depletion needs to be combined with additional treatment strategies. However, it cannot be formally excluded from the present work that continuous PLX5622 application would have shown a greater benefit and that only the interruption of treatment was unfavorable. In a recent study targeting peripheral neuropathy in aging mice, continuous treatment over 6 mo was well tolerated and reduced macrophage numbers in peripheral nerves by $\sim 70 \%$ without side effects, thereby ameliorating nerve structure and preserving muscle strength (27).

Neither with MRI-based morphometry, allowing followup of progressive brain atrophy, nor with the hurdle test, our new instrument for rating catatonia-related executive performance, did we see any long-term improvement of $\mathrm{Cnp}^{-/-}$mice by microglia depletion. This is not only an interesting negative finding for future treatment studies in white matter inflammation and catatonia but is also interesting mainly with respect to information on the obviously dissociating underlying mechanisms between PLX5622 responsive and nonresponsivesymptoms. The latter, namely brain atrophy or executive dysfunction, are probably related to progressive axonal degeneration or disturbed neuronal network or neurotransmitter functions, respectively, and thus no longer modulated by anti-inflammatory strategies alone.

In addition, we note here again that elimination of all microglia from the brain does not reduce brain volume despite an assumed loss of $10 \%$ of cells in the CNS, confirming the original work on microglial elimination using another CSF1R inhibitor, PLX3397 (8). In fact, Elmore and colleagues showed by quantification with Cavalieri stereology in WT mice that there is no reduction of brain volume after 7 days of PLX3397 treatment (8).

Whereas the repopulating microglia after depletion are described to be rejuvenated (i.e., to have lost their inflammatory memory and be back to a naive stage) $(28,29)$, the phenotype of leftover microglia under depletion observed here appears highly inflammatory, overactivated, and aggressive. As we show, PLX5622 in vitro stimulates microglia to conduct massive premortal phagocytosis in mixed glial cultures, selectively attacking OPCs but, remarkably, sparing astrocytes and other cells. Fitting well to our results, CSF1R signaling has been reported to decrease phagocytosis of microglia (30) and suppress the inflammatory phenotype of macrophages (31). Importantly, we find also in vivo hints of OPC phagocytosis by microglia when exposed to PLX5622, which may contribute to the reduction of PDGFR- $\alpha^{+}$cells upon CSF1R inhibition both in WT and $\mathrm{Cnp}^{-1-}$ mice. An additional direct toxic effect of PLX5622 on OPCs is less likely because culturing pure OPCs with a CSF1R inhibitor does not affect their viability (32). Moreover, we do not detect any appreciable decrease of oligodendrocyte numbers or myelin. An interesting, yet to be further explored idea is that a molecular similarity may play a causal role: CSF1R and PDGFR- $\alpha$ belong to the same family of receptor tyrosine kinases, as classified by their molecular structure (33). PLX5622 may also inhibit PDGFR- $\alpha$ signaling and thereby alter OPCs such that microglia are attracted to phagocytose them.

An unexpected facet of the present work, again emphasizing the importance of cellular interplay for PLX5622 to be effective, is the in vitro observation that CSF1R inhibition does not acclerate microglial death in pure microglial cultures. For this to occur, mixed glial cultures are necessary. Adding astrocyte-conditioned medium to pure microglial cultures reinstalls the death-inducing effect of PLX5622, suggesting that substances released by astrocytes are required to kill microglia under withdrawal of CSF1 activity. On the other hand, giving CSF1 to pure microglial cultures increases survival and proliferation just of DMSO control cells. Cultures containing any concentration of PLX5622 with or without CSF1 behave comparably and dissociate from this control curve. This indicates that PLX5622, acting by inhibiting receptor kinase signaling, is not overcome by the receptor agonist.

In agreement with our findings in $\mathrm{Cnp}^{-/-}$mice, it has been reported for an Alzheimer mouse model that the CD11c-positive microglial population increases in neurodegenerative disease, expresses lower levels of microglial signature genes such as Tmem119, and up-regulates expression of phagocytosis-related genes. This unique

stimulation with 3 different concentrations of PLX5622 or DMSO control. CSF1 was added where indicated. After $7 \mathrm{~d}$ of PLX5622, recovery medium was given for another $7 \mathrm{~d}$ where indicated. B) $\mathrm{GFAP}^{+}$area (indicating astrogliosis) and $\mathrm{CD}^{+}{ }^{+}$cells (indicating T lymphocyte infiltration) within CC in WT or $\mathrm{Cnp}^{-/-}$mice (age $35 \mathrm{wk}$ ) after 1 or 2 treatments with PLX5622 or control food (see design in Fig. 1E). Schematic overview is indicating ROI. C) Representative images and quantification of CD13 area within CC in WT or $\mathrm{Cnp}^{-/-}$mice (age $35 \mathrm{wk}$ ) after 1 or 2 treatments with PLX5622 or control food (see design in Fig. 1E). ROI quantified shown from $\mathrm{B}$. D) Representative orthogonal views of an Ibal ${ }^{+} \mathrm{PU} .1^{+} \mathrm{CD} 13^{+}$cell from a $\mathrm{Cnp}^{-1-}$ mouse treated once with PLX5622. Approximate area of shown image is indicated by the red box in the schematic overview on top. $E$ ) Representative images and quantification of $\mathrm{Iba1}^{+} \mathrm{PU} .1^{+} \mathrm{CD} 13^{+}$cells within $\mathrm{CC}$ in WT or $\mathrm{Cnp}^{-/-}$mice (age $35 \mathrm{wk}$ ) after 1 or 2 treatments with PLX5622 or control food (see design in Fig. 1E). Schematic overview is indicating ROI (3 neighboring fields of view quantified). Yellow arrows indicate triple positive cells. The white dashed line shows border of CC. $F$ ) Schematic overview of PLX5622 treatment and time points of brain harvest after PLX5622 treatment cessation (repopulation). G) IHC quantification of $\mathrm{Iba}^{+} \mathrm{PU} . \mathrm{I}^{+} \mathrm{CD} 13^{+}$cells (percentage of $\mathrm{CD} 13^{+}$cells of all Iba1 ${ }^{+} \mathrm{PU} .1^{+}$cells, ROI indicated in schematic overview), and of Iba1 ${ }^{+}$ Tmem119 ${ }^{-}$and $\mathrm{Ibal}^{+} \mathrm{Tmem} 119^{+}$cells in $\mathrm{Cnp}^{-/-}$mice after PLX5622 cessation at time points indicated in $F$. All data in $B, C, E, C$ were individually tested for Gaussian distribution using the Kolmogorov-Smirnov test. Nonparametric Kruskal-Wallis test was used for multiple group comparisons in $B$, left graph in $C, E$, $G$, followed by post hoc 2-tailed Mann-Whitney $U$ test. Two-way ANOVA was performed for right graph in $C$, followed by post hoc 2-tailed $t$ test. For the right graph in $G$ as indicated by "\$," 2-tailed Mann-Whitney $U$ test was performed on the proportion of Tmem119 ${ }^{-}$(green bar) $v$ s. Tmem119+ (gray bar) cells. REP, repopulation. All data are shown as means \pm SEM; $n$ indicated within bars. 
disease-associated microglia (DAM) subtype has even been claimed to potentially restrict neurodegeneration (18). We find the percentage of microglia displaying this phenotype particularly high under PLX5622, again supporting the strongly inflammatory profile of leftover cells. However, even though we did not observe any infiltration of monocytes into the brain of $\mathrm{Cnp}^{-/-}$mice at $23 \mathrm{wk}$, we cannot rule out that very few of the $\mathrm{Iba}^{+}$Tmem 119 cells are derived from earlier infiltrating monocytes that over time have lost their CD45 reactivity. For these cells to be tracked, lineage tracing techniques or bone marrow chimeras would be required.

Another interesting feature of the present work is the strong increase in $\mathrm{CD}_{13}{ }^{+}$cells in the $\mathrm{CC}$, particularly in $\mathrm{Cnp}^{-9-}$ mice under PLX5622, showing coexpression with the microglial and myeloid markers Iba1 and PU.1. In fact, brain pericytes can apparently adopt a microglial phenotype (34) and may serve as microglia-generating multipotent vascular stem cells after stroke (35). While, in WT miœ, repopulating microglia are replenished from their own sources by proliferation $(36,37)$, in our model of inflammation, the lack of microglia might be compensated from other cell sources. Thinking along these lines, we searched for first indirect indications of these cells giving rise to microglia shortly after cessation of PLX5622 treatment. Indeed, a stepwise decrease of triple-labeled cells was observed, coinciding with the increase in repopulating microglia.

In summary, the present work adds key observations for further planning of human treatment trials targeting brain inflammation based on CSF1R inhibition. Our findings do not support repeated treatment cycles to ablate microglia. Importantly, they clearly delineate differential responsiveness of the various symptoms characterizing white matter inflammation and catatonia, as exemplified here by catatonic signs vs. executive dysfunction and progressive brain atrophy. This observation would imply combination therapies to be considered in the future. Bearing in mind that microglia also have beneficial aspects during chronic inflammatory processes (38-40), their pure depletion seems just temporarily advantageous. Moreover, the aggressive phagocytosis of OPCs displayed by microglia under PLX5622 may be worthwhile considering when deciding on potential complementary treatments.

\section{ACKNOWLEDGMENTS}

This study was supported by the Max Planck Society and the Deutsche Forschungsgemeinschaft (DFG) Research Center for Nanoscale Microscopy and Molecular Physiology of the Brain (CNMPB). L.F.G.-A., H.J., and L.E.S. shared first authorship. H.M. is an employee of Synaptic Systems GmbH. The authors declare no competing financial or other interests.

\section{AUTHOR CONTRIBUTIONS}

K.A. Nave and H. Ehrenreich conceptualized, designed, and supervised the study; L. F. Garcia-Agudo, H. Janova, L. E. Sendler, S. Arinrad, A. A. Steixner, I. Hassouna, E.
Balmuth, A. Ronnenberg, N. Schopf, F. J. van der Flier, M. Begemann, H. Martens, M. S. Weber, S. Boretius, K.-A. Nave, and H. Ehrenreich conducted data acquisition, analysis, and interpretation; H. Ehrenreich together with L. F. Garcia-Agudo, H. Janova, and L. E. Sendler drafted the manuscript; $H$. Janova and $H$. Ehrenreich, together with L. F. Garcia-Agudo, L. E. Sendler, S. Arinrad, and A. A. Steixner drafted display items; and all authors read and approved the final version of the manuscript.

\section{REFERENCES}

1. Jahn, O., Tenzer, S., and Werner, H. B. (2009) Myelin proteomics: molecular anatomy of an insulating sheath. Mol. Neurobiol. 40, 55-72

2. Lappe-Siefke, C., Goebbels, S., Gravel, M., Nicksch, E., Lee, J., Braun, P. E., Griffiths, I. R., and Nave, K. A. (2003) Disruption of Cnpl uncouples oligodendroglial functions in axonal support and myelination. Nat. Genet. 33, 366-374

3. Hagemeyer, N., Goebbels, S., Papiol, S., Kästner, A., Hofer, S., Begemann, M., Gerwig, U. C., Boretius, S., Wieser, G. L., Ronnenberg, A., Gurvich, A., Heckers, S. H., Frahm, J., Nave, K. A., and Ehrenreich, H. (2012) A myelin gene causative of a catatonia-depression syndrome upon aging. EMBO Mol. Med. 4, 528-539

4. Janova, H., Arinrad, S., Balmuth, E., Mitjans, M., Hertel, J., Habes, M., Bittner, R. A., Pan, H., Goebbels, S., Begemann, M., Gerwig, U. C. Langner, S., Werner, H. B., KittelSchneider, S., Homuth, G. Davatzikos, C., Völzke, H., West, B. L., Reif, A., Grabe, H. J., Boretius, S., Ehrenreich, H., and Nave, K.A. (2018) Microglia ablation alleviates myelin-associated catatonic signs in mice. J. Clin. Invest. 128 , 734-745

5. Habes, M., Erus, G., Toledo, J. B., Zhang, T., Bryan, N., Launer, L. J. Rosseel, Y., Janowitz, D., Doshi, J., Van der Auwera, S., von Sarnowski, B., Hegenscheid, K., Hosten, N., Homuth, G., Völzke, H., Schminke, U., Hoffmann, W., Grabe, H. J., and Davatzikos, C. (2016) White matter hyperintensities and imaging patterns of brain ageing in the general population. Brain 139, 1164-1179

6. Fazekas, F., Kleinert, R, Offenbacher, H., Payer, F., Schmidt, R. Kleinert, G., Radner, H., and Lechner, H. (1991) The morphologic correlate of incidental punctate white matter hyperintensities on MR images. AINR Am. J. Neuroradiol 12, 915-921

7. Simpson, J, E, Ince, P. G, Higham, C. E, Gelsthorpe, C. $\mathbf{H}$, Fernando, M. S., Matthews, F., Forster, G., O'Brien, J. T., Barber, R. Kalaria, R. N., Brayne, C., Shaw, P. J., Stoeber, K., Williams, G. H., Lewis, C. E., and Wharton, S. B.; MRCCognitive Function and Ageing Neuropathology Study Group. (2007) Microglial activation in white matter lesions and nonlesional white matter of ageing brains. Neuropathol. Appl. Neurobiol 33, 670-683

8. Elmore,M. R., Najafi, A. R., Koike,M.A., Dagher, N. N., Spangenberg, E. E., Rice, R. A., Kitazawa, M., Matusow, B., Nguyen, H., West, B. L., and Green, K. N. (2014) Colony-stimulating factor 1 receptor signaling is necessary for microglia viability, unmasking a microglia progenitor cell in the adult brain. Neuron 82, 380-397

9. Dagher, N. N., Najafi, A. R., Kayala, K. M., Elmore, M. R., White, T. E. Medeiros, R., West, B. L., and Green, K. N. (2015) Colony-stimulating factor 1 receptor inhibition prevents microglial plaque association and improves cognition in 3xTg-AD mice. J. Neuroinflammation 12, 139

10. Ribbe, K. Friedrichs, $H$., Begemann, M., Grube, S., Papiol, S Kästner, A., Gerchen, M. F., Ackermann, V., Tarami, A., Treitz, A., Flögel, M., Adler, L., Aldenhoff, J. B., Becker-Emner, M., Becker, T., Czernik, A., Dose, M., Folkerts, H., Freese, R., Günther, R., Herpert. S., Hesse, D., Kruse, G., Kunze, H., Franz, M., Löhrer, F., Maier, W. Mielke, A., Müller-Isberner, R, Oestereich, C., Pajonk, F. G. Pollmächer, T., Schneider, U., Schwarz, H. J., Kröner-Herwig, B., Havemann-Reinecke, U., Frahm, J.,Stühmer, W., Falkai, P., Brose, N., Nave, K. A., and Ehrenreich, H. (2010) The cross-sectional GRAS sample: a comprehensive phenotypical data collection of schizophrenic patients. BMC Psychiatry 10, 91

11. Begemann, M., Grube, S., Papiol, S., Malzahn, D., Krampe, H., Ribbe, K. Friedrichs, H. Radyushkin, K. A. El-Kordi, A., Benseler, F. Hannke, K., Sperling, S., Schwerdtfeger, D., Thanhäuser, I., Gerchen, M. F., Ghorbani, M., Gutwinski, S., Hilmes, C., Leppert, R. Ronnenberg, A., Sowislo, J., Stawicki, S., Stödtke, M., Szuszies, C. Reim, K, Riggert, J., Eckstein, F, Falkai, P., Bickeböller, H., Nave K. A., Brose, N., and Ehrenreich, H. (2010) Modification of cognitive 
performance in schizophrenia by complexin 2 gene polymorphisms. Arch. Gen. Psychiatry 67, 879-888

12. American Psychiatric Association. (2000) Diagnostic and Statistical Manual of MentalDisonders, Fourth Edition, American Psychiatric Association, Washington, DC

13. Chen, E. Y., Shapleske, J., Luque, R, McKenna, P. J., Hodges, J. R., Calloway, S. P., Hymas, N. F., Dening, T. R., and Berrios, G. E. (1995) The Cambridge Neurological Inventory: a clinical instrument for assessment of soft neurological signs in psychiatric patients. Psychiatry Res. 56, 183-204

14. Periáñez,J.A., Ríos-Lago, M., Rodríguez-Sánchez,J. M.,Adrover-Roig, D., Sánchez-Cubillo, I., Crespo-Facorro, B., Quemada, J. I., and Barceló, F. (2007) Trail making test in traumatic brain injury, schizophrenia, and normal ageing: sample comparisons and normative data. Arch. Clin. Neuropsychol. 22, 433-447

15. Kuschinsky, K., and Hornykiewicz, O. (1972) Morphine catalepsy in the rat: relation to striatal dopamine metabolism. Eur.J. Pharmacol. 19, 119-122

16. Dere, E., Dahm, L., Lu, D., Hammerschmidt, K., Ju, A., Tantra, M., Kästner, A., Chowdhury, K, and Ehrenreich, H. (2014) Heterozygous ambral deficiency in mice: a genetic trait with autism-like behavior restricted to the female gender. Front Behav. Neurosci. 8, 181

17. Bennett, M. L., Bennett, F. C., Liddelow, S. A., Ajami, B., Zamanian, J. L., Fernhoff, N. B., Mulinyawe, S. B., Bohlen, C. J., Adil, A., Tucker, A., Weissman, I. L., Chang, E. F., Li, G., Grant, G. A., Hayden Gephart, M. G., and Barres, B.A. (2016) New tools for studying microglia in the mouse and human CNS. Proc. Nath Acad. Sci. USA 113, E1738-E1746

18. Keren-Shaul, H., Spinrad, A., Weiner, A., Matcovitch-Natan, O., Dvir-Szternfeld, R., Ulland, T. K., David, E., Baruch, K., Lara-Astaiso, D., Toth, B., Itzkovitz, S., Colonna, M., Schwartz, M., and Amit, I. (2017) A unique microglia type associated with restricting development of Alzheimer's disease. Cell 169, 1276-1290.e17

19. Chistiakov, D. A., Killingsworth, M. C., Myasoedova, V. A., Orekhov, A. N., and Bobryshev, Y. V. (2017) CD68/macrosialin: not just a histochemical marker. Lab. Invest. 97, 4-13

20. Ebner, F, Brandt, C., Thiele, P., Richter, D, Schliesser, U, Siffrin, V, Schueler, J., Stubbe, T., Ellinghaus, A., Meisel, C., Sawitzki, B., and Nitsch, R. (2013) Microglial activation milieu controls regulatory $\mathrm{T}$ cell responses. J. Immunol. 191, 5594-5602

21. Goldmann, T, Wieghofer, P., Müller, P.F.,Wolf, Y, Varol, D., Yona, S. Brendecke, S. M., Kierdorf, K., Staszewski, O., Datta, M., Luedde, T., Heikenwalder, M., Jung, S., and Prinz, M. (2013) A new type of microglia gene targeting shows TAK1 to be pivotal in CNS autoimmune inflammation. Nat. Neurosci. 16, 1618-1626

22. Wlodarczyk, A., Holtman, I. R., Krueger, M., Yogev, N., Bruttger, J., Khorooshi, R., Benmamar-Badel, A., de Boer-Bergsma, J. J., Martin, N. A., Karram, K., Kramer, I., Boddeke, E. W., Waisman, A., Eggen, B. J., and Owens, T. (2017) A novel microglial subset plays a key role in myelinogenesis in developing brain. EMBO J. 36, 3292-3308

23. Immig, K., Gericke, M., Menzel, F., Merz, F., Krueger, M., Schiefenhövel, F., Lösche, A., Jäger, K., Hanisch, U. K., Biber, K, and Bechmann, I. (2015) CD11c-positive cells from brain, spleen, lung, and liver exhibitsite-specificimmune phenotypes and plastically adapt to new environments. Glia 63, 611-625

24. Armulik, A., Genové, G., and Betsholtz, C. (2011) Pericytes: developmental, physiological, and pathological perspectives, problems, and promises. Dev. Cell 21, 193-215

25. Poggi, G., Boretius, S., Möbius, W., Moschny, N., Baudewig, J., Ruhwedel, T., Hassouna, I., Wieser, G. L., Werner, H. B., Goebbels, S., Nave, K. A., and Ehrenreich, H. (2016) Cortical network dysfunction caused by a subtle defect of myelination. Glia 64, 2025-2040
26. Chitu, V., Gokhan, S., Nandi, S., Mehler, M. F., and Stanley, E. R (2016) Emerging roles for CSF-1 receptor and its ligands in the ner vous system. Trends Neurosci. 39, 378-393

27. Yuan, X., Klein, D., Kerscher, S., West, B. L., Weis, J., Katona, I., and Martini, R. (2018) Macrophage depletion ameliorates peripheral neuropathy in aging mice. J. Neursci. 38, 4610-4620

28. Elmore, M. R. P., Hohsfield, L A., Kramár, E. A., Soreq, L, Lee, R. J. Pham, S. T., Najafi,A. R., Spangenberg, E. E., Wood, M.A, West, B. L., and Green, K. N. (2018) Replacement of microglia in the aged brain reverses cognitive, synaptic, and neuronal deficits in mice. Aging Cell 17, e12832

29. O'Neil, S. M., Witcher, K. G., McKim, D. B., and Godbout, J. P. (2018) Forced turnover of aged microglia induces an intermediate phenotype but does not rebalance CNS environmental cues driving priming to immune challenge. Acta Neuropathol. Commun. 6, 129

30. Brummer, E., and Stevens, D.A. (1994) Effect of macrophage colonystimulating factor (M-CSF) on macrophage morphology, phagocytosis, and intracellular multiplication of Histoplasma capsulatum. Int. J. Immunopharmacol. 16, 171-176

31. Caescu, C. I., Guo, X., Tesfa, L., Bhagat, T. D., Verma, A., Zheng, D. and Stanley, E. R. (2015) Colony stimulating factor-1 receptor signaling networks inhibit mouse macrophage inflammatory responses by induction of microRNA-21. Blood 125, e1-e13

32. Hagemeyer, N., Hanft, K. M., Akriditou, M. A., Unger, N., Park, E. S., Stanley, E. R., Staszewski, O., Dimou, L, and Prinz, M. (2017) Microglia contribute to normal myelinogenesis and to oligodendrocyte progenitor maintenance during adulthood. Acta Neuropathol. 134, 441-458

33. Ségaliny, A. I., Tellez-Gabriel, M., Heymann, M. F., and Heymann, D. (2015) Receptor tyrosine kinases: characterisation, mechanism of action and therapeuticinterests for bone cancers. J. Bone Oncol. 4, 1-12

34. Özen, I., Deierborg, T., Miharada, K., Padel, T., Englund, E., Genové, G., and Paul, G. (2014) Brain pericytes acquire a microglial phenotype after stroke. Acta Neuropathol 128, 381-396

35. Sakuma, R, Kawahara, M., Nakano-Doi, A., Takahashi, A., Tanaka,Y., Narita, A., Kuwahara-Otani, S., Hayakawa, T.,Yagi, H., Matsuyama, T., and Nakagomi, T. (2016) Brain pericytes serve as microgliagenerating multipotent vascular stem cells following ischemic stroke. J. Neuminflammation 13, 57

36. Zhan, L., Krabbe, G., Du, F., Jones, I., Reichert, M. C. Telpoukhovskaia, M., Kodama, L., Wang, C., Cho, S. H., Sayed, F., Li,Y, Le, D., Zhou, Y.,Shen,Y., West, B., and Gan, L. (2019) Proximal recolonization by self-renewing microglia reestablishes microglial homeostasis in the adult mouse brain. PLaS Biol. 17, e3000134

37. Huang,Y., Xu,Z., Xiong, S., Sun, F., Qin, G., Hu, G., Wang, J., Zhao, L., Liang, Y. X., Wu, T., Lu, Z., Humayun, M. S., So, K. F., Pan, Y., Li, N., Yuan, T. F., Rao, Y., and Peng, B. (2018) Repopulated microglia are solely derived from the proliferation of residual microglia after acute depletion. Nat. Neurosci. 21, 530-540

38. Hammond, T. R., Robinton, D., and Stevens, B. (2018) Microglia and the brain: complementary partners in development and disease. Annu. Rev. Cell Dev. Biol. 34, 523-544

39. Yamasaki, R., Lu, H., Butovsky, O., Ohno, N., Rietsch, A. M., Cialic, R. Wu, P. M., Doykan, C. E., Lin, J., Cotleur, A. C., Kidd, G., Zorlu, M. M., Sun, N., Hu, W., Liu, L., Lee, J. C., Taylor, S. E., Uehlein, L., Dixon, D. Gu, J., Floruta, C. M., Zhu, M., Charo, I. F., Weiner, H. L., and Ransohoff, R. M. (2014) Differential roles of microglia and monocytes in the inflamed central nervous system. J. Exp. Med. 211, 1533-1549

40. Aguzzi, A., Barres, B. A., and Bennett, M. L. (2013) Microglia: scapegoat, saboteur, or something else? Science 339, 156-161

Received for publication February 2, 2019. Accepted for publication April 2, 2019. 
PROJECT II 


\section{Project II: Brain erythropoietin fine-tunes a counterbalance between neurodifferentiation and microglia in the adult hippocampus}

\section{Overview and aims of Project II}

After the discovery that CNS cells express EPO and EPOR, several clinical trials and preclinical studies have reported the benefits of EPO treatment in brain disease. Here, our group has a leading role in the field. Ranging from stroke and traumatic brain injury to neuroinflammation and schizophrenia, EPO had beneficial effects, i.e. reducing histological damage and inflammatory responses while stimulating angiogenesis, neurogenesis, and preserving myelination ${ }^{96-100}$.

In the search for mechanistic insight to explain such observations, it was shown that 3 weeks of intraperitoneal EPO injections lead to a $20 \%$ increase of CTIP2 ${ }^{+}$CA1 pyramidal neurons in adult mice. These neurons would become integrated in the hippocampal circuitry and remain for at least 6 months upon continuous cognitive challenge ${ }^{73}$. Furthermore, EPO treatment also triggered an increase in dendritic spine densities and the differentiation of TBR $1^{+}$and TLE $4^{+}$immature neurons ${ }^{74}$.

The expression of endogenous EPO in neurons upon exposure to hypoxia, by means of reduced oxygen pressure or complex running wheel running as motor-cognitive challenge ${ }^{68,74}$, also led to increased numbers, activity, and dendritic spine densities of CA1 neurons. Combining inspiratory hypoxia with motor-cognitive challenge even produced a stronger, synergistic effect, for which EPOR expression by pyramidal neurons was required ${ }^{74}$. Importantly, during EPO treatment no increase in neuronal proliferation was found $\mathrm{d}^{73}$. This indicates that increased neurodifferentiation takes place upon enhanced EPO signaling in the brain, which in turn leads to a beneficial cognitive outcome. As if it was a cycle, this improved neuronal capacity would further promote the hypoxic environment in the brain (if the stimulus would continue), triggering more EPO expression and, yet again, boosting neurodifferentiation ${ }^{74}$.

Microglia are particularly interesting in this setting, since these cells have a critical role in the generation and maturation of newly born hippocampal neurons and synaptic network refinement ${ }^{20,60,62,85}$. Following the line of reporting the benefits of 
EPO as a therapeutical strategy, studies with EPO on microglia are typically directed at demonstrating the overall anti-inflammatory effect that EPO has after brain injury. The vast majority of these works are done in vitro with cell lines that resemble more closely monocytes or tissue macrophages than actual brain microglia ${ }^{101}$. However, it is well documented that EPO reduces microglial injury-induced proliferation, motility, and activity, and this positively influences neuronal recovery after damage $e^{75,76}$. Very interestingly, the number of microglia can be altered by exposure to exercise (i.e. functional hypoxia, endogenous EPO expression ${ }^{68}$ ), and prone them to be supportive of an increased neurogenesis and neurodifferentiation in the adult hippocampus ${ }^{66,79}$.

Taking into account that (1) EPO and exercise dampen microglia numbers, activity, and proliferation while promoting neurodifferentiation, (2) microglia have a critical role in neuronal development, and (3) microglia depend on CSF1R to survive and proliferate, the aims of Project II were to elucidate the effect of hypoxia and EPO on microglia numbers, proliferation, and activity in healthy, wild-type mice, in which EPO-enhanced neuronal differentiation is taking place. Moreover, we investigated if alterations of the CSF1R signaling pathway could contribute to the underlying mechanism.

During this work, I discovered a direct effect of EPO on microglia that acted in two phases. First, EPO triggered microglial apoptosis within $24 \mathrm{~h}$ of treatment, leading to reduced microglia numbers. Then, the apoptotic induction was neutralized and this reduced microglia population was maintained by decreased cell cycle/proliferation speed via IL-34 downregulation in hippocampal neurons by EPO. Reduced microglial numbers and proliferation were also found after treatment with hypoxia. Upon CSF1R inhibition and subsequent repopulation, the targeting of CSF1R pathway by EPO became very evident, since the microglia repopulation was decreased by $50 \%$ during the first week of PLX5622 withdrawal under EPO treatment. Furthermore, EPO also led to decreased microglia-neuron contacts and microglial metabolism in the CA1, pointing to an overall reduced microglial activity, and was paralleled by an increase of intermediate neuronal progenitors which became mature by the end of the EPO treatment (reproducing previous findings ${ }^{73,74}$ ). 
Importantly, these observations are dependent on microglial and neuronal EPOR expression, and represent a counterbalance between the decreased, dampened microglial population and an increased neuronal differentiation during augmented brain EPO signaling.

\section{Original publication}

Fernandez Garcia-Agudo, L.*, Steixner-Kumar, A. A.*, Curto, Y.*, Barnkothe, N., Hassouna, I., Jahne, S., Butt, U. J., Grewe, K., Weber, M. S., Green, K., Rizzoli, S., Nacher, J., Nave, K. A. \& Ehrenreich, H. Brain erythropoietin fine-tunes a counterbalance between neurodifferentiation and microglia in the adult hippocampus. Cell Rep 36, 109548, doi:10.1016/j.celrep.2021.109548 (2021).

This citation refers to the final version of the here attached submitted manuscript. *Equal contribution

\section{Personal contribution}

I was personally responsible for optimization and conduction of all laboratory procedures with the exception of qPCR, NanoSIMS, and scRNAseq experiments. I designed primers and supervised all $\mathrm{qPCR}$ procedures. I performed the analysis for IBA1, tdTomato, caspase-3, Ki67, EdU, and CTIP2+EdU histological quantifications, as well as for qPCR and flow cytometry. I did the immunostaining, embedding, and partially the analysis of the NanoSIMS experiment. I planned the breeding strategies to obtain EPOR knockout mice in $\mathrm{CX}_{3} \mathrm{CR} 1$-expressing cells, with subsequent confirmation of the genotype. I was also involved in the experimental planning, discussion and interpretation of the data, literature research, and all the necessary steps for manuscript submission to a journal, including drafting the manuscript and display items. 


\title{
Brain erythropoietin fine-tunes a counterbalance between neurodifferentiation and microglia in the adult hippocampus
}

\author{
Laura Fernandez Garcia-Agudo ${ }^{1 \S}$, Agnes A. Steixner-Kumar ${ }^{1 \S}$, Yasmina Curto ${ }^{1 \S}$, \\ Imam Hassouna ${ }^{1}$, Nadine Schopf ${ }^{1}$, Sebastian Jähne ${ }^{2}$, Umer Javed Butt ${ }^{1}$, Katharina Grewe ${ }^{2}$, \\ Martin S. Weber ${ }^{3}$, Kim Green ${ }^{4}$, Silvio Rizzoli ${ }^{2}$, Juan Nacher ${ }^{5}$, Klaus-Armin Nave ${ }^{6 *}$, \\ and Hannelore Ehrenreich ${ }^{1 *}$ \\ §Shared first authorship
}

\begin{abstract}
${ }^{1}$ Clinical Neuroscience, Max Planck Institute of Experimental Medicine, Göttingen, Germany ${ }^{2}$ Department of Neuro- and Sensory Physiology, University Medical Center Göttingen, Germany ${ }^{3}$ Institute of Neuropathology and Department of Neurology, UMG, Göttingen, Germany ${ }^{4}$ Department of Neurobiology and Behavior, Institute for Memory Impairments and Neurological Disorders, University of California, Irvine, CA, USA

${ }^{5}$ Neurobiology Unit, Program in Neurosciences and Interdisciplinary Research Structure for

Biotechnology and Biomedicine (BIOTECMED), Universitat de València, Burjassot, Spain ${ }^{6}$ Department of Neurogenetics, Max Planck Institute of Experimental Medicine, Göttingen, Germany
\end{abstract}

Running title: Neuron - microglia balance under EPO

Key words: Hypoxia, recombinant human EPO, neurogenesis, CSF1R, IL-34, PLX5622, microglia activity, apoptosis, proliferation

Word counts: Abstract 150 words; Text Body: 3823

\author{
*Correspondence: \\ Prof. Hannelore Ehrenreich, MD, DVM \\ Clinical Neuroscience \\ Max Planck Institute of Experimental Medicine \\ Hermann-Rein-Str.3, 37075 Göttingen, GERMANY \\ Phone +49-551-3899615; Fax +49-551-3899670 \\ E-Mail: ehrenreich@em.mpg.de \\ Prof. Klaus-Armin Nave, PhD \\ Neurogenetics \\ Max Planck Institute of Experimental Medicine \\ Hermann-Rein-Str.3, 37075 Göttingen, GERMANY \\ Phone: +49-551-3899754; Fax: +49-551-3899758 \\ E-Mail: nave@em.mpg.de
}




\title{
SUBMITTED MANUSCRIPT
}

\begin{abstract}
In postnatal cornu ammonis hippocampi, erythropoietin (EPO) expression drives the differentiation of new neurons, independent of DNA synthesis, and increases dendritic spine density. This substantial brain hardware upgrade is part of a regulatory cycle: During motor-cognitive challenge, neurons experience 'functional' hypoxia, triggering neuronal EPO production, which in turn promotes improved performance (EPO brain doping). Here, we show an unexpected involvement of resident microglia. During EPO upregulation and stimulated neurodifferentiation, either by functional or inspiratory hypoxia, we noted that microglia numbers decrease. Treating mice with recombinant human (rh)EPO or exposure to hypoxia recapitulates these changes and reveals that neuronally expressed IL-34 and microglial CSF1R are involved. Surprisingly, EPO affects microglia in phases, initially by stimulating apoptosis, later by reducing proliferation, and overall dampens microglia activity and metabolism, as proven by genetic targeting of microglial EPO receptor. We suggest that during accelerating neuronal differentiation, EPO acts as regulator of the CSF1R-dependent microglia.
\end{abstract}




\section{SUBMITTED MANUSCRIPT}

\section{INTRODUCTION}

Erythropoietin (EPO) is a hypoxia-inducible growth factor, expressed in brain (Brines and Cerami, 2005; Digicaylioglu et al., 1995; Jelkmann, 1992; Marti et al., 1996; Siren et al., 2009; Suresh et al., 2019). In numerous clinical trials and 'back-translational' rodent studies for deeper mechanistic insight, recombinant human (rh)EPO treatment consistently improved cognitive performance, including executive functions, many facets of learning, memory, attention, and processing speed. At the same time, it reduced brain matter loss (Adamcio et al., 2008; Ehrenreich et al., 2007a; Ehrenreich et al., 2007b; El-Kordi et al., 2009; Miskowiak et al., 2014; Miskowiak et al., 2015; Siren et al., 2006; Wustenberg et al., 2011). Searching for underlying mechanisms, we discovered that 3-week rhEPO treatment of mice leads to $20 \%$ increase in the number of pyramidal neurons and oligodendrocytes in cornu ammonis (CA) hippocampi in absence of altered cell proliferation or apoptosis (Hassouna et al., 2016; Wakhloo et al., 2020). An equivalent $\sim 20 \%$ of neurons showed elevated de-novo protein production. In EPO-treated NG2-CreERT2 mice, we directly confirmed enhanced differentiation of pre-existing oligodendrocyte precursors without elevated DNA synthesis (Hassouna et al., 2016). Regarding neuronal lineages, the picture is much more complex, with EPO apparently driving fast differentiation of diverse, non-dividing, local neuronal precursors (Hassouna et al., 2016; Wakhloo et al., 2020), similar to its established role in the hematopoietic system (Brown and Ceredig, 2019; Dessypris et al., 1988; Grover et al., 2014; Krantz, 1991). Exposure to motor-cognitive challenge, namely complex running wheels (CRW) (Liebetanz and Merkler, 2006), leads to endogenous hypoxia in pyramidal neurons, augmenting expression of EPO and EPO receptor (EPOR) (Butt et al., Mol Psychiatry, in press; Wakhloo et al., 2020). These in turn prompt via auto/paracrine signaling the emergence of newly generated $\mathrm{CA}$ neurons, enhance dendritic spine densities, and improve performance (EPO brain doping). Single cell RNA sequencing (scRNA-seq) in CA1, only $6 \mathrm{~h}$ after one intraperitoneal rhEPO injection, revealed rapid increase in newly differentiating neurons. Exposure to either moderate inspiratory hypoxia $\left(12 \% \mathrm{O}_{2}\right)$ or to CRW ('functional hypoxia') imitated the formation of new pyramidal neurons seen under rhEPO, and inspiratory hypoxia combined with CRW even acted synergistically. All these effects depend on pyramidal neuronal expression of the EPOR gene (Wakhloo et al., 2020). Thus, a novel model of neuroplasticity emerged in which neuronal networks, challenged by motor-cognitive tasks, drift into 'functional hypoxia', which in 


\section{SUBMITTED MANUSCRIPT}

turn triggers neuronal EPO expression. This regulatory brain EPO cycle causes lasting neuroplastic adaptation, which we coined 'brain hardware upgrade'. Importantly, these EPO-mediated adaptation processes likely also involve other brain cell types that express and/or bind EPO, at least in disease models (Brines and Cerami, 2005; Ott et al., 2015; Sargin et al., 2010; Siren et al., 2009).

In the physiological context of challenge-induced neuroplasticity, the contribution of microglia is of particular interest, but still entirely unexplored. In fact, microglia have crucial roles in neurotrophic support, neuro- and synaptogenesis including synaptic and axonal pruning or removal of dying neurons, and are constantly responding to neuronal signals by extending and withdrawing their processes from around synapses (Kierdorf and Prinz, 2017; Werneburg et al., 2017). Thereby, they shape developmental and postnatal neuronal circuits, the latter in an activity-dependent manner. Interestingly, recent work reports that microglia respond to neuronal activation by suppressing neuronal activity in the sense of a microglia-driven negative feedback mechanism. This mechanism operates similarly to inhibitory neurons, protects the brain from excessive activation, and depends on microglia sensing and catabolizing extracellular ATP that is released upon neuronal activation by neurons and astrocytes (Badimon et al., 2020).

The way, however, in which microglia co-regulate adult neurogenesis and particularly adult neurodifferentiation in various states of neuronal activation, and outside the classical neurogenesis niches, is still poorly understood (Butovsky and Weiner, 2018). The present study has been designed to explore in healthy mice how microglia behave in the context of EPO-mediated ample brain hardware upgrade in hippocampal CA1. Surprisingly, we show that EPO decreases microglia numbers, first by inducing apoptosis, followed by inhibiting proliferation. In parallel, EPO dampens microglia activity and metabolism. This effective EPO containment of microglia in CA1 involves the colony-stimulating factor 1 receptor (CSF1R) system and enables undisturbed neuronal differentiation. 


\section{RESULTS AND DISCUSSION}

Inspiratory as well as functional hypoxia induce endogenous EPO expression in brain and diminish microglia numbers in CA1

We first determined by qPCR the EPO expression in CA1 after 6h of strong inspiratory hypoxia (positive control; $6 \% \mathrm{O}_{2}$ ) and compared it to $6 \mathrm{~h}$ of functional hypoxia, employing our CRW paradigm of motor-cognitive challenge (Wakhloo et al., 2020). Under both conditions, EPO mRNA expression increased compared to normoxia baseline (Figure1A-B). Endogenous EPO induction in brain by functional and inspiratory hypoxia promotes adult hippocampal neurodifferentiation in $\mathrm{CA} 1$, similar to exogenously applied rhEPO (Hassouna et al., 2016; Wakhloo et al., 2020). We wondered how this would reflect on the microglial population dynamics, which in this context has remained unexplored. To elucidate the physiological effect of endogenous brain EPO on microglia, we exposed WT mice, starting at P28, to 3 weeks of CRW versus permanent moderate inspiratory hypoxia $\left(12 \% \mathrm{O}_{2}\right.$; Figure $\left.1 \mathrm{C}\right)$. In both conditions, IBA1+ microglia in CA1 pyramidal layer were reduced immediately after these 3 weeks (P49), compared to normoxia control mice (Figure1D). Importantly, this reduction was comparable to that obtained after treating WT mice with rhEPO (5000 IU/kg i.p. every other day for 3 weeks) versus placebo injections (Figure1E). Here, the amount of rhEPO reaching the brain in healthy rodents with an intact blood-brainbarrier is similar to the endogenously induced brain EPO (Ehrenreich et al., 2004). The decrease of microglia numbers in CA1 simultaneously with increased neurodifferentiation upon EPO (Hassouna et al., 2016; Wakhloo et al., 2020), validated rhEPO treatment as highly standardizable and convenient model procedure for the present study.

\section{Effect of rhEPO on microglia numbers and activity depends on microglial EPOR}

We next asked how long the reduction of microglia numbers seen on P49, i.e. immediately after cessation of rhEPO treatment, would last. To answer this question and, at the same time, to use a permanent cell label in addition to IBA1 staining, we treated $\mathrm{CX}_{3} \mathrm{CR} 1 \mathrm{CreERT2:tdTomato} \mathrm{mice} \mathrm{for} 3$ weeks with rhEPO according to our schedule. Notably, already 1 week later (P55), microglia numbers (all consistently tdTomato+IBA1+) were no longer different from placebo treated mice (Figure1F), pointing to a tight and time-limited regulation of microglia under EPO with fast repopulation thereafter. Since all tdTomato+ cells were also IBA1+, the possibility of 


\section{SUBMITTED MANUSCRIPT}

microglia losing their identity or transdifferentiating to other cell types upon EPO could be discarded.

We thus explored other reasons behind the decreased microglia numbers under rhEPO. On P49, caspase-3 staining revealed no enhanced apoptosis, whereas Ki67 was significantly diminished (Figure1G), pointing to a reduced cell cycle/proliferation of microglia after 3 weeks of rhEPO. Application of EdU for 1 week, starting immediately after rhEPO treatment cessation (P49), disclosed a trend for more proliferating microglia compared to placebo at P55 (Figure1H). This certainly contributes to the quick recovery of microglia numbers (Figure1F).

Microglial morphology is notorious for accurately reflecting the activation status of these cells (Sierra et al., 2016). Parameters of microglia process complexity (Figure1l) did not show differences between rhEPO and placebo groups. However, analysis of the microglia cell body revealed an increased perimeter/area ratio, consistent with a less active phenotype (Peskin et al., 2010) upon rhEPO treatment (Figure1J). The decreased number of contacts with Thy1-YFP+ pyramidal neurons further supports the reduced activity of microglia after 3 weeks of rhEPO (Figure1K), as does an abridged metabolic turnover, measured by ${ }^{15} \mathrm{~N}$-leucine incorporation into IBA1+ cells using NanoSIMS (Figure1L). This is in contrast to the increased ${ }^{15} \mathrm{~N}$-leucine incorporation in NeuN+ neurons upon rhEPO (Hassouna et al., 2016). Hence, in parallel to the rhEPOstimulated neurodifferentiation in CA1, resulting in a substantial number of new functional pyramidal neurons with their expectedly enhanced protein turnover (Hassouna et al., 2016; Wakhloo et al., 2020), microglia are decreased in number, metabolism and activity. To investigate whether the rhEPO effects on microglia depend on microglial EPOR, we selectively erased the EPOR in microglia by generating $\mathrm{CX}_{3} \mathrm{CR} 1 \mathrm{CreERT2}$ EPOR-KO mice. After tamoxifen-induced deletion and subsequent rhEPO treatment following our 3-week schedule, we found neither reduction of microglia numbers nor changes in cell body size (Figure1M-N). This supports direct effects of EPO on microglia that disappear after microglial EPOR elimination.

\section{Counterbalance between microglia and newly generated neurons upon EPO}

We previously reported EPO to powerfully drive neurodifferentiation, leading to increased numbers of immature or mature neurons, depending on the time point studied (Hassouna et al., 2016; Wakhloo et al., 2020). Since microglia are dampened

by EPO, but reportedly crucial for proper neuronal development and differentiation 


\section{SUBMITTED MANUSCRIPT}

(Hattori et al., 2020; Nandi et al., 2012), we wondered whether, when and how EPO would provide a physiological counterbalance between neuronal and microglial populations in the neurodifferentiation process. Treating mice for only 1 week with rhEPO or placebo resulted in reduced microglia numbers (Figure2A-B). Notably, at this early time point, caspase-3 or Ki67 were unaltered (Figure2C), however, microglia activity was already reduced (Figure2D). How was the observed microglia reduction achieved and could this indicate protection of ongoing neurodifferentiation? We first quantified mature CTIP2+ and immature TBR1+ neurons at the 1-week time point, as both are increased in the CA1 pyramidal layer upon rhEPO, the former after 3 weeks, the latter at 24h (Hassouna et al., 2016; Wakhloo et al., 2020). No differences were seen at 1 week of rhEPO treatment in either population, suggesting that this time point was too early to find mature neurons increased, and too late to see still the initial TBR1 wave of precursors (Figure2E). We thus hypothesized that after 1 week of rhEPO treatment, newly differentiating neurons would be in an intermediate stage, having further progressed along the maturation path (pseudotime trajectory (Wakhloo et al., 2020)), obtained by scRNA-seq of CA1 at $6 \mathrm{~h}$ after a single rhEPO injection (Figure2FG). Whereas TBR1 marks an early immature stage (Figure2H), we focused on a population of intermediately mature neurons in the pseudotime trajectory (Wakhloo et al., 2020), and selected Zbtb20 as marker, highly specific for maturing pyramidal neurons of CA1 (Nielsen et al., 2010; Nielsen et al., 2014; Xie et al., 2010) ( $p=2.31$ 63, Figure2I). Indeed, immunohistochemical quantification showed an increased number of ZBTB20+ cells in CA1 pyramidal layer after 1 week of rhEPO (Figure2J), confirming the ongoing wave of stimulated neurodifferentiation.

To elucidate the mechanisms that could have led to the observed reduction of IBA1+ cells after 1 week of rhEPO, we next quantified microglia at $24 \mathrm{~h}$ after a single rhEPO or placebo injection (Figure2K). At this early time point, no difference in IBA1+ cells yet appeared but, surprisingly, the number of caspase-3+ microglia was elevated in rhEPO treated mice (Figure2L). As EPO is usually associated with a strong anti-apoptotic role (Krantz, 1991; Siren et al., 2001) and has pro-apoptotic effects only in unphysiologically high doses, at least in neurons (Ehrenreich et al., 2005), we wondered whether such unexpected consequence of rhEPO would similarly be detectable in primary microglia in culture. Indeed, also pure microglia cultures revealed a rapid pro-apoptotic function of rhEPO in this cell type, reflected by increased caspase-3 expression after only $6 \mathrm{~h}$ (Figure2M). At the $24 \mathrm{~h}$ time point, the enhanced 
caspase-3 expression in culture had already disappeared (not shown). This suggests that EPO in vivo as well as in vitro quickly and just transiently induces apoptosis of microglia. This temporary apoptosis within the microglia population, prompted by EPO, is in perfect agreement with a recent report showing that microglia self-renewal is maintained by coupled proliferation and apoptosis, resulting in a stable microglia number (Askew et al., 2017). Thus, apoptosis is a physiological regulatory instrument in this cell type next to controlled proliferation, and with our data, we unify these effects for the first time to one particular factor, namely EPO, which mediates these regulating mechanisms in a phasic fashion. Together with our previous (Hassouna et al., 2016; Wakhloo et al., 2020) and present studies on neurodifferentiation, collectively, these data suggest a delicate counterbalance, orchestrated by EPO, between neuronal differentiation and microglial numbers and activity.

\section{Endogenous and exogenous EPO affects microglial proliferation via CSF1R}

We next hypothesized that EPO might interfere with CSF1R that is crucial for microglial proliferation and survival (Elmore et al., 2014). Thus, we depleted brains of microglia by feeding WT mice for 10 days the CSF1R inhibitor PLX5622. Immediately after inhibitor withdrawal, when fast microglia repopulation takes place (Dagher et al., 2015), we started our usual 3-week rhEPO treatment, and simultaneously added EdU to the drinking water for the first week. Since we were interested in observing how the neuronal population would respond to this challenge of the neuron-microglia counterbalance, we allowed 1 week of break after rhEPO treatment cessation (Figure3A-B), imitating the experimental paradigm that had led to an increase in CTIP2+ neurons of the CA1 pyramidal layer (Hassouna et al., 2016). Expectedly, we found no changes anymore in the overall IBA1+ cell numbers at this time point (Figure3C, compare Figure1F). However, the EdU+ microglia, marking proliferation during the first week of repopulation, were decreased upon rhEPO by around $50 \%$ (Figure $3 \mathrm{C}$ ). We replicated our previous finding of rhEPO increasing CTIP2+ neuron numbers (Hassouna et al., 2016) (Figure3D) but, surprisingly, this increase was similarly observed in PLX5622 treated mice, independent of rhEPO. This indicated that in absence of microglia, the neuronal differentiation advances to reach a ceiling effect, not amplified further by addition of rhEPO. As shown earlier (Hassouna et al., 2016), the proliferation of cells in the pyramidal layer was again slightly reduced upon rhEPO. However, no such changes were observed after PLX5622 treatment (Figure3D), 


\section{SUBMITTED MANUSCRIPT}

perhaps reflecting increased neuronal proliferation under CSF1R inhibition (Elmore et al., 2018). In summary, these findings underline again the counterbalance between microglia and neurons, with rhEPO treatment as well as CSF1R inhibition transiently reducing numbers of proliferating microglia, paralleled by augmented CA1 pyramidal neuron numbers (Figure3C-E).

For deeper mechanistic insight, we processed hippocampi of rhEPO or placebo treated mice (Figure 3F-G) in order to measure the expression of CSF1R and its ligands, CSF1 and IL-34. Flow cytometry revealed upregulation of CSF1R expression in $\mathrm{CD} 11 \mathrm{~b}+\mathrm{CD} 45$ lo cells upon rhEPO, while EPOR remained unchanged (Figure3H). The mRNA levels confirmed the trend of increased Csf1r expression, while Csf1 expression was unaffected. Most importantly, the neuronally expressed ligand //34 (Easley-Neal et al., 2019a) was significantly downregulated after rhEPO (Figure3l). This may suggest that the decrease of $1 / 34$, as part of a cross talk between neurons and microglia, adds to reducing microglia numbers during EPO-mediated neurodifferentiation.

We now wondered whether similar alterations in the CSF1R axis would be detectable in conditions of hypoxia-induced brain EPO, as demonstrated above (Figure1A-D). To address this question, we employed our hypoxia scRNA-seq data set, obtained from whole hippocampus after 5 days of daily exposure to $6 \% \mathrm{O}_{2}$ for 6 hours each (Butt et al., Mol Psychiatry, in press) (Figure4A), to explore the expression of Csf1r and its ligands Csf1 and I/34. In whole hippocampus, we observed despite their relatively scarce average expression a mild increase in $\operatorname{Csf1r}(\log \mathrm{FC}=0.16)$ and a mild decrease of //34 ( $\log F C=-0.12)$, whereas Csf1 was practically unchanged, i.e. log-fold change was close to zero (logFC=0.04), indicating basically unchanged levels of Csf1 even though statistically significant (Figure4B-C). A more detailed look at specific cell populations known to primarily express the respective genes, revealed under hypoxia a marked increase in Csf1r expression in microglia (Figure 4D), a negligible increase of Csf1 in glial cells (Figure4E), and a mild decrease of $/ / 34$ in glutamatergic neurons (Figure4F), consistent with our findings by $\mathrm{qPCR}$ and FACS following rhEPO treatment.

Among the CSF1R ligands, IL-34 is mainly produced by neurons and responsible for microglia maintenance in grey matter regions, as opposed to CSF1, which is mostly expressed by glia and responsible for maintenance of microglia in white matter regions 


\section{SUBMITTED MANUSCRIPT}

(Easley-Neal et al., 2019b). The observed decrease in //34 expression shown here, probably contributes to the counterbalance between neurodifferentiation/numbers of maturing neurons and numbers/activity of microglia under EPO. In fact, glutamatergic neuronal production of //34 diminishes after endogenous as well as exogenous EPO, likely to keep the microglia population reduced and less active, while increased neuronal differentiation/maturation proceeds under this growth factor. This explanation is in perfect agreement with the observation that microglia numbers decrease in CA1 after administration of an IL-34 blocking antibody (Obst et al., 2020). The upregulation of Csf1r in turn might well be a compensatory homeostatic feedback mechanism in response to decreased //34 expression. Together, these data once more imply a role for the CSF1R system in EPO-mediated effects on microglia and neurogenesis.

\section{Working model of a delicate counterbalance between neurodifferentiation and microglia in the adult hippocampal CA1 revealed by EPO}

During embryonic development, microglia were reported to assist the accurate differentiation of CTIP2+ and TBR1+ neurons, and these neuronal subpopulations are dependent on CSF1R signaling for survival (Hattori et al., 2020; Nandi et al., 2012). According to Hattori and coworkers, 'sanctuarization' from microglia in the midembryonic cortical plate is required for neurons to appropriately fine-tune the expression of molecules needed for proper differentiation, thus securing the establishment of functional cortical circuits (Hattori et al., 2020). Also in disease models and brain injury studies, decreased microglia proliferation, activity or motility upon rhEPO treatment has been described, together with improved neuronal proliferation or survival. In fact, rhEPO treatment in these conditions even prevented neurodegeneration, brain atrophy and cognitive decline (Mitkovski et al., 2015; Sargin et al., 2009; Siren et al., 2006; Wang et al., 2017; Zhang et al., 2019).

In contrast, such neurodifferentiation-microglia counterbalance in healthy postnatal and adult CA1 (or anywhere else outside the classical neurogenesis areas) has never been reported nor illuminated to understand its physiological significance and underpinnings. Just in the dentate gyrus, the number of microglia was found inversely correlated with the number of proliferating progenitor cells in the granule cell layer upon running (Gebara et al., 2013; Kohman et al., 2012). Therefore, the present work focused on the healthy adult hippocampal CA1 and the role of endogenous and exogenous EPO in coordinating conduct of different cell types to achieve proper brain 


\section{SUBMITTED MANUSCRIPT}

hardware upgrade as prerequisite for improved performance. As conclusion from the present study, a novel working model arises, in which the importance of a fine-tuned counterbalance between effective neurodifferentiation and microglia activity in CA1 during normal adulthood is discovered by studying EPO effects. This working model includes CSF1R and its neuronal ligand IL-34 in the way how tight regulation of microglia contributes to adult neurogenesis and in particular to adult neurodifferentiation. 


\section{SUBMITTED MANUSCRIPT}

\section{MATERIALS AND METHODS}

All experiments were approved by the local Animal Care and Use Committee (Niedersächsisches Landesamt für Verbraucherschutz und Lebensmittelsicherheit) and conducted in accordance with the German Animal Protection Law. In all experiments, investigators were unaware of group assignment or treatment condition ('fully blinded').

\section{Mice}

$\mathrm{CX}_{3} \mathrm{CR} 1 \mathrm{CreERT} 2$ mice were crossed to R26R-tdTomato reporter mice for genetic labeling of microglia (CX ${ }_{3}$ CR1CreERT2:tdTomato) or to EPOR-floxed (Wakhloo et al., 2020) animals to generate conditional EPOR deletion ( $\left.\mathrm{CX}_{3} \mathrm{CR} 1 \mathrm{CreERT2:EPOR}-\mathrm{KO}\right)$. CreERT2 activity was induced with tamoxifen $[10 \mathrm{mg} / \mathrm{ml}$ intraperitoneal (i.p.) injections over 5 consecutive days, from postnatal day 23 (P23) until P27]. Juvenile wildtype (WT) C57BL6N or Thy1-YFPH mice were treated as indicated in the figures. All mice used in this work were of male gender, except where indicated otherwise, and maintained on a $12 \mathrm{~h}$ light-dark cycle at $20-22^{\circ} \mathrm{C}$, with food and water ad libitum.

\section{Treatments}

For inspiratory hypoxia experiments, mice were put into custom-designed hypoxia chambers (Coy Laboratory Products, Grass Lake, MI, USA) at $6 \% \mathrm{O}_{2}$ for $6 \mathrm{~h} /$ day, either once on P32 (female mice), or on 5 consecutive days from P28 to P32. Other groups were exposed to $12 \% \mathrm{O}_{2}$ for 3 weeks from $\mathrm{P} 28$ to $\mathrm{P} 49$, starting with gradual reduction of $3 \% \mathrm{O}_{2}$ per day for 3 days. Complex running wheels (CRW (Wakhloo et al., 2020); TSE Systems, Bad Homburg, Germany) for voluntary running were placed into normoxia cages for $6 \mathrm{~h}$ on P32 (female mice), or for 3 weeks from P28 to P49. Recombinant human (rh) EPO (5000IU/kg body weight; NeoRecormon, Roche, Welwyn Garden City, UK) or placebo (PL; solvent control solution) were applied via i.p. injections $(0.01 \mathrm{ml} / \mathrm{g})$ either once or every other day for 1 or 3 weeks as indicated in treatment schemes. For nanoscale secondary ion mass spectrometry (NanoSIMS), mice obtained food pellets containing $1.025 \%$ L-leucine- ${ }^{15} \mathrm{~N}$ stable isotope (Sigma-Aldrich, St Louis, MN, USA) for 3 weeks between P28 and P49 (in parallel with EPO/PL injections). PLX5622 (1200 ppm in AIN-76A standard chow, Research Diets, New Brunswick, NJ, USA) or control food (AIN-76A standard chow), kindly provided by Plexxikon, were given for 10 days (P21-P30). EdU (0.2 mg/ml, Thermo Fisher Scientific, Waltham, MA, USA) was applied via drinking water in light-protected flasks and exchanged on alternate days for the period indicated in schemes. 


\section{SUBMITTED MANUSCRIPT}

\section{Quantitative RT-PCR}

Mice were anesthetized by i.p. injection of Avertin (tribromoethanol, Sigma-Aldrich) and perfused via left cardiac ventricle with Ringer's solution. RNA of one whole hippocampus per mouse was extracted using miRNeasy Mini Kit (217004, Qiagen, Hilden, Germany) following the manufacturer's instructions; cDNA was synthesized using SuperScript III (18080044, Thermo Fisher Scientific); RT-qPCR was performed with Power SYBR Green PCR Master Mix (4367660, Thermo Fisher Scientific). Fold changes in gene expression were calculated with the $\Delta \Delta \mathrm{Ct}$ method using Hprt1 as housekeeper.

The following primer pairs were used: for Epo, forward 5'-CATCTGCGACAGTCGAGTTCTG3' and reverse 5'-CACAACCCATCGTGACATTTTC-3'; for Csf1r, forward 5'GCAGTACCACCATCCACTTGTA-3' and reverse 5'-GTGAGACACTG TCCTTCAGTGC-3'; for Csf1, forward 5'-CCACATGATTGGGAATGGACAC-3' and reverse 5'GATCATCCAGCTGTTCCTGGTCTA-3'; for $1 / 34$, forward 5'-CTTTGGGAAACGAGAAT TTGGAGA-3' and reverse 5'-GCAATCCTGTAGTTGATGGGGAAG-3'; and for Hprt1, forward 5'-GCTTGCTGGTGAAAAGGACCTCTCGAAG-3' and reverse 5'-CCCTGAAGTACTCATT ATAGTCAAGGGCAT-3'.

\section{Immunohistochemistry}

Mice were anesthetized by i.p. injection of Avertin and perfused via left cardiac ventricle with Ringer's solution followed by $4 \%$ formaldehyde. The dissected brains were postfixed overnight in $4 \%$ formaldehyde and frozen at $-80^{\circ} \mathrm{C}$ after cryoprotection with $30 \%$ sucrose. Coronal sections of $30 \mu \mathrm{m}$ thickness were obtained with cryostat Leica CM1950 (Leica Microsystems, Wetzlar, Germany) and stored at $-20^{\circ} \mathrm{C}$ in $25 \%$ ethylene glycol and $25 \%$ glycerol in PBS. Following blocking and permeabilization with $5 \%$ normal horse serum (NHS) in $0.3 \%$ Triton X100 in PBS (PBST) for $1 \mathrm{~h}$ at room temperature (RT), primary antibodies IBA1 (chicken, 1:1000, 234006; Synaptic Systems, Göttingen, Germany), IBA1 (rabbit, 1:1000, ab178846; Abcam, Cambridge, UK), Ki67 (rabbit, 1:1000, NCL-Ki67p; Novocastra, Newcastle Upon Tyne, UK), caspase-3 (goat, 1:250, sc1225; Santa Cruz Biotechnologies, Heidelberg, Germany), CTIP2 (guinea pig, 1:1000, 325005; Synaptic Systems), TBR1 (rabbit, 1:500, ab183032; Abcam) and ZBTB20 (rabbit, 1:500, 362003; Synaptic Systems) were incubated in 5\%NHS with 0.3\%PBST over 2-3 nights at $4^{\circ} \mathrm{C}$. Secondary antibodies donkey anti-chicken Alexa-Fluor-488 (703546155; Jackson ImmunoResearch, Cambridgeshire, UK), donkey anti-chicken AlexaFluor-647 (1:500, 703605155; Jackson ImmunoResearch), goat anti-rabbit Alexa-Fluor-555 (1:500, A21428; Invitrogen by Thermo Fisher Scientific), donkey anti-guinea pig Cy5 (1:500, 706175148; Jackson ImmunoResearch) donkey anti-guinea pig Alexa-Fluor-488 (1:500, 706545148; Jackson ImmunoResearch), donkey anti-rabbit Alexa-Fluor-594 (1:500, D-301-CABS2; R\&D Systems, Wiesbaden, Germany), donkey anti-goat Alexa-Fluor-633 (1:500, 


\section{SUBMITTED MANUSCRIPT}

A21082; Invitrogen) and donkey anti-rabbit Alexa-Fluor-488 (1:500, A21206; Invitrogen) were incubated in $3 \% \mathrm{NHS}$ with $0.3 \% \mathrm{PBST}$ for $2 \mathrm{~h}$ at RT. EdU detection was done with Click-IT EdU Alexa-Fluor-647 Imaging kit (C10340; Invitrogen). Cell nuclei were stained with DAPI (1:5000; Millipore-Sigma, Burlington, MA, USA).

\section{NanoSIMS}

After immunohistochemistry of the sections, CA1 hippocampal regions were dissected and embedded in LR-White-Resin (AGR1281; Agar Scientific, Wetzlar, Germany) and accelerator mixture (AGR1283; Agar Scientific) following a dehydration protocol as described previously (Saka et al., 2014). Sections were further cut into 200nm thick sections with an EM-UC6 Ultramicrotome (Leica Microsystems) and placed on silicon wafers (Siegert Wafer $\mathrm{GmbH}$, Aachen, Germany). Epifluorescent imaging of IBA1 with a Nikon Ti-E inverted microscope and $100 x$ objective (NA 1.59) was followed by scanning with a $\mathrm{Cs}^{+}$primary ion beam in a nanoscale secondary ion mass spectrometry (NanoSIMS 50L) instrument (Cameca, Gennevilliers Cedex, France). Samples were eroded and ionized at $60 \mathrm{pA}$ for $3 \mathrm{~min}$, and the measurements were carried out at $2.5 \mathrm{pA}$ with a dwell time per pixel of $4000 \mathrm{~ms}$. From the resulting secondary ions, ${ }^{12} \mathrm{C}^{14} \mathrm{~N}^{-}$and ${ }^{12} \mathrm{C}^{15} \mathrm{~N}^{-}$were detected and measured, and are referred to as ${ }^{14} \mathrm{~N}$ and ${ }^{15} \mathrm{~N}$, respectively, in this work. The mass resolving power was tuned to enable optimal separation of ${ }^{12} \mathrm{C}^{15} \mathrm{~N}^{-}$from ${ }^{13} \mathrm{C}^{14} \mathrm{~N}$. For each measurement, 3 planes of $40 \times 40 \mu \mathrm{m}(256 \times 256$ pixels) were recorded in a total of 4 animals/group, drift-corrected, and summed for analysis using OpenMIMS-plugin (NRIMS) for ImageJ. The resulting NanoSIMS images were then aligned to corresponding fluorescent images in Adobe-Photoshop. IBA1-positive signals were selected and corresponding NanoSIMS regions quantified in Matlab (Mathworks, Ismaning, Germany) using a custom written plugin. IBA1-positive regions were normalized to negative ones and compared between conditions in GraphPad Prism8.

\section{Pure microglia culture}

Brains from P0-P1 WT mice were freed from meninges before digestion with trypsin/EDTA $0.05 \%$ for $10 \mathrm{~min}$ at $37^{\circ} \mathrm{C}$. Enzymatic reaction was stopped by adding microglia medium (10\% horse serum and $0.5 \%$ penicillin/streptomycin in DMEM; all from Invitrogen) supplemented with $400 \mathrm{IU} /$ brain of DNasel (Worthington Biochemical, Lakewood, NJ, USA). After mechanical trituration, cells were centrifuged $(10 \mathrm{~min}, 150 \mathrm{~g})$ and added to $10 \mathrm{ml}$ pre-warmed microglia medium into poly-D-lysine (PDL)-coated $(50 \mu \mathrm{g} / \mathrm{ml}) 75 \mathrm{~cm}^{2}$ cell-culture flask. Cells were incubated at $37^{\circ} \mathrm{C}$ and $5 \% \mathrm{CO}_{2}$ for $10-14$ days. Pure microglia were harvested by manual shaking of flask and seeded in astrocyte-conditioned medium (ACM) at densities of 20,000 cells/well on PDL-coated 12mm diameter glass-coverslips. ACM was obtained from mixed glial cultures grown in microglia medium for 5-7 days. After $24 \mathrm{~h}$, cells were stimulated with 0.3 or $3 \mathrm{IU} / \mathrm{ml}$ EPO or equivalent volume of solvent solution (placebo) for $6 \mathrm{~h}$ or $24 \mathrm{~h}$. 


\section{SUBMITTED MANUSCRIPT}

\section{Immunocytochemistry}

Mixed glial cultures were fixed with $2 \%$ acrolein and $3 \%$ formaldehyde in PBS, followed by permeabilization and blocking with $5 \%$ NHS in $0.1 \%$ PBST for $1 \mathrm{~h}$ at RT. Primary antibodies IBA1 (chicken, 1:1000, 234006; Synaptic Systems) and caspase-3 (goat, 1:500, sc1225; Santa Cruz Biotechnologies) were incubated with $1 \%$ NHS and $3 \%$ BSA in $0.05 \%$ PBST overnight at $4^{\circ} \mathrm{C}$. As secondary antibodies, donkey anti-chicken Alexa-Fluor-488 (703546155; Jackson ImmunoResearch) and donkey anti-goat Alexa-Fluor-633 (1:500, A21082; Invitrogen) were used in $1 \% \mathrm{NHS}$ and $3 \% \mathrm{BSA}$ in $0.05 \% \mathrm{PBST}$ for $1 \mathrm{~h}$ at RT. Cell nuclei were counterstained with DAPI (1:5000, Millipore-Sigma).

\section{Imaging and analysis}

For analysis of IBA1, CX ${ }_{3}$ CR1CreERT2:tdTomato, caspase-3, Ki67, EdU and CTIP2 a Nikon Ti2 Eclipse (Nikon, Tokyo, Japan) epifluorescent microscope with 40x objective (NA0.6) was used. Confocal imaging of IBA1, CTIP2, TBR1 and ZBTB20 was done with Leica TCS-SP5 inverted system equipped with $20 x$ objective (NA0.7), or $40 x$ objective (NA1.25) for morphological analysis of IBA1+ microglia. Image analysis and manual quantifications were done with Fiji or Imaris v9.1.0 software (Oxford-Instruments, Abingdon, UK) in 3-7 sections/animal $(-1.34$ to $-2.54 \mathrm{~mm}$ posterior from Bregma) and in hippocampal regions indicated in figure schemes. For morphological analysis of microglia, the following parameters were obtained with Imaris: filament dendrite length (sum, shown as "Process length (sum)"), filament full branch level (shown as "Full branch level"), and filament number of dendrite terminal points (shown as "Process terminal points"). Perimeter/area ratio was measured in Fiji by outlining the microglial cell body. A maximum of 20 cells/animal were analyzed. For analysis of IBA1 contacts to dendritic spines, a Leica TCS-SPE system with a 63x objective (NA1.4) was used. The number of IBA1+ contacts on principal apical dendrites of Thy1-YFP+

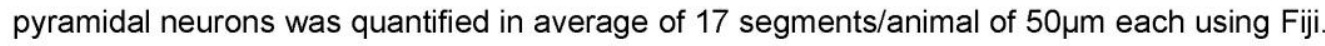
The segments were randomly selected from the CA1 radiatum layer. Pure microglia cultures were analyzed by imaging 3 different regions of interest (ROIs) in 3 biological replicates of $2050 \times 2050 \mu \mathrm{m}(7400 \times 7400$ pixels) each.

\section{Flow Cytometry}

Mice were anesthetized (i.p. Avertin) and perfused via left cardiac ventricle with Ringer's solution. One whole hippocampus per mouse was mechanically dissociated via dounce homogenization in $15 \mathrm{mM}$ HEPES, 0.5\%glucose and 1000IU DNasel (Worthington Biochemical) in HBSS. After washing, cells were stained with Hoechst3352 (1:500; Thermo Fisher Scientific) and Zombie NIR (1:100, 423105; BioLegend, San Diego, CA, USA). Blocking of Fc-receptors was done with CD16/32 antibody (rat, 1:100, 14016185; Thermo Fisher 


\section{SUBMITTED MANUSCRIPT}

Scientific) in fluorescence-activated cell sorting (FACS) buffer (2\% FCS, 0.01M EDTA pH8.0 and $0.01 \% \mathrm{NaN}_{3}$ in PBS). Primary antibodies CD11b Alexa-Fluor-488 (rat, 1:100, 53011282 ; eBioscience by Thermo Fisher Scientific) and CD45 PerCP-Cy5.5 (rat, 1:100, 103132; BioLegend) in FACS buffer were used in extracellular staining for microglia identification. After fixation and permeabilization with commercially available solutions (775775, Invitrogen), intracellular staining with CSF1R PE (rat, 1:100, 135505; BioLegend), EPOR (rabbit, 1:250, SA7378; Synaptic Systems) and donkey anti-rabbit Alexa-Fluor-594 (1:250, A21207; Invitrogen) was done in $0.1 \%$ saponin, $1 \% \mathrm{BSA}$ and $5 \% \mathrm{NHS}$ in PBS. Fluorescent minus one controls were processed in parallel. Filtered samples were acquired on BD-LSR-Fortessa (BDBiosciences, San Jose, CA, USA) and data was analyzed in FlowJo software (BD Biosciences).

\section{Single cell RNA sequencing}

Single cell RNA sequencing (scRNA-seq) data was obtained and processed as described in detail earlier [GSE144444 (Wakhloo et al., 2020) and GSE162079 (Butt et al., Mol Psychiatry, in press)]. In order to identify neuronal genes characteristic of an intermediate stage of maturity, differential expression testing was performed by contrasting cells with a pseudotime within or outside the range of 3-25. Top 30 candidate genes (sorted by $p$-value) were initially screened for expression patterns that indicated temporal upregulation during maturation and matched literature reports. The best candidate was selected for immunohistochemistry.

\section{Statistics}

Data is shown as mean \pm standard error of the mean (SEM). Statistical analyses were performed with GraphPad Prism5 or R4.0.0. Student's unpaired two- or one-tailed $t$ test were performed in normally distributed data and two-tailed Mann-Whitney $U$ test in non-parametric data. Differential expression analysis (scRNA-seq, whole hippocampus) was performed using the FindMarkers() function in Seurat-3.1.5 (Stuart et al., 2019) (two-tailed correlation-adjusted Mann-Whitney $U$ test). Reported $p$-values were adjusted for total number of genes $(n=18976)$ expressed in the dataset. Differential expression-testing used to identify intermediate neuronal markers on pseudotime trajectory (scRNA-seq, CA1) was performed in Monocle-2.16.0 (Qiu et al., 2017), using the function differentialGeneTest(), and false-discovery rate adjusted pvalues were reported. 


\section{References}

Adamcio, B., Sargin, D., Stradomska, A., Medrihan, L., Gertler, C., Theis, F., Zhang, M., Muller, M., Hassouna, I., Hannke, K., et al. (2008). Erythropoietin enhances hippocampal long-term potentiation and memory. BMC Biol 6, 37.

Askew, K., Li, K., Olmos-Alonso, A., Garcia-Moreno, F., Liang, Y., Richardson, P., Tipton, T., Chapman, M.A., Riecken, K., Beccari, S., et al. (2017). Coupled Proliferation and Apoptosis Maintain the Rapid Turnover of Microglia in the Adult Brain. Cell Rep 18, 391-405.

Badimon, A., Strasburger, H.J., Ayata, P., Chen, X., Nair, A., Ikegami, A., Hwang, P., Chan, A.T., Graves, S.M., Uweru, J.O., et al. (2020). Negative feedback control of neuronal activity by microglia. Nature $586,417-423$.

Brines, M., and Cerami, A. (2005). Emerging biological roles for erythropoietin in the nervous system. Nat Rev Neurosci 6, 484-494.

Brown, G., and Ceredig, R. (2019). Modeling the Hematopoietic Landscape. Frontiers in cell and developmental biology 7, 104-104.

Butovsky, O., and Weiner, H.L. (2018). Microglial signatures and their role in health and disease. Nat Rev Neurosci 19, 622-635.

Butt, U.J., Steixner-Kumar, A.A., Depp, C., Sun, T., Hassouna, I., Wustefeld, L., Arinrad, S., Zillmann, M.R., Schopf, N., Fernandez Garcia-Agudo, L., et al. (Mol Psychiatry, in press). Functional hypoxia as primarily neuronal response to brain activity.

Dagher, N.N., Najafi, A.R., Kayala, K.M., Elmore, M.R., White, T.E., Medeiros, R., West, B.L., and Green, K.N. (2015). Colony-stimulating factor 1 receptor inhibition prevents microglial plaque association and improves cognition in 3xTg-AD mice. J Neuroinflammation 12, 139.

Dessypris, E., Graber, S., Krantz, S., and Stone, W. (1988). Effects of recombinant erythropoietin on the concentration and cycling status of human marrow hematopoietic progenitor cells in vivo. Blood 72, 2060-2062.

Digicaylioglu, M., Bichet, S., Marti, H.H., Wenger, R.H., Rivas, L.A., Bauer, C., and Gassmann, M. (1995). Localization of specific erythropoietin binding sites in defined areas of the mouse brain. Proc Natl Acad Sci U S A 92, 3717-3720.

Easley-Neal, C., Foreman, O., Sharma, N., Zarrin, A.A., and Weimer, R.M. (2019a). CSF1R Ligands IL-34 and CSF1 Are Differentially Required for Microglia Development and Maintenance in White and Gray Matter Brain Regions. Front Immunol 10, 2199.

Easley-Neal, C., Foreman, O., Sharma, N., Zarrin, A.A., and Weimer, R.M. (2019b). CSF1R Ligands IL-34 and CSF1 Are Differentially Required for Microglia Development and Maintenance in White and Gray Matter Brain Regions. Frontiers in immunology 10, 2199-2199. Ehrenreich, H., Degner, D., Meller, J., Brines, M., Behe, M., Hasselblatt, M., Woldt, H., Falkai, P., Knerlich, F., Jacob, S., et al. (2004). Erythropoietin: a candidate compound for neuroprotection in schizophrenia. Mol Psychiatry 9, 42-54.

Ehrenreich, H., Fischer, B., Norra, C., Schellenberger, F., Stender, N., Stiefel, M., Siren, A.L., Paulus, W., Nave, K.A., Gold, R., et al. (2007a). Exploring recombinant human erythropoietin in chronic progressive multiple sclerosis. Brain 130, 2577-2588.

Ehrenreich, H., Hasselblatt, M., Knerlich, F., von Ahsen, N., Jacob, S., Sperling, S., Woldt, H., Vehmeyer, K., Nave, K.A., and Siren, A.L. (2005). A hematopoietic growth factor, thrombopoietin, has a proapoptotic role in the brain. Proc Natl Acad Sci U S A 102, 862-867.

Ehrenreich, H., Hinze-Selch, D., Stawicki, S., Aust, C., Knolle-Veentjer, S., Wilms, S., Heinz, G., Erdag, S., Jahn, H., Degner, D., et al. (2007b). Improvement of cognitive functions in chronic schizophrenic patients by recombinant human erythropoietin. Mol Psychiatry 12, 206220.

El-Kordi, A., Radyushkin, K., and Ehrenreich, H. (2009). Erythropoietin improves operant conditioning and stability of cognitive performance in mice. BMC Biol 7, 37.

Elmore, M.R., Najafi, A.R., Koike, M.A., Dagher, N.N., Spangenberg, E.E., Rice, R.A., Kitazawa, M., Matusow, B., Nguyen, H., West, B.L., et al. (2014). Colony-stimulating factor 1 receptor signaling is necessary for microglia viability, unmasking a microglia progenitor cell in the adult brain. Neuron 82, 380-397. 
Elmore, M.R.P., Hohsfield, L.A., Kramar, E.A., Soreq, L., Lee, R.J., Pham, S.T., Najafi, A.R., Spangenberg, E.E., Wood, M.A., West, B.L., et al. (2018). Replacement of microglia in the aged brain reverses cognitive, synaptic, and neuronal deficits in mice. Aging Cell 17, e12832. Gebara, E., Sultan, S., Kocher-Braissant, J., and Toni, N. (2013). Adult hippocampal neurogenesis inversely correlates with microglia in conditions of voluntary running and aging. Frontiers in Neuroscience 7.

Grover, A., Mancini, E., Moore, S., Mead, A.J., Atkinson, D., Rasmussen, K.D., O'Carroll, D., Jacobsen, S.E.W., and Nerlov, C. (2014). Erythropoietin guides multipotent hematopoietic progenitor cells toward an erythroid fate. The Journal of experimental medicine 211, 181-188. Hassouna, I., Ott, C., Wustefeld, L., Offen, N., Neher, R.A., Mitkovski, M., Winkler, D., Sperling, S., Fries, L., Goebbels, S., et al. (2016). Revisiting adult neurogenesis and the role of erythropoietin for neuronal and oligodendroglial differentiation in the hippocampus. Mol Psychiatry 21, 1752-1767.

Hattori, Y., Naito, Y., Tsugawa, Y., Nonaka, S., Wake, H., Nagasawa, T., Kawaguchi, A., and Miyata, T. (2020). Transient microglial absence assists postmigratory cortical neurons in proper differentiation. Nat Commun 11, 1631.

Jelkmann, W. (1992). Erythropoietin: structure, control of production, and function. Physiological reviews 72, 449-489.

Kierdorf, K., and Prinz, M. (2017). Microglia in steady state. The Journal of Clinical Investigation 127, 3201-3209.

Kohman, R.A., DeYoung, E.K., Bhattacharya, T.K., Peterson, L.N., and Rhodes, J.S. (2012). Wheel running attenuates microglia proliferation and increases expression of a proneurogenic phenotype in the hippocampus of aged mice. Brain Behav Immun 26, 803-810.

Krantz, S.B. (1991). Erythropoietin. Blood 77, 419-434.

Liebetanz, D., and Merkler, D. (2006). Effects of commissural de- and remyelination on motor skill behaviour in the cuprizone mouse model of multiple sclerosis. Exp Neurol 202, 217-224.

Marti, H.H., Wenger, R.H., Rivas, L.A., Straumann, U., Digicaylioglu, M., Henn, V., Yonekawa, Y., Bauer, C., and Gassmann, M. (1996). Erythropoietin gene expression in human, monkey and murine brain. Eur J Neurosci 8, 666-676.

Miskowiak, K.W., Ehrenreich, H., Christensen, E.M., Kessing, L.V., and Vinberg, M. (2014). Recombinant human erythropoietin to target cognitive dysfunction in bipolar disorder: a double-blind, randomized, placebo-controlled phase 2 trial. J Clin Psychiatry 75, 1347-1355.

Miskowiak, K.W., Vinberg, M., Macoveanu, J., Ehrenreich, H., Koster, N., Inkster, B., Paulson, O.B., Kessing, L.V., Skimminge, A., and Siebner, H.R. (2015). Effects of Erythropoietin on Hippocampal Volume and Memory in Mood Disorders. Biol Psychiatry 78, 270-277.

Mitkovski, M., Dahm, L., Heinrich, R., Monnheimer, M., Gerhart, S., Stegmuller, J., Hanisch, U.K., Nave, K.A., and Ehrenreich, H. (2015). Erythropoietin dampens injury-induced microglial motility. J Cereb Blood Flow Metab 35, 1233-1236.

Nandi, S., Gokhan, S., Dai, X.M., Wei, S., Enikolopov, G., Lin, H., Mehler, M.F., and Stanley, E.R. (2012). The CSF-1 receptor ligands IL-34 and CSF-1 exhibit distinct developmental brain expression patterns and regulate neural progenitor cell maintenance and maturation. Dev Biol 367, 100-113.

Nielsen, J.V., Blom, J.B., Noraberg, J., and Jensen, N.A. (2010). Zbtb20-induced CA1 pyramidal neuron development and area enlargement in the cerebral midline cortex of mice. Cereb Cortex 20, 1904-1914.

Nielsen, J.V., Thomassen, M., Mollgard, K., Noraberg, J., and Jensen, N.A. (2014). Zbtb20 defines a hippocampal neuronal identity through direct repression of genes that control projection neuron development in the isocortex. Cereb Cortex 24, 1216-1229.

Obst, J., Simon, E., Martin-Estebane, M., Pipi, E., Barkwill, L.M., Gonzalez-Rivera, I., Buchanan, F., Prescott, A.R., Faust, D., Fox, S., et al. (2020). Inhibition of IL-34 Unveils TissueSelectivity and Is Sufficient to Reduce Microglial Proliferation in a Model of Chronic Neurodegeneration. Front Immunol 11, 579000.

Ott, C., Martens, H., Hassouna, I., Oliveira, B., Erck, C., Zafeiriou, M.P., Peteri, U.K., Hesse, D., Gerhart, S., Altas, B., et al. (2015). Widespread Expression of Erythropoietin Receptor in Brain and Its Induction by Injury. Mol Med 21, 803-815. 
Peskin, A.P., Dima, A.A., Chalfoun, J., and Elliott, J.T. (2010). Predicting Segmentation Accuracy for Biological Cell Images. Paper presented at: Advances in Visual Computing (Berlin, Heidelberg: Springer Berlin Heidelberg).

Qiu, X., Mao, Q., Tang, Y., Wang, L., Chawla, R., Pliner, H.A., and Trapnell, C. (2017). Reversed graph embedding resolves complex single-cell trajectories. Nature methods 14, 979. Saka, S.K., Vogts, A., Kröhnert, K., Hillion, F., Rizzoli, S.O., and Wessels, J.T. (2014). Correlated optical and isotopic nanoscopy. Nature Communications 5, 3664.

Sargin, D., Friedrichs, H., El-Kordi, A., and Ehrenreich, H. (2010). Erythropoietin as neuroprotective and neuroregenerative treatment strategy: comprehensive overview of 12 years of preclinical and clinical research. Best Pract Res Clin Anaesthesiol 24, 573-594.

Sargin, D., Hassouna, I., Sperling, S., Siren, A.L., and Ehrenreich, H. (2009). Uncoupling of neurodegeneration and gliosis in a murine model of juvenile cortical lesion. Glia 57, 693-702.

Sierra, A., de Castro, F., del Río-Hortega, J., Rafael Iglesias-Rozas, J., Garrosa, M., and Kettenmann, H. (2016). The "Big-Bang" for modern glial biology: Translation and comments on Pío del Río-Hortega 1919 series of papers on microglia. Glia 64, 1801-1840.

Siren, A.L., Fasshauer, T., Bartels, C., and Ehrenreich, H. (2009). Therapeutic potential of erythropoietin and its structural or functional variants in the nervous system. Neurotherapeutics 6, 108-127.

Siren, A.L., Fratelli, M., Brines, M., Goemans, C., Casagrande, S., Lewczuk, P., Keenan, S., Gleiter, C., Pasquali, C., Capobianco, A., et al. (2001). Erythropoietin prevents neuronal apoptosis after cerebral ischemia and metabolic stress. Proc Natl Acad Sci U S A 98, 40444049.

Siren, A.L., Radyushkin, K., Boretius, S., Kammer, D., Riechers, C.C., Natt, O., Sargin, D., Watanabe, T., Sperling, S., Michaelis, T., et al. (2006). Global brain atrophy after unilateral parietal lesion and its prevention by erythropoietin. Brain 129, 480-489.

Stuart, T., Butler, A., Hoffman, P., Hafemeister, C., Papalexi, E., Mauck, W.M., 3rd, Hao, Y., Stoeckius, M., Smibert, P., and Satija, R. (2019). Comprehensive Integration of Single-Cell Data. Cell 177, 1888-1902 e1821.

Suresh, S., Rajvanshi, P.K., and Noguchi, C.T. (2019). The Many Facets of Erythropoietin Physiologic and Metabolic Response. Front Physiol 10, 1534.

Wakhloo, D., Scharkowski, F., Curto, Y., Javed Butt, U., Bansal, V., Steixner-Kumar, A.A., Wustefeld, L., Rajput, A., Arinrad, S., Zillmann, M.R., et al. (2020). Functional hypoxia drives neuroplasticity and neurogenesis via brain erythropoietin. Nat Commun 11, 1313.

Wang, R., Li, J., Duan, Y., Tao, Z., Zhao, H., and Luo, Y. (2017). Effects of Erythropoietin on Gliogenesis during Cerebral Ischemic/Reperfusion Recovery in Adult Mice. Aging Dis 8, 410419.

Werneburg, S., Feinberg, P.A., Johnson, K.M., and Schafer, D.P. (2017). A microglia-cytokine axis to modulate synaptic connectivity and function. Current opinion in neurobiology $47,138-$ 145.

Wustenberg, T., Begemann, M., Bartels, C., Gefeller, O., Stawicki, S., Hinze-Selch, D., Mohr, A., Falkai, P., Aldenhoff, J.B., Knauth, M., et al. (2011). Recombinant human erythropoietin delays loss of gray matter in chronic schizophrenia. Mol Psychiatry 16, 26-36, 21.

Xie, Z., Ma, X., Ji, W., Zhou, G., Lu, Y., Xiang, Z., Wang, Y.X., Zhang, L., Hu, Y., Ding, Y.Q., et al. (2010). Zbtb20 is essential for the specification of CA1 field identity in the developing hippocampus. Proceedings of the National Academy of Sciences 107, 6510-6515.

Zhang, S.J., Wang, R.L., Zhao, H.P., Tao, Z., Li, J.C., Ju, F., Han, Z.P., Ma, Q.F., Liu, P., Ma, S.B., et al. (2019). MEPO promotes neurogenesis and angiogenesis but suppresses gliogenesis in mice with acute ischemic stroke. Eur J Pharmacol 849, 1-10. 


\section{SUBMITTED MANUSCRIPT}

\section{Acknowledgements}

This study was supported by the Max Planck Society, the Deutsche Forschungsgemeinschaft (DFG, German Research Foundation) Research Center for Nanoscale Microscopy and Molecular Physiology of the Brain (CNMPB) as well as by the DFG -TRR 274/1 2020 - 408885537. UJB has received a PhD stipend from National University of Sciences and Technology (NUST), Faculty Development Program Abroad 2014/15 Pakistan. AASK has held a stipend of the IMPRS-GGNB Ph.D. Program Neurosciences (DFG Grant GSC 226), Göttingen. JN is supported by the Spanish Ministry of Science and Innovation (Grant RTI2018-098269-B-I00) and KAN by the Adelson Medical Research Foundation and an ERC Advanced Grant.

\section{Author contributions}

Concept, design and supervision of the study: HE

Data acquisition/analysis/interpretation:

LFGA, AASK, YC, IH, SJ, UJB, NS, KaG, MSW, SR, JN, KG, KAN, and HE

Drafting manuscript: LFGA, AASK, YC, together with HE

Drafting display items: LFGA, AASK, YC, together with HE

All authors read and approved the final version of the manuscript.

\section{Competing interest statement}

The authors declare no competing financial or other interests.

\section{Code availability}

Analysis scripts are accessible on GitHub:

https://github.com/AgnesSteixner/Fernandez_Garcia-Agudo_et_al_EPO_microglia 


\section{SUBMITTED MANUSCRIPT}

\section{FIGURE LEGENDS}

Figure 1: Inspiratory and functional hypoxia induce brain EPO expression and diminish microglia numbers - imitation by rhEPO and dependence on EPOR.

(A) Treatment scheme and hippocampal area of analysis for (B) EPO mRNA expression (normalized to Hprt1) in P32 WT C57BL/6 mice, exposed for 6h to normoxia $\left(21 \% \mathrm{O}_{2} ; \mathrm{N}\right)$, functional hypoxia upon complex running wheel performance (CRW), or inspiratory hypoxia $\left(6 \% \mathrm{O}_{2} ; \mathrm{H}\right)$. (C) Scheme for normoxia, CRW or inspiratory hypoxia $\left(12 \% \mathrm{O}_{2}\right)$ exposure extended to 3 weeks and area of IBA1 quantification, given in (D). (E) IBA1 quantification after 3 weeks of rhEPO or placebo (PL) treatment. (F) Quantification of tdTomato+IBA1+ cells 1 week after cessation of rhEPO versus placebo (PL) treatment of $\mathrm{CX}_{3} \mathrm{CR} 1 \mathrm{CreERT2:tdTomato} \mathrm{mice.} \mathrm{(G)} \mathrm{Quantification} \mathrm{of}$ caspase-3+ and Ki67+ microglia in mice of $(E)$. (H) Scheme for administration of EdU for 1 week after rhEPO or placebo treatment cessation and area/quantification of IBA1+EdU+ cells. (I) Morphological analysis of microglia processes in mice of (E). (J) Morphological analysis of microglia cell bodies in mice of $(E)$. (K) Density of IBA1 ${ }^{+}$ contacts on apical dendrites of Thy1-YFP+ pyramidal neurons after 3 weeks of rhEPO or placebo treatment and illustration thereof. (L) NanoSIMS experiment after ${ }^{15} \mathrm{~N}$ leucine enriched food, provided for the same 3-week duration as rhEPO or placebo; representative images and calculated ${ }^{15} \mathrm{~N} /{ }^{14} \mathrm{~N}$ ratio in IBA1+ cells as a measure of ${ }^{15} \mathrm{~N}$ leucine incorporation (normalized to IBA1- areas); area of analysis shown in (A). (M) IBA1 quantification in $\mathrm{CX}_{3} \mathrm{CR} 1 \mathrm{CreERT2:EPOR-KO}$ mice after 3 weeks of rhEPO or placebo treatment and $(\mathrm{N})$ morphological analysis of microglia cell bodies. All graphs show mean \pm SEM with $\mathrm{n}$ numbers in bars and unpaired two-tailed $t$ tests, except for $(\mathrm{L})$, where a two-tailed Mann-Whitney $U$ test was performed. Analyses were conducted in the area shown in $(\mathrm{C})$, except otherwise indicated.

Figure 2: Counterbalance between microglia and newly generated neurons upon EPO. (A) Scheme for 1 week of rhEPO or placebo (PL) treatment in P28 WT C57BL/6 mice and hippocampal area of analysis for (B) IBA1 as well as (C) quantifications of caspase-3+ and Ki67+ microglia. (D) Morphological analysis of microglia cell bodies. (E) Representative illustrating images and quantifications of cells with neuronal markers CTIP2 and TBR1. (F) Single cell RNA sequencing (scRNA-seq) analysis after 6h of a single rhEPO or placebo injection. (G) Pseudotime trajectory of glutamatergic cells of CA1 (Wakhloo et al., 2020). (H) Tbr1 expression along the pseudotime 


\section{SUBMITTED MANUSCRIPT}

trajectory/neuronal maturation stages (Wakhloo et al., 2020); expression indicated as $\log 10$ (normalized expression+0.1). (I) Selection of a population of neurons with intermediate maturity and identification of Zbtb2O as marker, transiently increased during maturation, i.e. highly expressed in this population. (J) Quantification and representative illustrating image of ZBTB20 in mice from (A). (K) Scheme for $24 \mathrm{~h}$ of rhEPO or placebo treatment. (L) Quantification of IBA1+ and caspase-3+ microglia. (M) Percentage of IBA1+caspase-3+ cells in pure microglia cultures after 6h of rhEPO or placebo addition. All graphs show mean \pm SEM with $n$ numbers in bars and unpaired $t$ tests (two-tailed, one-tailed in (D)); scRNA-seq data from 3 mice/group; in vitro data represent 3 measurements from 3 biological replicates.

Figure 3: Endogenous and exogenous EPO affects microglial proliferation via CSF1R. (A) Treatment scheme for the CSF1R inhibition experiment starting in P21 WT C57BL/6 mice with 10 days of control food (CF) or PLX5622 (PLX), followed by 3 weeks of rhEPO or placebo (PL); EdU applied from P30 to P36. (B) Hippocampal area of analysis. (C) Quantifications of all IBA1+ and proliferating IBA1+EdU+ microglia. (D) Quantifications of all CTIP2+ and proliferating CTIP2+EdU+ neurons. (E) Representative images from animals treated with PLX5622 and rhEPO or placebo. (F) Scheme for 3 weeks of rhEPO or placebo treatment. (G) Area of analysis for $(\mathbf{H})$ flow cytometry analysis of median fluorescent intensity (MFI) of CSF1R and EPOR in nucleated, single, viable microglial cells (Hoechst+ZombieNIR-CD11b+CD45lo shown in ellipse-shaped gate) and (I) mRNA expression of Csf1r, Csf1 and I/34 (normalized to Hprt1). All graphs show mean \pm SEM with $\mathrm{n}$ numbers in bars or graph; all unpaired two-tailed $t$ tests.

Figure 4: Expression of Csf1r and its ligands Csf1 and I/34 under hypoxia (scRNA-seq). (A) Acquisition scheme of the scRNA-seq data set (Butt et al., Mol Psychiatry, in press) following normoxia or hypoxia $\left(6 \% \mathrm{O}_{2}, 6 \mathrm{~h} /\right.$ day, 5 days) treatment, and hippocampal area of analysis. (B) UMAP embedding of cell populations of the hippocampus. (C) Expression of Csf1r, Csf1 and //34 in whole hippocampus. (D) Expression of Csf1r in microglia. (E) Expression of Csf1 in glial cells (including microglia, OPC, oligodendrocytes, ependymal cells and astrocytes). (F) Expression of I/34 in glutamatergic neurons. Bonferroni-corrected p-values of correlation-adjusted two-tailed Mann-Whitney $U$ tests reported in (C-F); scRNA-seq data based on 2 mice/group. 
SUBMITTED MANUSCRIPT

Fernandez Garcia-Agudo et al Figure 1

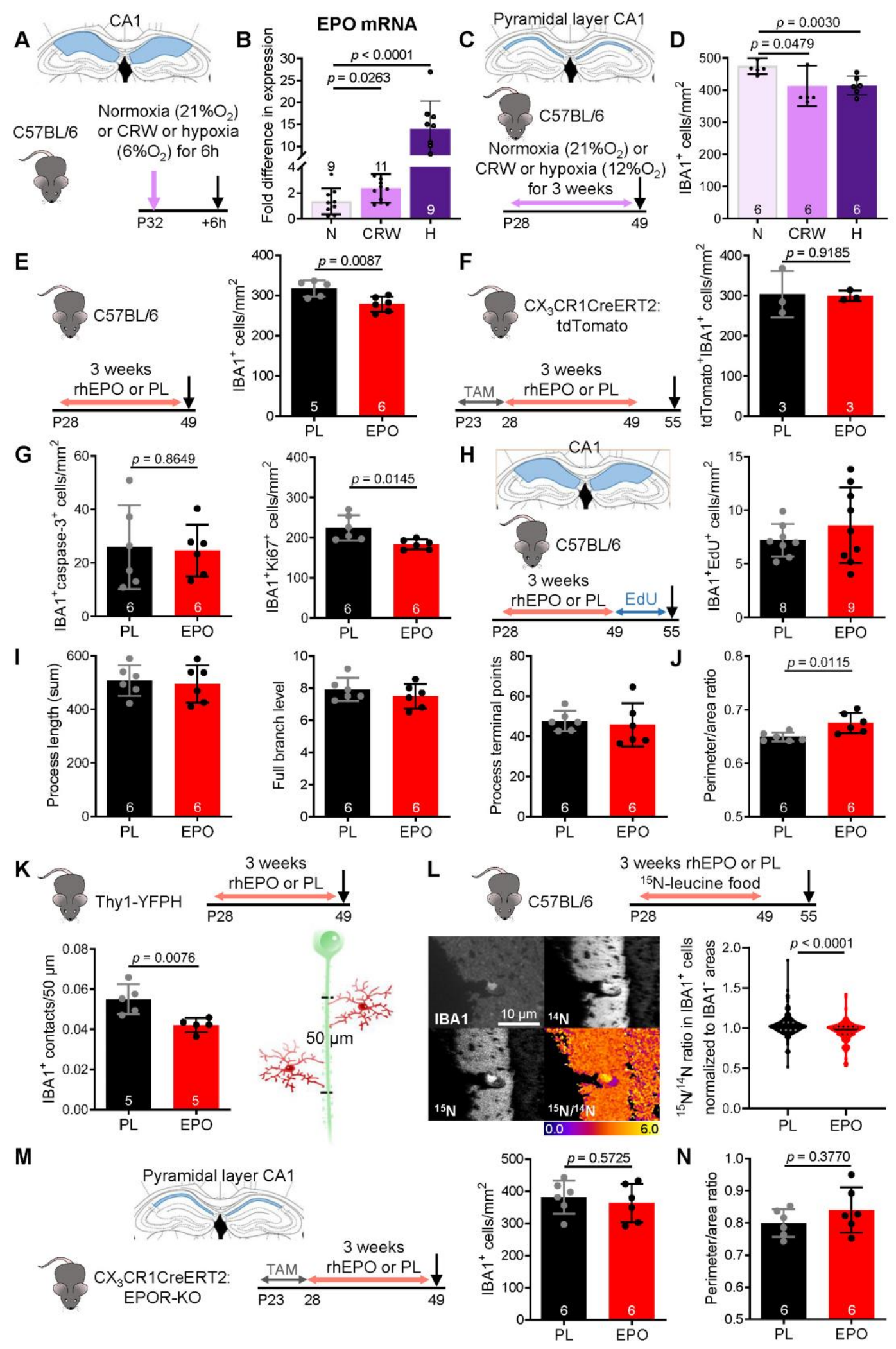




\section{SUBMITTED MANUSCRIPT}

Fernandez Garcia-Agudo et al Figure 2

A

Pyramidal layer CA1

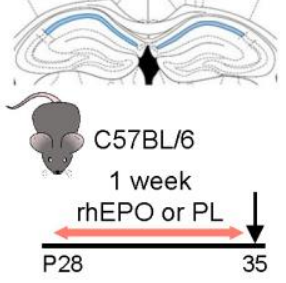

D

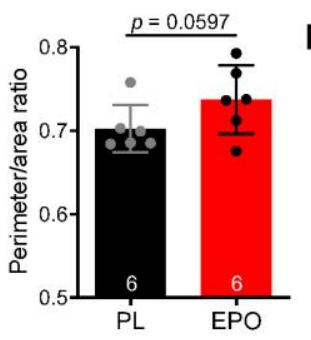

$\mathbf{F}$

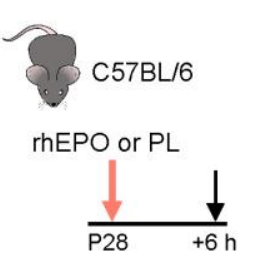

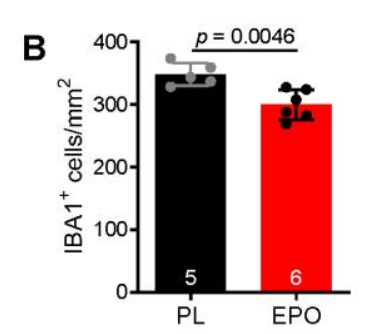

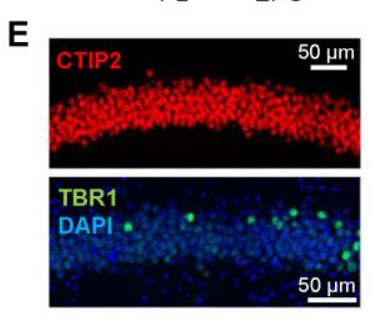

G

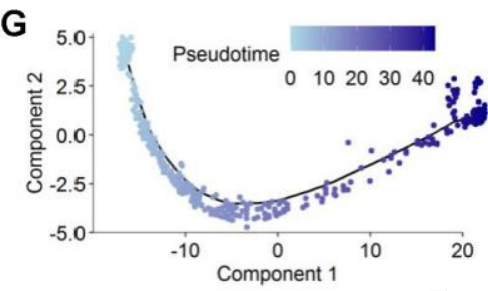

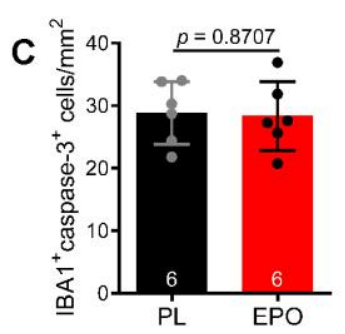
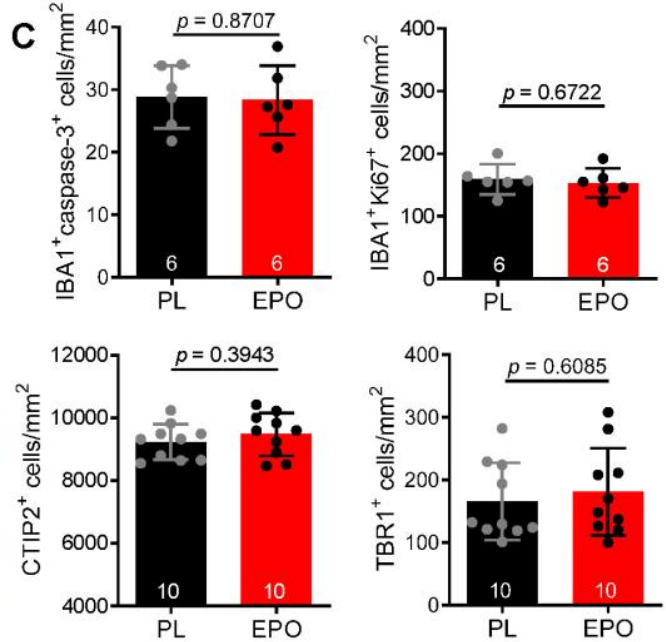

H Tbr1 expression

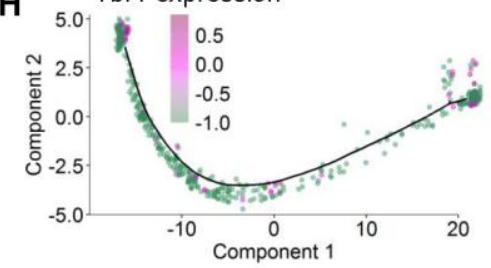

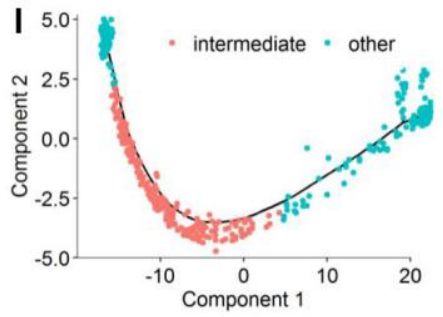
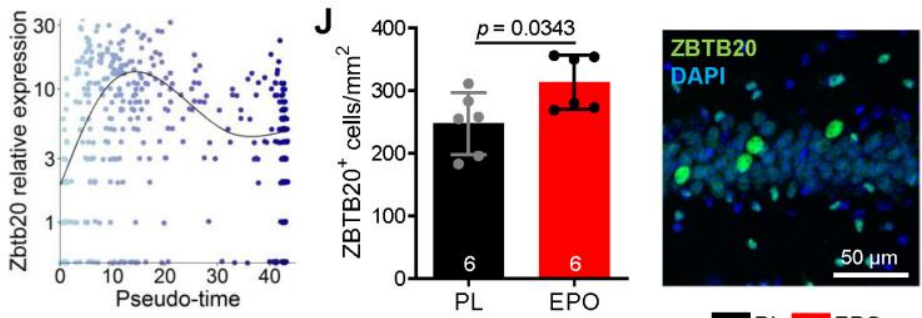

K

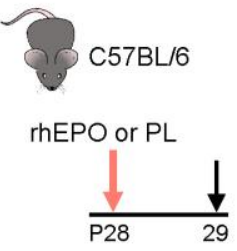

L

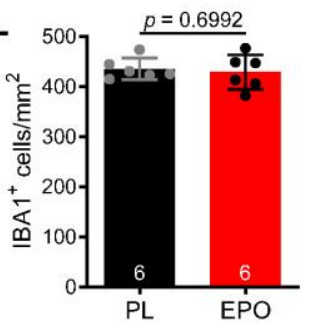

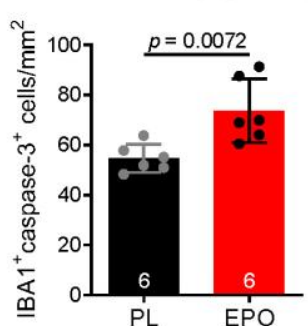

$\square \mathrm{PL}$ EPO

M

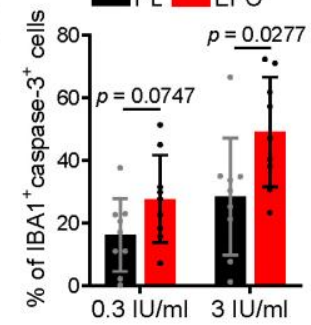




\section{SUBMITTED MANUSCRIPT}

Fernandez Garcia-Agudo et al Figure 3

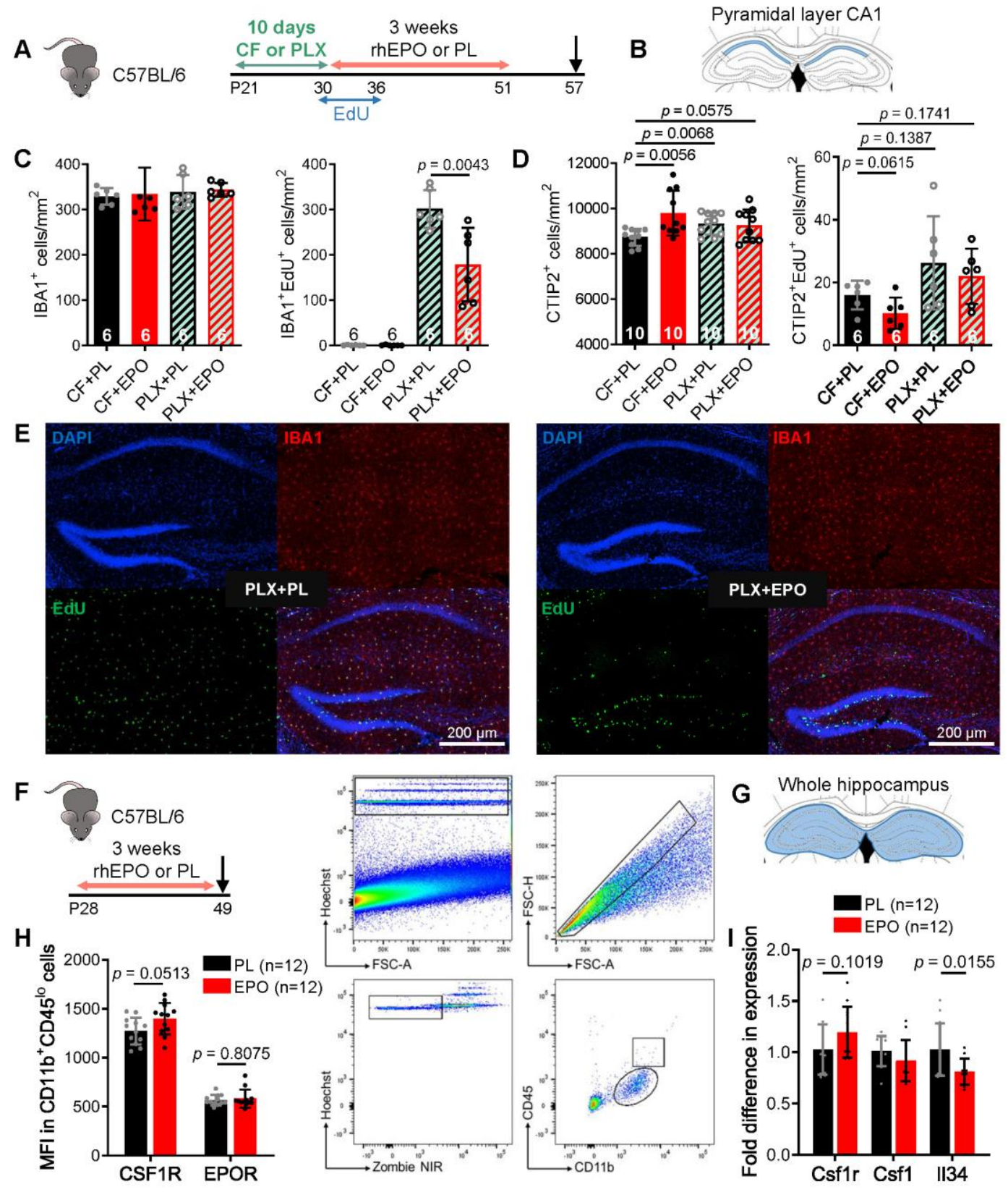




\section{SUBMITTED MANUSCRIPT}

Fernandez Garcia-Agudo et al Figure 4

A

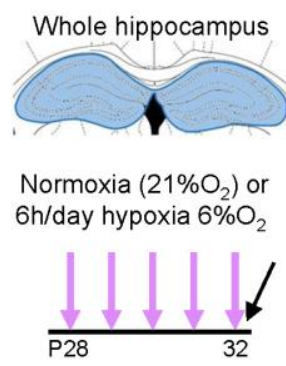

B

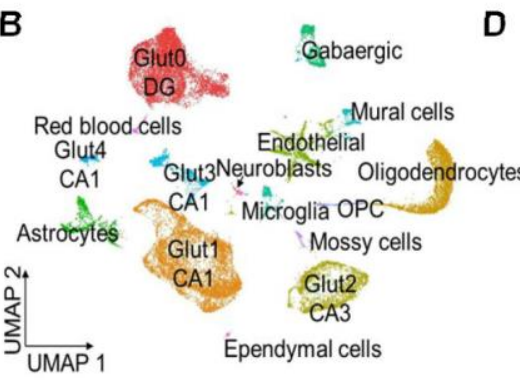

C Csf1r, Csf1 and $/ / 34$ in whole hippocampus
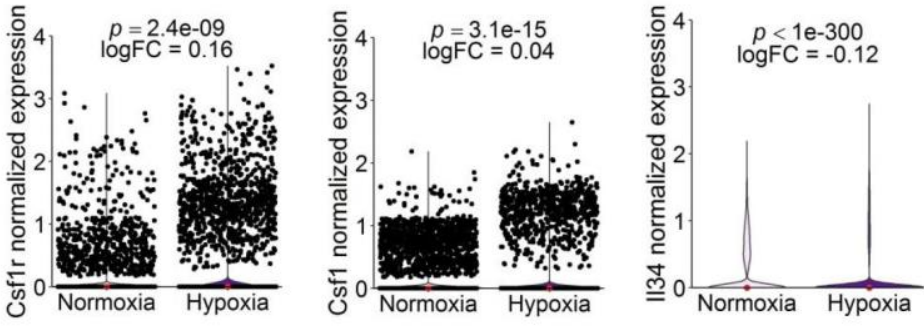

D Csf1r in microglia E Csf1 in glial cells

F

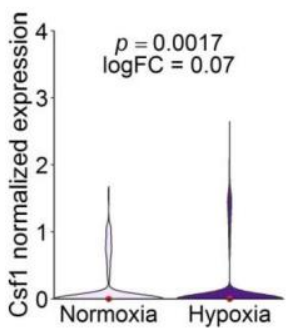

F $\quad 1 / 34$ in glutamatergic
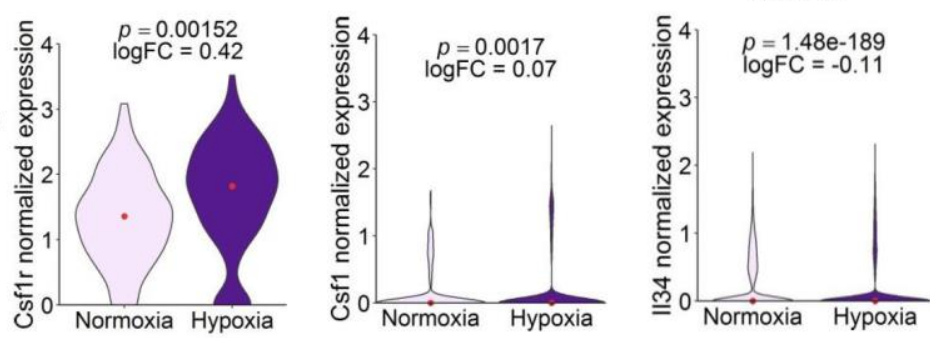
CONCLUSIONS AND OUTLOOK 
This thesis is one more evidence of the extreme relevance of microglia in the normal and diseased brain. Abnormal microglial numbers, whether too high or too low, have undeniable local consequences that reach the cognitive level. As if they could sense their own population, changes in the density of microglia come accompanied by altered basal microglial activity. Indeed, this is a very plastic brain component. Since they depend on CSF1R for survival, microglial numbers and activity can be modulated by targeting the CSF1R axis.

It is clear that the outcome of manipulating microglia is entirely context-dependent. In health, microglia are performing their surveillance tasks, including neuronal development regulation. When they encounter a situation of increased neuronal differentiation, i.e. by a neuro-protective agent like hypoxia or EPO, it would seem like microglia are signaled to reduce the possible 'aggressiveness' of their pruning. Like this, more neurons can mature and develop new contacts. Of note, decrease of microglia numbers via apoptosis and reduced proliferation does nothing but further emphasize this boost in neurodifferentiation: microglia depleted brains have the same increase in CA1 neurons as those treated with EPO. Decreased production of IL-34, ligand of CSF1R, is likely behind the mechanism that explains the benefits of EPO and hypoxia. We documented the effect that altering the signaling components of the CSF1R pathway has in neuron numbers, something that was only previously shown in the embryonic and early postnatal development. Could EPO also promote increased neurodifferentiation in aged, non-diseased brains? Does its effect on microglia still apply when trying to target an altered, over-activated population as that of the aged CNS?

In disease, increased microglial numbers and aberrant activation produce an inflammatory environment in the brain that can eventually turn into neuron degeneration and cognitive decline. In the case of catatonia, this neuroinflammation is triggered by alterations of myelin structural components like CNP, which do not produce motoric impairments. While gene therapy for these patients is still far away, anti-inflammatory treatment focused on microglial population dynamics can be of aid. For this, the CSF1R inhibitor PLX5622 has proven itself useful in the relief of the catatonic signs. We discovered, however, that a careful approach must be taken in order to control the highly inflammatory DAM population that is left during 
PLX5622 treatment. Perhaps dose-response in vitro studies with the system we describe for efficient PLX5622-triggered microglia depletion would further enlighten the best ways to apply this compound and, later on, translate to the clinic.

It would be highly interesting to combine both treatments, EPO and PLX5622, in health and disease. Could EPO, or hypoxia, lead to a dramatic neuro-regeneration of a catatonic brain, if applied simultaneously with PLX5622? What cognitive consequences could this have if performed on healthy animals? Indeed, apart from targeting microglia, both treatments seem to have direct (EPO) or indirect (PLX5622) effects on neurons. Perhaps it is all a question of finding the right equilibrium between all components to bring a diseased brain back to health, or to promote a healthy brain to be, well, more extraordinary. 


\section{BIBLIOGRAPHY}


1 Río-Hortega, P. d. El "Tercer Elemento" de los Centros Nerviosos. I. La Microglía en Estado Normal. Boletín de la Sociedad Española de Biología VIII, 67-82 (1919).

2 Río-Hortega, P. d. El "Tercer Elemento" de los Centros Nerviosos. III. Naturaleza Probable de la Microglía. Boletín de la Sociedad Española de Biología VIII, 108-121 (1919).

3 Ito, D., Imai, Y., Ohsawa, K., Nakajima, K., Fukuuchi, Y. \& Kohsaka, S. Microglia-specific localisation of a novel calcium binding protein, Iba1. Brain Res Mol Brain Res 57, 1-9, doi:10.1016/S0169-328X(98)00040-0 (1998).

4 McKercher, S. R., Torbett, B. E., Anderson, K. L., Henkel, G. W., Vestal, D. J., Baribault, H., Klemsz, M., Feeney, A. J., Wu, G. E., Paige, C. J. \& Maki, R. A. Targeted disruption of the PU.1 gene results in multiple hematopoietic abnormalities. EMBO J15, 5647-5658 (1996).

5 Mezey, É., Chandross, K. J., Harta, G., Maki, R. A. \& McKercher, S. R. Turning blood into brain: Cells bearing neuronal antigens generated in vivo from bone marrow. Science 290, 1779-1782, doi:10.1126/science.290.5497.1779 (2000).

6 Ransohoff, R. M. \& Perry, V. H. Microglial physiology: unique stimuli, specialized responses. Annu Rev Immunol 27, 119-145, doi:10.1146/annurev.immunol.021908.132528 (2009).

7 Alliot, F., Godin, I. \& Pessac, B. Microglia derive from progenitors, originating from the yolk sac, and which proliferate in the brain. Dev Brain Res 117, 145-152, doi:10.1016/s0165-3806(99)001133 (1999).

8 Ginhoux, F., Greter, M., Leboeuf, M., Nandi, S., See, P., Gokhan, S., Mehler, M. F., Conway, S. J., Ng, L. G., Stanley, E. R., Samokhvalov, I. M. \& Merad, M. Fate mapping analysis reveals that adult microglia derive from primitive macrophages. Science 330, 841-845, doi:10.1126/science.1194637 (2010).

9 Ransohoff, R. M. \& Cardona, A. E. The myeloid cells of the central nervous system parenchyma. Nature 468, 253-262, doi:10.1038/nature09615 (2010).

10 Bennett, M. L., Bennett, F. C., Liddelow, S. A., Ajami, B., Zamanian, J. L., Fernhoff, N. B., Mulinyawe, S. B., Bohlen, C. J., Adil, A., Tucker, A., Weissman, I. L., Chang, E. F., Li, G., Grant, G. A., Hayden Gephart, M. G. \& Barres, B. A. New tools for studying microglia in the mouse and human CNS. PNAS 113, E1738-1746, doi:10.1073/pnas.1525528113 (2016).

11 Ajami, B., Bennett, J. L., Krieger, C., Tetzlaff, W. \& Rossi, F. M. Local self-renewal can sustain CNS microglia maintenance and function throughout adult life. Nat Neurosci 10, 1538-1543, doi:10.1038/nn2014 (2007).

12 Lawson, L. J., Perry, V. H. \& Gordon, S. Turnover of resident microglia in the normal adult mouse brain. Neuroscience 48, 405-415, doi:10.1016/0306-4522(92)90500-2 (1992).

13 Askew, K., Li, K., Olmos-Alonso, A., Garcia-Moreno, F., Liang, Y., Richardson, P., Tipton, T., Chapman, M. A., Riecken, K., Beccari, S., Sierra, A., Molnar, Z., Cragg, M. S., Garaschuk, O., Perry, V. H. \& Gomez-Nicola, D. Coupled Proliferation and Apoptosis Maintain the Rapid Turnover of Microglia in the Adult Brain. Cell Rep 18, 391-405, doi:10.1016/j.celrep.2016.12.041 (2017).

14 Blinzinger, K. \& Kreutzberg, G. Displacement of synaptic terminals from regenerating motoneurons by microglial cells. Zeitschrift fur Zellforschung und mikroskopische Anatomie (Vienna, Austria : 1948) 85, 145-157, doi:10.1007/bf00325030 (1968).

15 Nimmerjahn, A., Kirchhoff, F. \& Helmchen, F. Resting microglial cells are highly dynamic surveillants of brain parenchyma in vivo. Science 308, 1314-1318, doi:10.1126/science.1110647 (2005).

16 Davalos, D., Grutzendler, J., Yang, G., Kim, J. V., Zuo, Y., Jung, S., Littman, D. R., Dustin, M. L. \& Gan, W. B. ATP mediates rapid microglial response to local brain injury in vivo. Nat Neurosci 8, 752-758, doi:10.1038/nn1472 (2005).

$17 \mathrm{Li}$, Q. \& Barres, B. A. Microglia and macrophages in brain homeostasis and disease. Nat ReV Immunol 18, 225-242, doi:10.1038/nri.2017.125 (2018).

18 Kierdorf, K. \& Prinz, M. Microglia in steady state. J Clin Invest 127, 3201-3209, doi:10.1172/JCI90602 (2017).

19 Prinz, M., Jung, S. \& Priller, J. Microglia Biology: One Century of Evolving Concepts. Cell 179, 292-311, doi:10.1016/j.cell.2019.08.053 (2019).

20 Schafer, D. P., Lehrman, E. K., Kautzman, A. G., Koyama, R., Mardinly, A. R., Yamasaki, R., Ransohoff, R. M., Greenberg, M. E., Barres, B. A. \& Stevens, B. Microglia sculpt postnatal neural circuits in an activity and complement-dependent manner. Neuron 74, 691-705, doi:10.1016/j.neuron.2012.03.026 (2012).

21 Tremblay, M.-È., Lowery, R. L. \& Majewska, A. K. Microglial Interactions with Synapses Are Modulated by Visual Experience. PLOS Biol 8, e1000527, doi:10.1371/journal.pbio.1000527 (2010). 
22 Wake, H., Moorhouse, A. J., Jinno, S., Kohsaka, S. \& Nabekura, J. Resting microglia directly monitor the functional state of synapses in vivo and determine the fate of ischemic terminals. $J$ Neurosci 29, 3974-3980, doi:10.1523/JNEUROSCI.4363-08.2009 (2009).

23 Eyo, U. B., Peng, J., Swiatkowski, P., Mukherjee, A., Bispo, A. \& Wu, L. J. Neuronal hyperactivity recruits microglial processes via neuronal NMDA receptors and microglial P2Y12 receptors after status epilepticus. $J$ Neurosci 34, 10528-10540, doi:10.1523/JNEUROSCI.041614.2014 (2014).

24 Dissing-Olesen, L., LeDue, J. M., Rungta, R. L., Hefendehl, J. K., Choi, H. B. \& MacVicar, B. A. Activation of neuronal NMDA receptors triggers transient ATP-mediated microglial process outgrowth. J Neurosci 34, 10511-10527, doi:10.1523/JNEUROSCI.0405-14.2014 (2014).

25 Koizumi, S., Shigemoto-Mogami, Y., Nasu-Tada, K., Shinozaki, Y., Ohsawa, K., Tsuda, M., Joshi, B. V., Jacobson, K. A., Kohsaka, S. \& Inoue, K. UDP acting at P2Y6 receptors is a mediator of microglial phagocytosis. Nature 446, 1091-1095, doi:10.1038/nature05704 (2007).

26 Badimon, A., Strasburger, H. J., Ayata, P., Chen, X., Nair, A., Ikegami, A., Hwang, P., Chan, A. T., Graves, S. M., Uweru, J. O., Ledderose, C., Kutlu, M. G., Wheeler, M. A., Kahan, A., Ishikawa, M., Wang, Y. C., Loh, Y. E., Jiang, J. X., Surmeier, D. J., Robson, S. C., Junger, W. G., Sebra, R., Calipari, E. S., Kenny, P. J., Eyo, U. B., Colonna, M., Quintana, F. J., Wake, H., Gradinaru, V. \& Schaefer, A. Negative feedback control of neuronal activity by microglia. Nature 586, 417-423, doi:10.1038/s41586-020-2777-8 (2020).

27 Harrison, J. K., Jiang, Y., Chen, S., Xia, Y., Maciejewski, D., McNamara, R. K., Streit, W. J., Salafranca, M. N., Adhikari, S., Thompson, D. A., Botti, P., Bacon, K. B. \& Feng, L. Role for neuronally derived fractalkine in mediating interactions between neurons and CX3CR1-expressing microglia. PNAS 95, 10896 -10901 (1998).

28 Paolicelli, R. C., Bolasco, G., Pagani, F., Maggi, L., Scianni, M., Panzanelli, P., Giustetto, M., Ferreira, T. A., Guiducci, E., Dumas, L., Ragozzino, D. \& Gross, C. T. Synaptic pruning by microglia is necessary for normal brain development. Science 333, 1456-1458, doi:10.1126/science.1202529 (2011).

29 Rogers, J. T., Morganti, J. M., Bachstetter, A. D., Hudson, C. E., Peters, M. M., Grimmig, B. A., Weeber, E. J., Bickford, P. C. \& Gemma, C. CX3CR1 deficiency leads to impairment of hippocampal cognitive function and synaptic plasticity. $J$ Neurosci 31, 16241-16250, doi:10.1523/jneurosci.3667-11.2011 (2011).

30 Guneykaya, D., Ivanov, A., Hernandez, D. P., Haage, V., Wojtas, B., Meyer, N., Maricos, M., Jordan, P., Buonfiglioli, A., Gielniewski, B., Ochocka, N., Comert, C., Friedrich, C., Artiles, L. S., Kaminska, B., Mertins, P., Beule, D., Kettenmann, H. \& Wolf, S. A. Transcriptional and translational differences of microglia from male and female brains. Cell Rep 24, 2773-2783 e2776, doi:10.1016/j.celrep.2018.08.001 (2018).

31 Schwarz, J. M., Sholar, P. W. \& Bilbo, S. D. Sex differences in microglial colonization of the developing rat brain. J Neurochem 120, 948-963, doi:10.1111/j.1471-4159.2011.07630.x (2012).

32 Masuda, T., Sankowski, R., Staszewski, O., Bottcher, C., Amann, L., Sagar, Scheiwe, C., Nessler, S., Kunz, P., van Loo, G., Coenen, V. A., Reinacher, P. C., Michel, A., Sure, U., Gold, R., Grun, D., Priller, J., Stadelmann, C. \& Prinz, M. Spatial and temporal heterogeneity of mouse and human microglia at single-cell resolution. Nature 566, 388-392, doi:10.1038/s41586-019-0924-X (2019).

33 Grabert, K., Michoel, T., Karavolos, M. H., Clohisey, S., Baillie, J. K., Stevens, M. P., Freeman, T. C., Summers, K. M. \& McColl, B. W. Microglial brain region-dependent diversity and selective regional sensitivities to aging. Nat Neurosci 19, 504-516, doi:10.1038/nn.4222 (2016).

34 Gomez Perdiguero, E., Klapproth, K., Schulz, C., Busch, K., Azzoni, E., Crozet, L., Garner, H., Trouillet, C., de Bruijn, M. F., Geissmann, F. \& Rodewald, H. R. Tissue-resident macrophages originate from yolk-sac-derived erythro-myeloid progenitors. Nature 518, 547-551, doi:10.1038/nature13989 (2015).

35 Hickman, S. E., Kingery, N. D., Ohsumi, T. K., Borowsky, M. L., Wang, L. C., Means, T. K. \& El Khoury, J. The microglial sensome revealed by direct RNA sequencing. Nat Neurosci 16, 18961905, doi:10.1038/nn.3554 (2013).

36 Cronk, J. C., Filiano, A. J., Louveau, A., Marin, I., Marsh, R., Ji, E., Goldman, D. H., Smirnov, I., Geraci, N., Acton, S., Overall, C. C. \& Kipnis, J. Peripherally derived macrophages can engraft the brain independent of irradiation and maintain an identity distinct from microglia. J Exp Med 215, 1627-1647, doi:10.1084/jem.20180247 (2018).

37 Stanley, E. R. \& Heard, P. M. Factors regulating macrophage production and growth. Purification and some properties of the colony stimulating factor from medium conditioned by mouse L cells. The Journal of biological chemistry 252, 4305-4312 (1977). 
38 Stanley, E. R., Chen, D. M. \& Lin, H. S. Induction of macrophage production and proliferation by a purified colony stimulating factor. Nature 274, 168-170, doi:10.1038/274168a0 (1978).

39 Ségaliny, A. I., Tellez-Gabriel, M., Heymann, M.-F. \& Heymann, D. Receptor tyrosine kinases: Characterisation, mechanism of action and therapeutic interests for bone cancers. J Bone Oncol4, 1-12, doi:10.1016/j.jbo.2015.01.001 (2015).

40 Yeung, Y. G., Jubinsky, P. T., Sengupta, A., Yeung, D. C. \& Stanley, E. R. Purification of the colony-stimulating factor 1 receptor and demonstration of its tyrosine kinase activity. PNAS 84, 1268-1271, doi:10.1073/pnas.84.5.1268 (1987).

41 Lin, H., Lee, E., Hestir, K., Leo, C., Huang, M., Bosch, E., Halenbeck, R., Wu, G., Zhou, A., Behrens, D., Hollenbaugh, D., Linnemann, T., Qin, M., Wong, J., Chu, K., Doberstein, S. K. \& Williams, L. T. Discovery of a cytokine and its receptor by functional screening of the extracellular proteome. Science 320, 807-811, doi:10.1126/science.1154370 (2008).

42 Sasmono, R. T., Oceandy, D., Pollard, J. W., Tong, W., Pavli, P., Wainwright, B. J., Ostrowski, M. C., Himes, S. R. \& Hume, D. A. A macrophage colony-stimulating factor receptor-green fluorescent protein transgene is expressed throughout the mononuclear phagocyte system of the mouse. Blood 101, 1155-1163, doi:10.1182/blood-2002-02-0569 (2003).

43 Kondo, Y. \& Duncan, I. D. Selective reduction in microglia density and function in the white matter of colony-stimulating factor-1-deficient mice. $J$ Neurosci Res 87, 2686-2695, doi:10.1002/jnr.22096 (2009).

44 Wang, Y., Szretter, K. J., Vermi, W., Gilfillan, S., Rossini, C., Cella, M., Barrow, A. D., Diamond, M. S. \& Colonna, M. IL-34 is a tissue-restricted ligand of CSF1R required for the development of Langerhans cells and microglia. Nat Immunol 13, 753-760, doi:10.1038/ni.2360 (2012)

45 Erblich, B., Zhu, L., Etgen, A. M., Dobrenis, K. \& Pollard, J. W. Absence of colony stimulation factor-1 receptor results in loss of microglia, disrupted brain development and olfactory deficits. PLOS ONE 6, e26317, doi:10.1371/journal.pone.0026317 (2011).

46 Kana, V., Desland, F. A., Casanova-Acebes, M., Ayata, P., Badimon, A., Nabel, E., Yamamuro, K., Sneeboer, M., Tan, I. L., Flanigan, M. E., Rose, S. A., Chang, C., Leader, A., Le Bourhis, H., Sweet, E. S., Tung, N., Wroblewska, A., Lavin, Y., See, P., Baccarini, A., Ginhoux, F., Chitu, V., Stanley, E. R., Russo, S. J., Yue, Z., Brown, B. D., Joyner, A. L., De Witte, L. D., Morishita, H., Schaefer, A. \& Merad, M. CSF-1 controls cerebellar microglia and is required for motor function and social interaction. $J E_{X p} \operatorname{Med} 216,2265-2281$, doi:10.1084/jem.20182037 (2019).

47 Easley-Neal, C., Foreman, O., Sharma, N., Zarrin, A. A. \& Weimer, R. M. CSF1R ligands IL-34 and CSF1 are differentially required for microglia development and maintenance in white and gray matter brain regions. Front Immunol 10, 2199, doi:10.3389/fimmu.2019.02199 (2019).

48 Wei, S., Nandi, S., Chitu, V., Yeung, Y.-G., Yu, W., Huang, M., Williams, L. T., Lin, H. \& Stanley, E. R. Functional overlap but differential expression of CSF-1 and IL-34 in their CSF-1 receptor-mediated regulation of myeloid cells. JLeukoc Biol 88, 495-505, doi:10.1189/jlb.1209822 (2010)

49 Otero, K., Turnbull, I. R., Poliani, P. L., Vermi, W., Cerutti, E., Aoshi, T., Tassi, I., Takai, T., Stanley, S. L., Miller, M., Shaw, A. S. \& Colonna, M. Macrophage colony-stimulating factor induces the proliferation and survival of macrophages via a pathway involving DAP12 and betacatenin. Nat Immunol 10, 734-743, doi:10.1038/ni.1744 (2009).

50 Dagher, N. N., Najafi, A. R., Kayala, K. M., Elmore, M. R., White, T. E., Medeiros, R., West, B. L. \& Green, K. N. Colony-stimulating factor 1 receptor inhibition prevents microglial plaque association and improves cognition in 3xTg-AD mice. $J$ Neuroinflammation 12, 139 , doi:10.1186/s12974-015-0366-9 (2015).

51 Elmore, M. R., Najafi, A. R., Koike, M. A., Dagher, N. N., Spangenberg, E. E., Rice, R. A., Kitazawa, M., Matusow, B., Nguyen, H., West, B. L. \& Green, K. N. Colony-stimulating factor 1 receptor signaling is necessary for microglia viability, unmasking a microglia progenitor cell in the adult brain. Neuron 82, 380-397, doi:10.1016/j.neuron.2014.02.040 (2014).

52 Huang, Y., Xu, Z., Xiong, S., Sun, F., Qin, G., Hu, G., Wang, J., Zhao, L., Liang, Y. X., Wu, T., Lu, Z., Humayun, M. S., So, K. F., Pan, Y., Li, N., Yuan, T. F., Rao, Y. \& Peng, B. Repopulated microglia are solely derived from the proliferation of residual microglia after acute depletion. Nat Neurosci 21, 530-540, doi:10.1038/s41593-018-0090-8 (2018).

53 Zhan, L., Sohn, P. D., Zhou, Y., Li, Y. \& Gan, L. A Mac2-positive progenitor-like microglial population survives independent of CSF1R signaling in adult mouse brain. bioRxiv, 722090, doi:10.1101/722090 (2019).

54 Hattori, Y., Naito, Y., Tsugawa, Y., Nonaka, S., Wake, H., Nagasawa, T., Kawaguchi, A. \& Miyata, T. Transient microglial absence assists postmigratory cortical neurons in proper differentiation. Nat Commun 11, 1631, doi:10.1038/s41467-020-15409-3 (2020). 
55 Nandi, S., Gokhan, S., Dai, X. M., Wei, S., Enikolopov, G., Lin, H., Mehler, M. F. \& Stanley, E. $\mathrm{R}$. The CSF-1 receptor ligands IL-34 and CSF-1 exhibit distinct developmental brain expression patterns and regulate neural progenitor cell maintenance and maturation. Dev Biol 367, 100-113, doi:10.1016/j.ydbio.2012.03.026 (2012).

56 Nandi, S., Cioce, M., Yeung, Y. G., Nieves, E., Tesfa, L., Lin, H., Hsu, A. W., Halenbeck, R., Cheng, H. Y., Gokhan, S., Mehler, M. F. \& Stanley, E. R. Receptor-type protein-tyrosine phosphatase zeta is a functional receptor for interleukin-34. The Journal of biological chemistry 288, 21972-21986, doi:10.1074/jbc.M112.442731 (2013).

57 Eriksson, P. S., Perfilieva, E., Björk-Eriksson, T., Alborn, A.-M., Nordborg, C., Peterson, D. A. \& Gage, F. H. Neurogenesis in the adult human hippocampus. Nature Medicine 4, 1313-1317, doi:10.1038/3305 (1998).

58 Boldrini, M., Fulmore, C. A., Tartt, A. N., Simeon, L. R., Pavlova, I., Poposka, V., Rosoklija, G. B., Stankov, A., Arango, V., Dwork, A. J., Hen, R. \& Mann, J. J. Human hippocampal neurogenesis persists throughout aging. Cell stem cell 22, 589-599.e585, doi:10.1016/j.stem.2018.03.015 (2018).

59 Sorrells, S. F., Paredes, M. F., Cebrian-Silla, A., Sandoval, K., Qi, D., Kelley, K. W., James, D., Mayer, S., Chang, J., Auguste, K. I., Chang, E. F., Gutierrez, A. J., Kriegstein, A. R., Mathern, G. W., Oldham, M. C., Huang, E. J., Garcia-Verdugo, J. M., Yang, Z. \& Alvarez-Buylla, A. Human hippocampal neurogenesis drops sharply in children to undetectable levels in adults. Nature 555, 377-381, doi:10.1038/nature25975 (2018).

60 Sierra, A., Encinas, J. M., Deudero, J. J., Chancey, J. H., Enikolopov, G., Overstreet-Wadiche, L. S., Tsirka, S. E. \& Maletic-Savatic, M. Microglia shape adult hippocampal neurogenesis through apoptosis-coupled phagocytosis. Cell stem cell 7, 483-495, doi:10.1016/j.stem.2010.08.014 (2010).

61 Diaz-Aparicio, I., Paris, I., Sierra-Torre, V., Plaza-Zabala, A., Rodriguez-Iglesias, N., MarquezRopero, M., Beccari, S., Huguet, P., Abiega, O., Alberdi, E., Matute, C., Bernales, I., Schulz, A., Otrokocsi, L., Sperlagh, B., Happonen, K. E., Lemke, G., Maletic-Savatic, M., Valero, J. \& Sierra, A. Microglia actively remodel adult hippocampal neurogenesis through the phagocytosis secretome. J Neurosci 40, 1453-1482, doi:10.1523/JNEUROSCI.0993-19.2019 (2020).

62 Elmore, M. R. P., Hohsfield, L. A., Kramar, E. A., Soreq, L., Lee, R. J., Pham, S. T., Najafi, A. R., Spangenberg, E. E., Wood, M. A., West, B. L. \& Green, K. N. Replacement of microglia in the aged brain reverses cognitive, synaptic, and neuronal deficits in mice. Aging Cell 17, e12832, doi:10.1111/acel.12832 (2018).

63 Choi, S. H., Veeraraghavalu, K., Lazarov, O., Marler, S., Ransohoff, R. M., Ramirez, J. M. \& Sisodia, S. S. Non-cell-autonomous effects of presenilin 1 variants on enrichment-mediated hippocampal progenitor cell proliferation and differentiation. Neuron 59, 568-580, doi:10.1016/j.neuron.2008.07.033 (2008).

64 Monje, M. L., Toda, H. \& Palmer, T. D. Inflammatory blockade restores adult hippocampal neurogenesis. Science 302, 1760-1765, doi:10.1126/science.1088417 (2003).

65 Seki, T. \& Arai, Y. Age-related production of new granule cells in the adult dentate gyrus. Neuroreport 6, 2479-2482, doi:10.1097/00001756-199512150-00010 (1995).

66 Gebara, E., Sultan, S., Kocher-Braissant, J. \& Toni, N. Adult hippocampal neurogenesis inversely correlates with microglia in conditions of voluntary running and aging. Front Neurosci 7, 145, doi:10.3389/fnins.2013.00145 (2013)

67 van Praag, H., Kempermann, G. \& Gage, F. H. Running increases cell proliferation and neurogenesis in the adult mouse dentate gyrus. Nature Neuroscience 2, 266-270, doi:10.1038/6368 (1999).

68 Butt, U. J., Steixner-Kumar, A. A., Depp, C., Sun, T., Hassouna, I., Wustefeld, L., Arinrad, S., Zillmann, M. R., Schopf, N., Fernandez Garcia-Agudo, L., Bode, U., Ronnenberg, A., Hindermann, M., Goebbels, S., Bonn, S., Katschinski, D. M., Nave, K. A. \& Ehrenreich, H. Hippocampal neurons respond to brain activity with functional hypoxia. Mol Psychiatry, doi:10.1038/s41380-020-00988-w (2021).

69 Fan, M., Zhu, L. \& Zhang, K. Oxygen, a Key Factor Regulating Cell Behavior during Neurogenesis and Cerebral Diseases. Front Mol Neurosci 4, 5, doi:10.3389/fnmol.2011.00005 (2011).

70 Zhu, X. H., Yan, H. C., Zhang, J., Qu, H. D., Qiu, X. S., Chen, L., Li, S. J., Cao, X., Bean, J. C., Chen, L. H., Qin, X. H., Liu, J. H., Bai, X. C., Mei, L. \& Gao, T. M. Intermittent hypoxia promotes hippocampal neurogenesis and produces antidepressant-like effects in adult rats. $J$ Neurosci 30, 12653-12663, doi:10.1523/JNEUROSCI.6414-09.2010 (2010). 
71 Chen, Z. Y., Asavaritikrai, P., Prchal, J. T. \& Noguchi, C. T. Endogenous erythropoietin signaling is required for normal neural progenitor cell proliferation. The Journal of biological chemistry 282 25875-25883, doi:10.1074/jbc.M701988200 (2007).

72 Shingo, T., Sorokan, S. T., Shimazaki, T. \& Weiss, S. Erythropoietin regulates the in vitro and in vivo production of neuronal progenitors by mammalian forebrain neural stem cells. J Neurosci21, 9733-9743, doi:10.1523/JNEUROSCI.21-24-09733.2001 (2001).

73 Hassouna, I., Ott, C., Wustefeld, L., Offen, N., Neher, R. A., Mitkovski, M., Winkler, D., Sperling, S., Fries, L., Goebbels, S., Vreja, I. C., Hagemeyer, N., Dittrich, M., Rossetti, M. F., Krohnert, K., Hannke, K., Boretius, S., Zeug, A., Hoschen, C., Dandekar, T., Dere, E., Neher, E., Rizzoli, S. O., Nave, K. A., Siren, A. L. \& Ehrenreich, H. Revisiting adult neurogenesis and the role of erythropoietin for neuronal and oligodendroglial differentiation in the hippocampus. Mol Psychiatry 21, 1752-1767, doi:10.1038/mp.2015.212 (2016).

74 Wakhloo, D., Scharkowski, F., Curto, Y., Javed Butt, U., Bansal, V., Steixner-Kumar, A. A., Wustefeld, L., Rajput, A., Arinrad, S., Zillmann, M. R., Seelbach, A., Hassouna, I., Schneider, K., Qadir Ibrahim, A., Werner, H. B., Martens, H., Miskowiak, K., Wojcik, S. M., Bonn, S., Nacher, J., Nave, K. A. \& Ehrenreich, H. Functional hypoxia drives neuroplasticity and neurogenesis via brain erythropoietin. Nat Commun 11, 1313, doi:10.1038/s41467-020-15041-1 (2020).

75 Mitkovski, M., Dahm, L., Heinrich, R., Monnheimer, M., Gerhart, S., Stegmuller, J., Hanisch, U. K., Nave, K. A. \& Ehrenreich, H. Erythropoietin dampens injury-induced microglial motility. J Cereb Blood Flow Metab 35, 1233-1236, doi:10.1038/jcbfm.2015.100 (2015).

76 Sargin, D., Hassouna, I., Sperling, S., Siren, A. L. \& Ehrenreich, H. Uncoupling of neurodegeneration and gliosis in a murine model of juvenile cortical lesion. Glia 57, 693-702, doi:10.1002/glia.20797 (2009).

77 Carro, E., Nuñez, A., Busiguina, S. \& Torres-Aleman, I. Circulating insulin-like growth factor i mediates effects of exercise on the brain. JNeurosci 20, 2926-2933, doi:10.1523/JNEUROSCI.2008-02926.2000 (2000).

78 Trejo, J. L., Carro, E. \& Torres-Alemán, I. Circulating insulin-like growth factor I mediates exercise-induced increases in the number of new neurons in the adult hippocampus. $J$ Neurosci 21, 1628-1634, doi:10.1523/JNEUROSCI.21-05-01628.2001 (2001).

79 Kohman, R. A., DeYoung, E. K., Bhattacharya, T. K., Peterson, L. N. \& Rhodes, J. S. Wheel running attenuates microglia proliferation and increases expression of a proneurogenic phenotype in the hippocampus of aged mice. Brain, behavior, and immunity 26, 803-810, doi:10.1016/j.bbi.2011.10.006 (2012).

80 Zang, J., Liu, Y., Li, W., Xiao, D., Zhang, Y., Luo, Y., Liang, W., Liu, F. \& Wei, W. Voluntary exercise increases adult hippocampal neurogenesis by increasing GSK-3beta activity in mice. Neuroscience 354, 122-135, doi:10.1016/j.neuroscience.2017.04.024 (2017).

81 Ekdahl, C. T., Kokaia, Z. \& Lindvall, O. Brain inflammation and adult neurogenesis: the dual role of microglia. Neuroscience 158, 1021-1029, doi:10.1016/j.neuroscience.2008.06.052 (2009).

$82 \mathrm{He}, \mathrm{P}$. \& Shen, Y. Interruption of beta-catenin signaling reduces neurogenesis in Alzheimer's disease. J Neurosci 29, 6545-6557, doi:10.1523/JNEUROSCI.0421-09.2009 (2009).

83 Holtman, I. R., Raj, D. D., Miller, J. A., Schaafsma, W., Yin, Z., Brouwer, N., Wes, P. D., Möller, T., Orre, M., Kamphuis, W., Hol, E. M., Boddeke, E. W. G. M. \& Eggen, B. J. L. Induction of a common microglia gene expression signature by aging and neurodegenerative conditions: a coexpression meta-analysis. Acta Neuropathol Commun 3, 31, doi:10.1186/s40478-015-0203-5 (2015).

84 Keren-Shaul, H., Spinrad, A., Weiner, A., Matcovitch-Natan, O., Dvir-Szternfeld, R., Ulland, T. K., David, E., Baruch, K., Lara-Astaiso, D., Toth, B., Itzkovitz, S., Colonna, M., Schwartz, M. \& Amit, I. A unique microglia type associated with restricting development of Alzheimer's disease. Cell 169, 1276-1290.e1217, doi:10.1016/j.cell.2017.05.018 (2017).

85 Butovsky, O. \& Weiner, H. L. Microglial signatures and their role in health and disease. Nat Rev Neurosci 19, 622-635, doi:10.1038/s41583-018-0057-5 (2018).

86 Green, K. N., Crapser, J. D. \& Hohsfield, L. A. To Kill a Microglia: A Case for CSF1R Inhibitors. Trends Immunol 41, 771-784, doi:10.1016/j.it.2020.07.001 (2020).

87 Mosher, K. I. \& Wyss-Coray, T. Microglial dysfunction in brain aging and Alzheimer's disease. Biochem Pharmacol 88, 594-604, doi:10.1016/j.bcp.2014.01.008 (2014).

88 Parkhurst, Christopher N., Yang, G., Ninan, I., Savas, Jeffrey N., Yates, John R., Lafaille, Juan J., Hempstead, Barbara L., Littman, Dan R. \& Gan, W.-B. Microglia promote learningdependent synapse formation through brain-derived neurotrophic factor. Cell 155, 1596-1609, doi:10.1016/j.cell.2013.11.030 (2013). 
89 Fernandez Garcia-Agudo, L., Janova, H., Sendler, L. E., Arinrad, S., Steixner, A. A., Hassouna, I., Balmuth, E., Ronnenberg, A., Schopf, N., van der Flier, F. J., Begemann, M., Martens, H., Weber, M. S., Boretius, S., Nave, K. A. \& Ehrenreich, H. Genetically induced brain inflammation by Cnp deletion transiently benefits from microglia depletion. FASEB J 33, 8634-8647, doi:10.1096/fj.201900337R (2019).

90 Janova, H., Arinrad, S., Balmuth, E., Mitjans, M., Hertel, J., Habes, M., Bittner, R. A., Pan, H., Goebbels, S., Begemann, M., Gerwig, U. C., Langner, S., Werner, H. B., Kittel-Schneider, S., Homuth, G., Davatzikos, C., Volzke, H., West, B. L., Reif, A., Grabe, H. J., Boretius, S., Ehrenreich, H. \& Nave, K. A. Microglia ablation alleviates myelin-associated catatonic signs in mice. J Clin Invest 128, 734-745, doi:10.1172/JCI97032 (2018).

91 Rice, R. A., Pham, J., Lee, R. J., Najafi, A. R., West, B. L. \& Green, K. N. Microglial repopulation resolves inflammation and promotes brain recovery after injury. Glia 65, 931-944, doi:10.1002/glia.23135 (2017).

92 Monji, A., Kato, T. \& Kanba, S. Cytokines and schizophrenia: Microglia hypothesis of schizophrenia. Psychiatry and clinical neurosciences 63, 257-265, doi:10.1111/j.14401819.2009.01945.x (2009).

93 Nave, K. A. \& Ehrenreich, H. Myelination and oligodendrocyte functions in psychiatric diseases. JAMA Psychiatry 71, 582-584, doi:10.1001/jamapsychiatry.2014.189 (2014).

94 Hagemeyer, N., Goebbels, S., Papiol, S., Kastner, A., Hofer, S., Begemann, M., Gerwig, U. C., Boretius, S., Wieser, G. L., Ronnenberg, A., Gurvich, A., Heckers, S. H., Frahm, J., Nave, K. A. \& Ehrenreich, H. A myelin gene causative of a catatonia-depression syndrome upon aging. $E M B O$ Mol Med 4, 528-539, doi:10.1002/emmm.201200230 (2012).

95 Tandon, R., Heckers, S., Bustillo, J., Barch, D. M., Gaebel, W., Gur, R. E., Malaspina, D., Owen, M. J., Schultz, S., Tsuang, M., van Os, J. \& Carpenter, W. Catatonia in DSM-5. Schizophrenia Research 150, 26-30, doi:10.1016/j.schres.2013.04.034 (2013).

96 Adamcio, B., Sargin, D., Stradomska, A., Medrihan, L., Gertler, C., Theis, F., Zhang, M., Muller, M., Hassouna, I., Hannke, K., Sperling, S., Radyushkin, K., El-Kordi, A., Schulze, L., Ronnenberg, A., Wolf, F., Brose, N., Rhee, J. S., Zhang, W. \& Ehrenreich, H. Erythropoietin enhances hippocampal long-term potentiation and memory. BMC Biol 6, 37, doi:10.1186/17417007-6-37 (2008).

97 Ehrenreich, H., Fischer, B., Norra, C., Schellenberger, F., Stender, N., Stiefel, M., Siren, A. L., Paulus, W., Nave, K. A., Gold, R. \& Bartels, C. Exploring recombinant human erythropoietin in chronic progressive multiple sclerosis. Brain 130, 2577-2588, doi:10.1093/brain/awm203 (2007).

98 Ehrenreich, H., Hinze-Selch, D., Stawicki, S., Aust, C., Knolle-Veentjer, S., Wilms, S., Heinz, G., Erdag, S., Jahn, H., Degner, D., Ritzen, M., Mohr, A., Wagner, M., Schneider, U., Bohn, M., Huber, M., Czernik, A., Pollmacher, T., Maier, W., Siren, A. L., Klosterkotter, J., Falkai, P., Ruther, E., Aldenhoff, J. B. \& Krampe, H. Improvement of cognitive functions in chronic schizophrenic patients by recombinant human erythropoietin. Mol Psychiatry 12, 206-220, doi:10.1038/sj.mp.4001907 (2007).

99 Siren, A. L., Fasshauer, T., Bartels, C. \& Ehrenreich, H. Therapeutic potential of erythropoietin and its structural or functional variants in the nervous system. Neurotherapeutics 6, 108-127, doi:10.1016/j.nurt.2008.10.041 (2009).

100 Suresh, S., Rajvanshi, P. K. \& Noguchi, C. T. The Many Facets of Erythropoietin Physiologic and Metabolic Response. Front Physiol 10, 1534, doi:10.3389/fphys.2019.01534 (2019).

101 Butovsky, O., Jedrychowski, M. P., Moore, C. S., Cialic, R., Lanser, A. J., Gabriely, G., Koeglsperger, T., Dake, B., Wu, P. M., Doykan, C. E., Fanek, Z., Liu, L., Chen, Z., Rothstein, J. D., Ransohoff, R. M., Gygi, S. P., Antel, J. P. \& Weiner, H. L. Identification of a unique TGFbeta-dependent molecular and functional signature in microglia. Nat Neurosci 17, 131-143, doi:10.1038/nn.3599 (2014).

The illustration of page 22 was created with BioRender. 
